Board of Governors of the Federal Reserve System

International Finance Discussion Papers

Number 1316

April 2021

\title{
Price Setting and Volatility: Evidence from Oil Price Volatility Shocks
}

Matthew Klepacz

Please cite this paper as:
Klepacz, Matthew (2021). "Price Setting and Volatility: Evidence from Oil Price Volatility
Shocks," International Finance Discussion Papers 1316. Washington: Board of Governors
of the Federal Reserve System, https://doi.org/10.17016/IFDP.2021.1316.

NOTE: International Finance Discussion Papers (IFDPs) are preliminary materials circulated to stimulate discussion and critical comment. The analysis and conclusions set forth are those of the authors and do not indicate concurrence by other members of the research staff or the Board of Governors. References in publications to the International Finance Discussion Papers Series (other than acknowledgement) should be cleared with the author(s) to protect the tentative character of these papers. Recent IFDPs are available on the Web at www.federalreserve.gov/pubs/ifdp/. This paper can be downloaded without charge from the Social Science Research Network electronic library at www.ssrn.com. 


\title{
Price Setting and Volatility: Evidence from Oil Price Volatility Shocks
}

\author{
Matthew Klepacz*
}

This Version: November 2020

\begin{abstract}
How do changes in aggregate volatility alter the impulse response of output to monetary policy? To analyze this question, I study whether individual prices in Producer Price Index micro data are more likely to change and to move in the same direction when aggregate volatility is high, which would increase aggregate price flexibility and reduce the effectiveness of monetary policy. Taking advantage of plausibly exogenous oil price volatility shocks and heterogeneity in oil usage across industries, I find that price changes are more dispersed and less frequent, implying that prices are less likely to move in the same direction when aggregate volatility is high. This contrasts with findings in the literature about idiosyncratic volatility. I use a state-dependent pricing model to interpret my findings. Random menu costs are necessary for the model to match the positive empirical relationship between oil price volatility and price change dispersion. This is the case because random menu costs reduce the extent to which firms with prices far from their optimum all act in a coordinated fashion when volatility increases. The model implies that increases in aggregate volatility do not substantially reduce the ability of monetary policy to stimulate output.
\end{abstract}

JEL: E30, E31, E50

Keywords: Volatility, Ss model, Menu cost, Monetary policy, Oil

*Division of International Finance, Board of Governors of the Federal Reserve System, Washington D.C. 20551 USA. E-mail: matthew.t.klepacz@frb.gov. I would like to thank Simon Gilchrist, Adam Guren, Raphael Schoenle, and Stephen Terry for their valuable guidance and support on this project. I am also thankful for comments from seminar participants at various universities and conferences. This research was conducted with restricted access to the Bureau of Labor Statistics (BLS) data. The views expressed here are those of the author and should not be interpreted as reflecting the views of the BLS, the Federal Reserve Board of Governors, or any other person associated with the Federal Reserve System. I thank my project coordinator, Ryan Ogden, for his substantial help and effort. All remaining errors are my own. 


\section{Introduction}

Do changes in aggregate volatility alter the ability of monetary policy to stimulate the economy? During periods of high volatility, the economy is buffeted by large macroeconomic shocks that are likely to impact price changes. Policy makers are concerned that policy effectiveness may decrease during these periods. This paper examines the role of time varying aggregate volatility in price setting and its implications for monetary policy.

Monetary policy effectiveness is dependent on the flexibility of the aggregate price level, which is determined both by the frequency of price change and by the extent to which firms change their price in the same direction after monetary stimulus. A key measure of the extent to which price changes move together is price change dispersion. I analyze whether price change frequency and dispersion are affected by heightened volatility and find that price change dispersion increases during periods of greater volatility while price change frequency decreases or is unaffected.

I use well-measured and plausibly exogenous oil price volatility shocks to study how price setting behavior responds to changes in the volatility of a common shock. While many commodity prices exhibit time varying volatility, as Figure 1 shows, oil price shocks are advantageous in studying how prices react to changes in a common source of volatility for three reasons. First, oil price volatility has large variation over time. Secondly, heterogeneity in oil usage across sectors allows me to construct industry specific exposure to oil price shocks in the spirit of Bartick (1991). Industries that rely on oil more intensively as an input would be expected to have stronger responses to oil price volatility shocks. Lastly, the industry specific oil demand variables are plausibly exogenous aggregate volatility shocks. Oil prices are also a specific source of volatility that the FOMC is concerned about, as the following quote shows.

What will happen with the price of oil? The uncertainties are sizable, and progress toward our goals and, by implication, the appropriate stance of monetary policy will depend on how these uncertainties evolve.

Janet Yellen, June 6, 2016

My main finding is that increased oil price volatility leads to relative increases in price change dispersion, and relative decreases in price change frequency, which implies that monetary policy is not less effective. I show this by using heterogeneity in long run oil usage, and find that industries more exposed to oil exhibit greater price change dispersion and lower price change frequency in response to increases in oil price volatility than industries with low oil exposure. The results are 


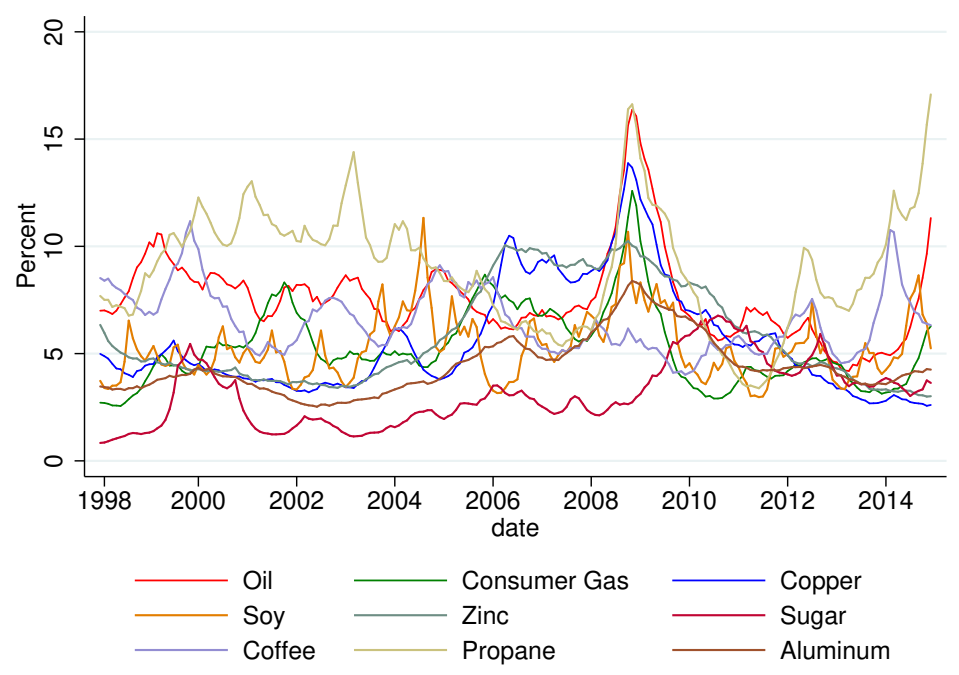

Figure 1: Commodity Price Volatility Shocks

NotE: Each line represents the stochastic volatility, $100 * e^{\sigma_{t}}$, of it's respective price series. The volatility measure is constructed as follows. For each real commodity price series an $\operatorname{AR}(1)$ process with time varying volatility, where volatility follows a mean reverting AR(1) process, is estimated. Specifically, for each real commodity price an AR(1) process with time varying volatility is estimated: $\log P_{t}^{C}=\rho_{C} \log P_{t-1}^{C}+e^{\sigma_{c, t}} \nu_{t}^{C}$ where $P_{t}^{C}$ is the price of commodity $C$ at time $t$, and volatility follows the process: $\sigma_{c, t}=\left(1-\rho_{\sigma}^{C}\right) \bar{\sigma}^{C}+\rho_{\sigma}^{C} \sigma_{c, t-1}+\phi^{C} \nu_{\sigma, t}^{C}$.

robust to various measures of volatility, oil price series, additional control variables, and hold both within and outside of the 2008 crisis period.

Monetary policy has the ability to stimulate output by changing the supply of money in a basic monetary framework. However, if prices are completely flexible, then monetary policy has no effect on output. Micro-price data shows that prices change approximately twice a year for both consumer and producer goods. Yet the selection of prices that do change is also important for monetary non-neutrality. After conditioning on price change frequency, greater dispersion of price changes lowers the fraction of price changes that are affected by a change in money, and is therefore a key measure of the degree of monetary non-neutrality. This is illustrated in Figure 2. The top and bottom left panels show a disperse and less disperse desired price change distribution prior to a monetary shock. Both distributions feature positive price changes in red on the right and negative price changes in green on the left, but have on average positive price changes.

The top and bottom right panels show the distribution after a positive monetary shock. An increase in the supply of money shifts the desired price change distribution to the right, with more positive price changes than prior to the shock. The purple area shows the increase in positive 


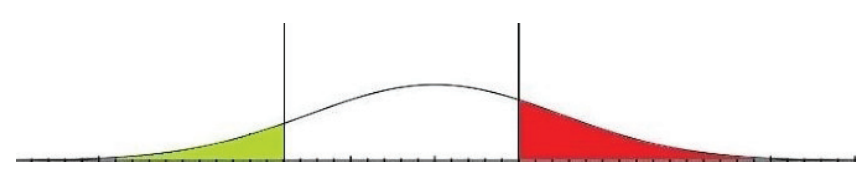

(a) No Shock

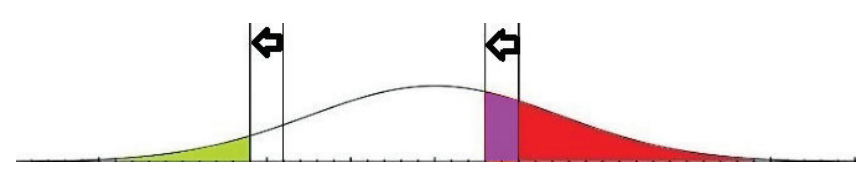

(b) Positive Monetary Shock

Disperse Desired Price Change Distribution

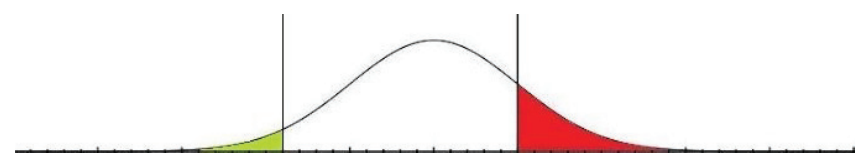

(a) No Shock

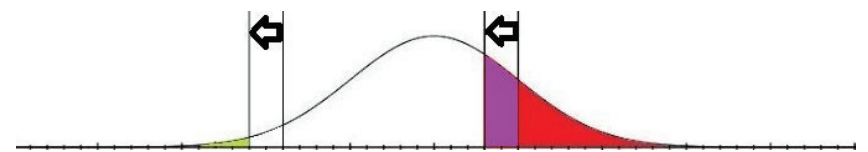

(b) Positive Monetary Shock

Figure 2: Less Disperse Desired Price Change Distribution

price changes. The figures show that the monetary shock has greater inflationary consequences in the less disperse distribution, as more desired prices are close to the adjustment threshold. Heightened aggregate volatility causes the price change distribution to be more disperse, which leads to decreased inflationary effects and increased real effects of monetary policy.

A general equilibrium price setting model with fixed costs of price adjustment that matches the micro-pricing facts is used to quantify the effects of monetary policy during periods of increased aggregate volatility. Changes in volatility have two mechanisms through which they affect firm price setting in a model with fixed costs of adjustment, a real options effect and a volatility effect. The real options effect increases the region of inactivity in the model, by pushing the action and inaction bands outward, thereby decreasing frequency of price adjustment. The volatility effect increases the variance of the common aggregate shock that affects firms. Increases in volatility to a common shock imply that larger shocks will affect firms, but the resultant price changes will be synchronized in the direction of the common cost shock which decreases price change dispersion. This stands in contrast to changes in idiosyncratic volatility, where the volatility effect pushes more price changes in both directions and increases price change dispersion.

I first show that a menu cost model with heterogeneous and random menu costs, such as in Dotsey et al. (1999) or Luo and Villar (2020), is able to match the positive relationship between 
price change dispersion and oil price volatility. ${ }^{1}$ Firms draw menu costs from a non-degenerate distribution, which increases the randomness of which prices will change. Firms have a substantial probability of a large menu cost such that the price will almost never change, which attenuates the price response to a more volatile common shock. During a period of increased oil price volatility some price changes will be more extreme, but due to the firm specific random menu cost a substantial portion of price changes will be reacting to their idiosyncratic productivity shock which decreases the synchronization of price change direction in response the common shock. This feature also dampens the increase in price change frequency, by having some fixed costs be large enough such that a firm would never choose to change the price that period.

The model with random menu costs is then augmented to include time varying idiosyncratic volatility. With this new mechanism, the model is able to match the empirical facts in Vavra (2014). Increases in idiosyncratic volatility increase both price change frequency and price change dispersion. This exercise demonstrates that the use of random menu costs, rather than the fixed menu cost featured in Vavra (2014), are also consistent with the effects of idiosyncratic volatility.

Finally, I show that the random menu cost model is able to quantitatively match the empirical results. The model is extended to a multisector setting, where sectors are heterogeneous in their oil usage and pricing behavior. The empirically observed oil price and volatility series are simulated in the model, which generates model implied pricing moments to directly map the model to the data. A regression using model generated data shows that it can match the positive empirical relative relationship between oil price volatility and price change dispersion.

The multisector model is then used to quantify the effectiveness of monetary policy to stimulate consumption during a period of increased oil price volatility. I find that in the general equilibrium model the graphical intuition about the empirical results holds, and that monetary policy is only slightly less effective. The model shows that monetary policy's ability to stimulate consumption on impact of the shock falls by $0.5 \%$ during a one standard deviation increase in oil price volatility. ${ }^{2}$ The small decrease in ability to generate real effects is due to a small increase in price change frequency, which balances out the increase in effectiveness due to the increase in price change dispersion.

\footnotetext{
${ }^{1}$ I show in Appendix A.3 that a model featuring fixed menu costs similar to Golosov and Lucas (2007) and Midrigan (2011) predicts a negative counterfactual relationship between price change dispersion and oil price volatility. This type of model with a fixed menu cost predicts decreased price change dispersion in response to an oil price volatility shock, and the dispersion falls more for sectors with greater oil usage. An increase in oil price volatility is a common shock, and this causes more prices to change and move in the direction of the cost shock which decreases price change dispersion.

${ }^{2}$ The monetary shock is a permanent increase of 0.002 to log nominal output.
} 
Aggregate and idiosyncratic volatility can both increase price change dispersion, but they have different implications for the effectiveness of monetary policy. My results suggest that policy makers need to consider the source of volatility, aggregate or idiosyncratic, in order to effectively manage the tradeoff between inflation and output stabilization.

The paper is organized as follows. Section II describes the micro-price data and oil price volatility processes. Section III analyzes the micro-price data and shows that price changes are more dispersed and less frequent during periods of high oil price volatility for industries with greater sensitivity to oil. Section IV presents and calibrates a quantitative price setting model with first and second moment oil price shocks. Section V discusses model implications for monetary policy effectiveness during periods of heightened oil price volatility. Section VI discusses supporting time series evidence. Section VII concludes.

\section{I.1 Related Literature}

This paper contributes to our understanding of the effects of volatility on the economy. The literature includes the seminal paper on volatility of Bloom (2009) and the introduction of volatility into a general equilibrium framework of Bloom et al. (2018). Fernandez-Villaverde et al. (2015) study the effects of changes in fiscal policy volatility in a New Keynesian model with quadratic adjustment costs for pricing. This paper differs by studying the effects of oil price volatility in a model with fixed costs of adjustment for pricing while matching micro-pricing facts.

Within the literature on the association between volatility and price setting behavior, Vavra (2014) and Bachmann et al. (2019) are most closely related to this paper. Vavra (2014) studies the impact of idiosyncratic volatility shocks on price setting moments over time. He uses CPI data to document the distribution of final goods prices over the business cycle and shows that the cross sectional variance of price changes as well as frequency of price adjustment are countercyclical. The paper then shows that these two facts are matched by a standard menu cost model with second moment shocks to idiosyncratic productivity, while a model with only first moment shocks makes the counterfactual prediction that price change dispersion and frequency of adjustment are negatively correlated. Bachmann et al. (2019) asks how business forecast uncertainty affects the frequency of price change. They find that increased uncertainty about production increases price flexibility. My paper differs by examining the effects of a aggregate source of volatility on price setting behavior.

More broadly in the price setting literature, papers have investigated how various sources

of volatility affect prices. Baley and Blanco (2019) construct a model with menu costs and 
imperfect information about idiosyncratic productivity, and find that this mechanism strengthens the volatility effect and increases price flexibility due to uncertainty. Drenik and Perez (2016) use the manipulation of inflation statistics in Argentina to understand the role of informational frictions on price level dispersion. They find that the manipulation of statistics is associated with greater price level dispersion, and construct a price setting model with noisy information about inflation and find monetary policy is more effective when there is less precise information. Berger and Vavra (2019) document a positive relationship between exchange rate pass-through and item level price change dispersion.

This paper contributes to the literature on state dependent models of price setting consistent with micro-data facts by introducing new empirical facts on the relationship between pricing behavior and oil price volatility. The model of Golosov and Lucas (2007) features a very strong selection effect, where only large price changes occur. Many papers such as Midrigan (2011), Nakamura and Steinsson (2010), and Karadi and Reiff (2019) have since argued that the selection effect is weaker than in the Golosov and Lucas model. In particular, Midrigan (2011) introduces leptokurtic productivity shocks, which increases the dispersion of price changes. This reduces the mass of prices that would change for a small monetary shock, increasing monetary non-neutrality. Nakamura and Steinsson (2010) introduce real rigidities into the menu cost model through a multisector model. Heterogeneity amongst sectors in frequency and average size of price change increases monetary non-neutrality by a factor of three. Karadi and Reiff (2019) show that idiosyncratic productivity shocks that feature stochastic volatility better matches the response to large VAT changes, and argue that this model would feature a degree of non-neutrality between that of the Midrigan model and Golosov and Lucas model. Luo and Villar (2020) document that the price change distribution skewness increases as the rate of inflation increases and argue that the previous set of models are unable to match this empirical fact. They augment the model with random menu costs to increase the randomness of price changes in order to fit this fact.

Lastly, this paper also discusses the effects of second moment oil price shocks on the economy. Bloom (2009) and Stein and Stone (2010) also use oil price shocks as a plausibly exogenous source of volatility on investment decisions. Studying the effects of oil price shocks themselves, Blanchard and Galí (2007) construct a model with nominal rigidities in price and wage setting, where firms and consumers use oil to study the declining role of oil in the US economy over time. They show that a combination of a decrease in wage rigidity, increase in monetary policy credibility, and decrease in oil consumption for both firms and consumers can decrease the importance of oil price shocks in 
their model. Clark and Terry (2010) use a Bayesian vector autoregression framework and show that energy price pass-through has declined over time starting from the 1970's. Chen (2009) also studies oil price pass-through into inflation across countries using a time varying pass-through coefficient. She finds a long run pass-through of 16 percent for the US over the period of 1970 to 2006, and a short run pass-through of slightly less than 1 percent over one quarter. Elder and Serletis (2010) find a negative effect of oil price uncertainty on investment. Jo (2014) uses a VAR with stochastic volatility to study the effects of oil price volatility on real economic activity and finds that an increase in oil price volatility decreases industrial production. While my model abstracts away from a monetary policy rule that includes oil prices, papers such as Kilian and Lewis (2011) and Bodenstein et al. (2012) study the monetary policy response to oil price shocks.

\section{Data Sources and Methods}

\section{II.1 Micro-Price Data}

This paper constructs industry level measures of relevant price statistics using confidential item level micro-data underlying the producer price index from the Bureau of Labor Statistics. ${ }^{3}$ The item-level data starts in 1998 and extends through 2014. ${ }^{4}$ Each month around 100,000 prices are collected from about 25,000 reporters. Prices are collected for the entire U.S. production sector.

The item level data are transaction based prices collected from a survey that asks producers for the price of an item each month. Items are sampled in a three stage procedure. The BLS first creates a list of establishments within an industry. The second stage is selecting price forming units within each industry, which are created by clustering establishments. The third and final stage is selecting specific items within a price forming unit to sample. The BLS uses a probabilistic technique to select items within a price setting unit, where items are weighted proportional to the value of the category within the unit. ${ }^{5}$ This procedure ensures goods are uniquely identified, and that the prices are respresentative of the entire U.S. production sector.

I restrict the pricing data to a subset of items within the PPI. Only manufacturing industries

\footnotetext{
${ }^{3}$ The data set has been studied before in Gilchrist et al. (2017), Goldberg and Hellerstein (2009), Gorodnichenko and Weber (2016), and Nakamura and Steinsson (2008) along with several other papers.

${ }^{4}$ The BLS collects this price data from the view of the firm rather than the consumer, thus price collected is the revenue received by a producer and does not include sales or excise taxes. This is in contrast to the CPI which is the out of pocket expenditure for a consumer for a given item.

${ }^{5}$ Further details about the BLS sampling process is in Appendix B.2.1.
} 


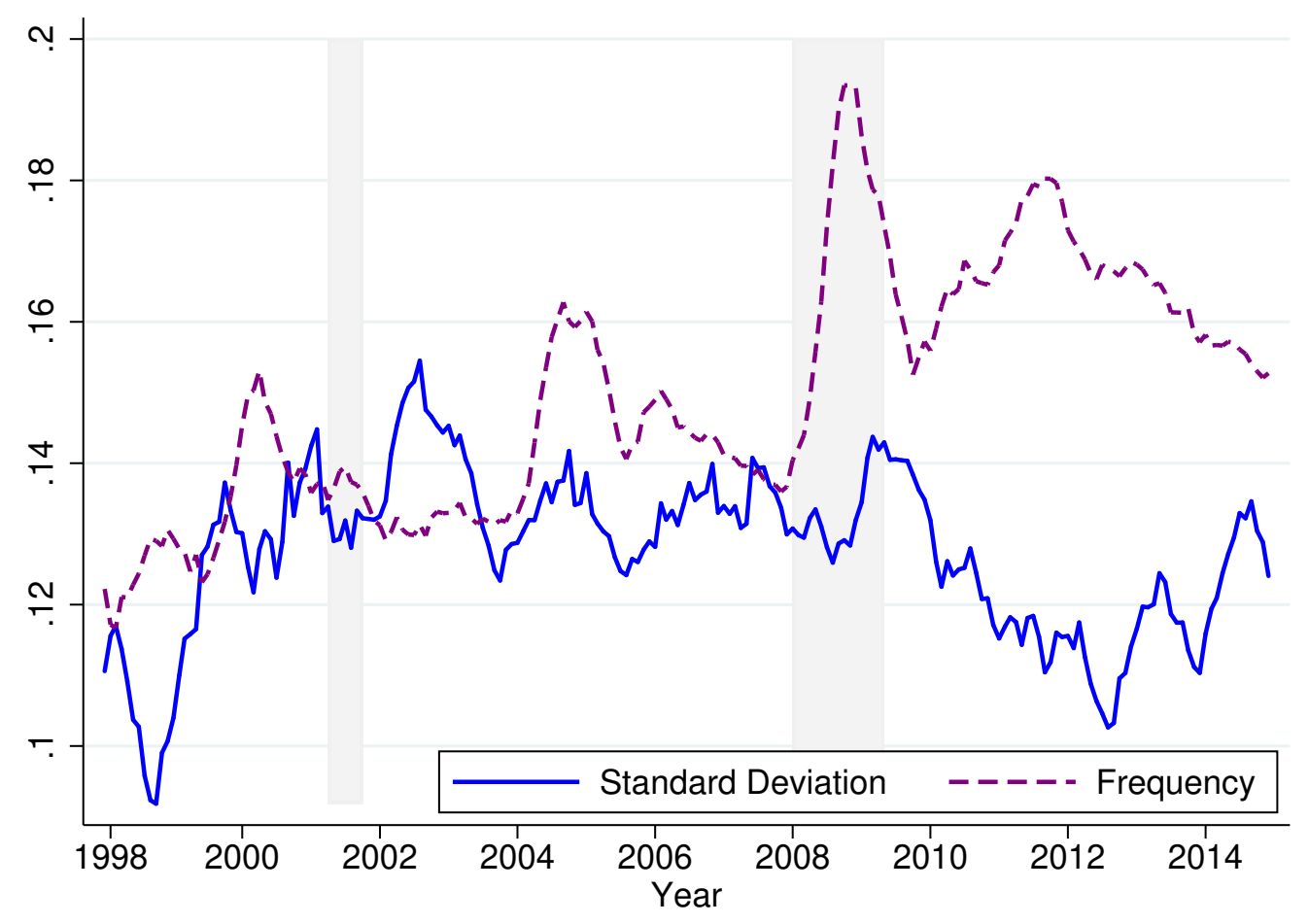

Figure 3: Monthly Standard Deviation of Price Changes

Note: Data is seasonally adjusted with X-12 seasonal filter and presented as 6 month moving average.

are included which enables the study of price setting in markets where goods are not homogeneous and firms have some price setting power. ${ }^{6}$ Gopinath and Itskhoki (2010) make the same restriction in their study of international producer pricing data. Manufacturing industries are also a setting where oil is used as an input for production. This leaves 81 four digit NAICS industries in the microlevel data sample. While the PPI collects data on finished goods, intermediate goods, and crude materials, only finished goods products are used in the construction of these statistics. Aggregate price statistics are calculated by first constructing an item level unweighted statistic within each four digit NAICS industry. Industry price statistics are then aggregated using value added weights to construct the weighted mean of each price setting moment. ${ }^{7}$

The focus of the empirical section of the paper is to study the effect of oil price volatility on producer price change frequency and dispersion. Price change frequency is defined as the fraction

\footnotetext{
${ }^{6}$ This includes goods that have a two digit NAICS code of 31, 32, or 33. However it excludes all items in NAICS 324, Petroleum and Coal manufacturing industry, as these industries view oil price volatility as both profit and cost volatility.

${ }^{7}$ This is the similar to the method Nakamura and Steinsson (2008) use to construct PPI price statistics. Their procedure is to first take the average price statistic within an item group, then take a median across item groups.
} 
of item level price changes in industry $j$ during month $t$. Dispersion is measured as the standard deviation of price changes. ${ }^{8}$ Producer price change dispersion is measured at the industry-month level as $S . D \cdot j, t=\sqrt{\frac{1}{I} \sum_{i=1}^{I}\left(d p_{i, j, t}-\overline{d p_{i, j, t}}\right)^{2}}$, where $i$ indexes items within industry $j$ during month $t$. Price change dispersion is calculated using only non-zero price changes. ${ }^{9}$

Figure 3 shows the aggregate price change frequency and standard deviation during the 1998 to 2014 data sample. Price change frequency varies between 12 and 19\% over the time period. Price change dispersion also shows a large amount of variation over time ranging from 0.09 during 1999 up to 0.15 during 2003. During the Great Recession, price change frequency increased from 0.14 to 0.16 , while the dispersion measure increased from 0.13 to 0.14 , an increase of $7 \%$. This stands in contrast with Berger and Vavra (2019) who find the IQR of price change dispersion nearly doubles from 0.09 to 0.17 in the international producer price data set. ${ }^{10}$

Table 1 documents the business cycle moments of the aggregate pricing moments. Column (1) shows that the standard deviation of price changes is countercyclical and increases during the two recession periods in the sample. Column (2) shows that price change frequency increases during recessions but is not statistically significant. These facts are qualitatively consistent with the findings of Vavra (2014) and Bachmann et al. (2019).

To further substantiate the similarities between consumer and producer prices, Table 2 shows price statistics for both the CPI and the PPI. The most notable difference between the two data sets is that there are more small price changes in the PPI than the CPI. ${ }^{11}$ Lastly, the correlation between the monthly inflation measures of consumer prices and producer prices is 0.8 over the 1998 to 2014 time period. ${ }^{12}$ Temporary sales are not common in the PPI, so sales filtering techniques are not applied.

\footnotetext{
${ }^{8}$ In Appendix B, I show the results are robust to using the interquartile range of price changes as a measure of dispersion in Table 15 and 26. The interquartile range is calculated for the same set of non-zero item level price changes within an industry at time $t$.

${ }^{9}$ Price change dispersion is typically constructed using only non-zero price changes such as in Vavra (2014), Berger and Vavra (2019), Luo and Villar (2020). Similar results are obtained however when including zeros in the standard deviation of price changes measure and results are in Appendix B.3.3.

${ }^{10}$ I find that the IQR of price change dispersion increases from 0.07 to 0.09 in the PPI during the Great Recession.

${ }^{11}$ Nakamura and Steinsson (2008) show that there is a high correlation between the frequency of price change within narrow item groups between the CPI and PPI data.

${ }^{12} \mathrm{~A}$ comparison of the CPI and PPI inflation rates are shown in Appendix B.2.2.
} 


\begin{tabular}{|c|c|c|}
\hline Dependent Variable: & S.D. & Frequency \\
\hline & (1) & (2) \\
\hline Non-recession mean & $\begin{array}{c}0.127^{* * *} \\
(0.004)\end{array}$ & $\begin{array}{c}0.148^{* * *} \\
(0.013)\end{array}$ \\
\hline Recession Dummy & $\begin{array}{l}0.008^{* *} \\
(0.004)\end{array}$ & $\begin{array}{c}0.017 \\
(0.013)\end{array}$ \\
\hline $\mathrm{N}$ & 204 & 204 \\
\hline
\end{tabular}

Table 1: Business Cycle Properties of Pricing Moments

NotE: Sample period: 1998:M1 to 2014:M12 at a monthly frequency. S.D. is the standard deviation of price changes and Frequency is the frequency of price changes. Number of observation=204. Newey-West standard errors with lag length of 12 reported in parentheses: ${ }^{*} p<.10{ }^{* *} p<.05$; and ${ }^{* * *} p<.01$.

\begin{tabular}{|c|c|c|c|c|c|c|}
\hline Moment: & Frequency & Average Size & Fraction Up & Fraction Small & S.D. & Skewness \\
\hline CPI & 0.15 & 0.08 & 0.65 & 0.12 & 0.08 & 0.12 \\
\hline PPI & 0.15 & 0.07 & 0.60 & 0.22 & 0.13 & 0.10 \\
\hline
\end{tabular}

Table 2: Consumer and Producer Price Index Moments

Note: All CPI moments calculated for 1988-2012 from Vavra (2014) except for fraction of small price changes which is calculated for 1977-2014 from Luo and Villar (2020). PPI moments calculated for 1998-2014 are author's calculation. Small price changes are defined as $\left|d p_{i, t}\right|<0.01$.

\section{II.2 Oil Prices}

I measure oil prices using the average monthly West Texas Intermediate (WTI) spot price of oil, a particular grade of light and sweet crude oil traded in Cushing, Oklahoma. ${ }^{13}$ The WTI oil price is beneficial to use because it is available at daily frequency, and allows construction of within month volatility of oil prices. ${ }^{14}$ I argue that oil price and volatility movements are plausibly exogenous to disaggregated U.S. industries. ${ }^{15}$ Evidence in favor of this is that many large price movements can be traced to events that are unrelated to the U.S. Rather they can be explained by events in large oil producing regions such as the Middle East or South America, or changes in demand elsewhere in the world.

This section will briefly summarize the evolution of oil price changes over time that are seen

\footnotetext{
${ }^{13}$ Storage capacity in Cushing, OK accounts for about $13 \%$ of total U.S. oil storage.

${ }^{14}$ Oil prices can also be measured using Brent spot prices or composite Refined Acquisition Cost (RAC) prices. WTI prices are a primary benchmark and are more closely associated with U.S. production. A full set of results using Brent and RAC prices are in Appendix B.2.4. These alternative oil price results show very similar results as WTI.

${ }^{15}$ Oil prices do respond to changes in oil demand and supply, such as movements in the aggregate U.S. economy or supply disruptions.
} 


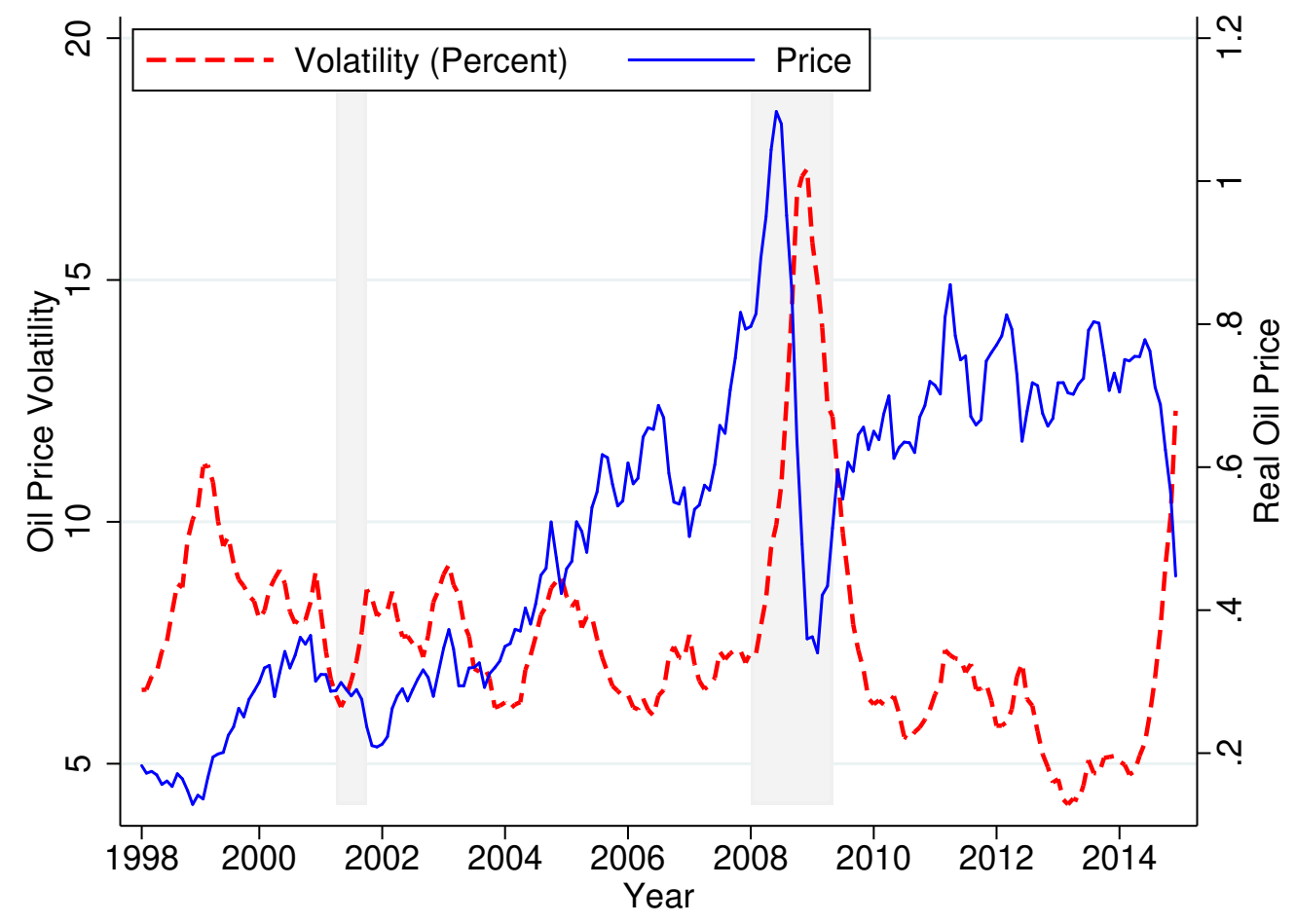

Figure 4: Stochastic Oil Volatility and Real Oil Price

Note: WTI nominal monthly oil price deflated by PPI finished goods index on right vertical axis and stochastic volatility, $100 * e^{\sigma_{t}}$, on the left vertical axis.

in Figure $4 .{ }^{16}$ There was a spike in the price and volatility of oil during late 2002 and 2003 related to the Venezuelan oil strike from December 2002 to February 2003 and the Iraq war in 2003. The nominal price of oil then increased over 350 percent from 2003 until the middle of 2008. Hamilton (2009) and Kilian (2008) attribute this to an increase in demand from Asia. Oil prices plummeted from $\$ 134$ in June 2008 to $\$ 34$ in February 2009 due to anticipation of a global recession while oil price volatility more than doubled during the associated period. Another spike in oil prices and volatility occurred in 2011 and is associated with the Libyan uprising. Between June 2014 and January 2015 the price of oil fell nearly fifty percent. This decline is attributed by Baumeister and Kilian (2015) to a decline in global activity.

\footnotetext{
${ }^{16}$ Additional discussion about the potential causes of oil price changes are in Appendix B.2.4.
} 


\section{II.3 Oil Price Volatility}

This section estimates the latent oil price volatility process. The preferred method of measuring oil price volatility is with a stochastic volatility model that estimates independent first and second moment shocks from the single process for oil prices. This process will also be consistent with the modeling section. In Appendix B.3.1 I estimate GARCH volatility and construct realized volatility and show these measures give similar results.

I assume real oil prices follow an AR(1) process with time varying volatility, where volatility follows a mean reverting AR(1) process. ${ }^{17}$ Specifically,

$$
\begin{gathered}
\log P_{t}^{o}=\rho_{o} \log P_{t-1}^{o}+e^{\sigma_{t}} \nu_{t} \\
\sigma_{t}=\left(1-\rho_{\sigma}\right) \bar{\sigma}+\rho_{\sigma} \sigma_{t-1}+\phi \nu_{\sigma, t}
\end{gathered}
$$

where $\left\{\nu_{t}\right\} \sim \mathrm{N}(0,1),\left\{\nu_{\sigma, t}\right\} \sim \mathrm{N}(0,1)$, and $\bar{\sigma}$ is the unconditional mean of $\sigma_{t}$. The shock to oil price volatility $\nu_{\sigma, t}$ is assumed to be independent of the level shock $\nu_{t}$. The postulated oil price process is the same as in Plante and Traum (2012) or Blanchard and Galí (2007) with time varying volatility.

The parameters are estimated using Bayesian Markov Chain Monte Carlo methods. Due to the nonlinear interaction between the innovations to oil price shocks and volatility, the Kalman filter cannot be used but a particle filter can evaluate the likelihood, as proposed by Fernandez-Villaverde et al. (2015). Markov Chain Monte Carlo is used to sample from the posterior distribution. Following Born and Pfeifer (2014), a backward smoothing routine is then used to extract the historical distribution of shocks from the model. Prior and posterior distributions are shown in Table 3, and are similar to other estimates such as in Plante and Traum (2012). ${ }^{18}$

\section{Empirical Analysis}

\section{III.1 Oil Price Pass-Through}

Before moving to the main analysis, I examine the pass-through of oil prices to producer prices to show that oil price inflation affects producer price setting behavior. I estimate the pass-through

\footnotetext{
${ }^{17}$ Nominal oil prices are deflated by the PPI finished goods index.

${ }^{18}$ Further estimation details for the stochastic volatility process are in Appendix B.1.
} 


\begin{tabular}{ccccc}
\hline Parameter & Prior & \multicolumn{3}{c}{ Posterior } \\
& & Mean & Median & $95 \%$ PI \\
\hline$\rho_{o}$ & Uniform $(0,1)$ & 0.999 & 0.999 & $(0.998,0.999)$ \\
$\rho_{\sigma}$ & Uniform(0,1) & 0.887 & 0.943 & $(0.574,0.999)$ \\
$\phi$ & Uniform(0,6) & 0.140 & 0.127 & $(0.053,0.276)$ \\
$\bar{\sigma}$ & Uniform(-20,20) & -2.607 & -2.602 & $(-3.000,-2.234)$ \\
\hline
\end{tabular}

Table 3: Priors and Posteriors of Stochastic Volatility Oil Process

Note: Stochastic Volatility priors for real oil price process with time varying volatility. Process estimated using monthly WTI data from 1986 to 2014.

\begin{tabular}{ccc}
\hline Short Run Pass-Through & & 12 Month Cumulative Response \\
\cline { 1 - 1 }$\left(0.010^{* * *}\right.$ & $0.086^{* * *}$ \\
$(0.003)$ & $(0.017)$ \\
\hline
\end{tabular}

Table 4: Pass-Through Regression

Note: Sample period: 1998:M1 to 2014:M12 at a monthly frequency. Number of observation=10,106. Number of industries $=66 . R^{2}=0.06$. Robust asymptotic standard errors reported in parentheses are clustered at the industry level: ${ }^{*} p<.10 ; * * p<.05$; and ${ }^{* * *} p<.01$.

equation:

$$
\pi_{j, t}=\alpha_{j}+\sum_{i=0}^{12} b_{i}\left(\Delta \log P_{t-i}^{o}\right)+\epsilon_{j, t}
$$

where $\pi_{j, t}$ is monthly producer price inflation for a NAICS 4 industry $j, \alpha_{j}$ are industry fixed effects, and $\Delta \log P_{t}^{o}$ are monthly changes in the real price of oil. The regression includes 12 months of lagged real oil price changes. ${ }^{19}$ The results are in Table 4 .

The short run pass-through is the coefficient $b_{0}$, the impact of a change of oil prices on producer prices during the same month. ${ }^{20}$ The coefficient is positive and statistically significant. Given that the average industry in the sample has an oil share of $0.8 \%$, the size of the pass-through is large. It can be interpreted as $1.0 \%$ of a change in oil price inflation is passed-through to producer prices. ${ }^{21}$

The cumulative response after 12 months is $\sum_{i=0}^{12} b_{i}$, and implies that $8.6 \%$ of a change in oil prices is passed-through over a year. ${ }^{22}$ One reason pass-through can be large is that oil prices can pass-through not only through a direct cost channel, but also through changes in other material

\footnotetext{
${ }^{19}$ Additional oil price lags do not substantially change the results.

${ }^{20}$ Restricting oil prices to pass-through with at least a one month lag does not change the results. The short run pass-through coefficient is $b_{1}=0.013$ and the 12 month cumulative response is $\sum_{i=1}^{12} b_{i}=0.076$ in this specification.

${ }^{21}$ Industry specific pass-through controlling for time and industry fixed effects is in Appendix B.4.2.

${ }^{22}$ Exchange rate pass-through regressions generally find a cumulative response close to 0.3 .
} 
costs due to input output linkages.

These pass-through estimates imply short run and long run pass-through of oil prices to industry inflation for manufacturing industries. This is important because the pass-through estimates imply industries price setting behavior reacts to changes in the real price of oil, and could be impacted by the volatility of oil prices. In the next section I will show that oil price volatility affects both the frequency and dispersion of price changes.

\section{III.2 Price Setting Behavior and Oil Price Volatility}

As motivating evidence before exploiting heterogeneity in industry oil share, I first estimate the time series relationship between pricing moments and oil price volatility. Oil price volatility is an aggregate volatility shock to firms. The time series relationship does not control for all common shocks and is not causal. Variation in industry price change frequency and dispersion over time allows me to run the following regressions:

$$
\begin{aligned}
& S . D \cdot j, t=\eta_{S D} * \Delta \log \left(P_{t-1}^{o}\right)+\lambda_{S D} * \sigma_{t-1}+\gamma_{S D}^{\prime} X_{j, t}+\alpha_{S D, j}+\epsilon_{S D, j t} \\
& \text { Frequency }_{j, t}=\eta_{F} * \Delta \log \left(P_{t-1}^{o}\right)+\lambda_{F} * \sigma_{t-1}+\gamma_{F}^{\prime} X_{j, t}+\alpha_{F, j}+\epsilon_{F, j t}
\end{aligned}
$$

where $t$ indexes time and $j$ indexes industry, $S . D_{\cdot j, t}$ is monthly industry price change standard deviation, and Frequency ${ }_{j, t}$ is monthly industry price change frequency. These specifications map a change in oil price inflation and oil price volatility into the average change in price change standard deviation or frequency after controlling for industry heterogeneity with the use of industry fixed effects, movements in aggregate financial conditions, and idiosyncratic volatility. The results for both dependent variables are in Table $5 .^{23}$

Economy wide financial conditions are controlled for with the excess bond premium measure of Gilchrist and Zakrajsek (2012). Industry level idiosyncratic volatility is controlled for using median stock price realized volatility within industry $j$ at time $t$, a common proxy for uncertainty such as in Bloom et al. (2007). Industry fixed effects control for time invariant differences between industries, and the average industry item level inflation rate and industrial production changes are included to control for movements in industry prices and production. The unit of observation is monthly price change dispersion or frequency at the 4-digit NAICS level. This level of industry

\footnotetext{
${ }^{23}$ Similar results are obtained using the interquartile range of price changes and are in Appendix B.3.3.
} 


\begin{tabular}{|c|c|c|c|c|}
\hline \multirow[t]{2}{*}{ Dependent Variable: } & \multicolumn{2}{|c|}{ S.D. } & \multicolumn{2}{|c|}{ Frequency } \\
\hline & (1) & $(2)$ & (3) & (4) \\
\hline$\Delta \log \left(P_{t-1}^{o}\right)$ & $\begin{array}{c}0.007 \\
(0.009)\end{array}$ & & $\begin{array}{l}-0.036 \\
(0.025)\end{array}$ & \\
\hline$\sigma_{t-1}$ & $\begin{array}{c}0.259^{* * *} \\
(0.073)\end{array}$ & & $\begin{array}{c}0.014 \\
(0.149)\end{array}$ & \\
\hline$[\text { Durable }=0]^{*} \Delta \log \left(P_{t-1}^{o}\right)$ & & $\begin{array}{l}-0.004 \\
(0.008)\end{array}$ & & $\begin{array}{l}-0.037 \\
(0.026)\end{array}$ \\
\hline$[\text { Durable }=1]^{*} \Delta \log \left(P_{t-1}^{o}\right)$ & & $\begin{array}{c}0.016 \\
(0.014)\end{array}$ & & $\begin{array}{l}-0.035 \\
(0.026)\end{array}$ \\
\hline$[\text { Durable }=0]^{*} \sigma_{t-1}$ & & $\begin{array}{c}0.305^{* * * *} \\
(0.102)\end{array}$ & & $\begin{array}{c}0.097 \\
(0.156)\end{array}$ \\
\hline$[\text { Durable }=1]^{*} \sigma_{t-1}$ & & $\begin{array}{c}0.227^{* * * *} \\
(0.083)\end{array}$ & & $\begin{array}{l}-0.044 \\
(0.157)\end{array}$ \\
\hline $\mathrm{EBP}_{t-1}$ & $\begin{array}{c}0.002 \\
(0.002)\end{array}$ & $\begin{array}{c}0.002 \\
(0.002)\end{array}$ & $\begin{array}{c}0.002 \\
(0.004)\end{array}$ & $\begin{array}{c}0.002 \\
(0.004)\end{array}$ \\
\hline Realized Stock $\mathrm{Vol}_{j, t}$ & $\begin{array}{c}0.009 \\
(0.013)\end{array}$ & $\begin{array}{c}0.010 \\
(0.013)\end{array}$ & $\begin{array}{c}0.137^{* * *} \\
(0.018)\end{array}$ & $\begin{array}{c}0.138^{* * *} \\
(0.018)\end{array}$ \\
\hline$\pi_{j, t}$ & $\begin{array}{c}0.083 \\
(0.115)\end{array}$ & $\begin{array}{c}0.087 \\
(0.111)\end{array}$ & $\begin{array}{c}1.320^{* * *} \\
(0.340)\end{array}$ & $\begin{array}{c}1.326^{* * *} \\
(0.340)\end{array}$ \\
\hline$\Delta I P_{j, t}$ & $\begin{array}{c}0.004 \\
(0.016)\end{array}$ & $\begin{array}{c}0.001 \\
(0.015)\end{array}$ & $\begin{array}{c}-0.053^{*} \\
(0.032)\end{array}$ & $\begin{array}{l}-0.057^{*} \\
(0.032)\end{array}$ \\
\hline Industr & Yes & Yes & Yes & Yes \\
\hline Number of Industries & 63 & 63 & 63 & 63 \\
\hline $\mathrm{N}$ & 10,586 & 10,586 & 10,586 & 10,586 \\
\hline
\end{tabular}

Table 5: Price Setting Behavior and Macroeconomic Shocks

Note: Sample period: 1998:M1 to 2014:M12 at a monthly frequency. The dependent variable is the standard deviation of price change of a 4-digit NAICS industry in the manufacturing sector in column (1) and (2), and the frequency of price change in column (3) and (4). All industries within the oil producing NAICS 324 sector are excluded. $\Delta \log \left(P_{t-1}^{o}\right)$ and $\sigma_{t-1}$ are real oil price inflation and oil price volatility using the extracted stochastic volatility measure. [Durable $=1$ ] is an indicator variable if industry $j$ is a durable goods industry, $\pi_{j, t}$ is the average item level inflation rate for industry $j$, Realized Stock $\operatorname{Vol}_{j, t}$ is the median industry realized stock volatility of industry $j$ at time $t, \mathrm{EBP}$ is the excess bond premium, and $\Delta I P_{j, t}$ is the change in the industrial production index of industry $j$ at time $t$. Robust asymptotic standard errors reported in parentheses are double clustered at the industry-month level: ${ }^{*} p<.10$; $^{* *} p<.05$; and ${ }^{* * *} p<.01$.

aggregation includes on average nearly 500 items at the industry month level, allowing me to construct reasonably precise price change dispersion and frequency while limiting the amount of heterogeneity within an industry.

Column (1) shows the baseline results when price change standard deviation is the dependent variable. Oil price inflation and volatility are included with a one month lag which reduces the potential endogeneity. The second row shows the coefficient of interest for oil price volatility. 
The results show that increases in oil price volatility increase the average producer price change dispersion. ${ }^{24} \mathrm{~A}$ one standard deviation increase in oil price volatility implies that the average price change dispersion will increase by is 0.005 . This estimate implies a $4 \%$ increase in price change dispersion relative to the mean for the average industry since the unweighted average price change standard deviation is 0.109 . The excess bond premium does not affect price change dispersion in this regression. Realized stock volatility is positively associated with price change dispersion, but is not statistically significant. Oil price inflation and lagged industry inflation are positive but insignificant.

Column (3) is the baseline estimate when price change frequency is the dependent variable. The estimated coefficient for oil price volatility is nearly zero. Realized stock volatility is positive and highly significant, suggesting that increases in idiosyncratic volatility are associated with increases in price change frequency. Industry inflation is also highly correlated with price change frequency. ${ }^{25}$

Columns (2) and (4) separate the effect of oil price inflation and volatility into durable and non-durable goods industries for price change dispersion and frequency. Barsky et al. (2007) show that it is the flexibility of durable goods that matters for monetary policy. The regression results show that there is not a differential effect of oil price volatility on price change dispersion or frequency for durable goods relative to non-durable goods.

The previous regressions show that producer pricing change dispersion is correlated with oil price volatility over time, while price change frequency has no relationship. Further, it suggests that increases in idiosyncratic volatility are associated with increased price change frequency. However it does not identify how changes in oil price volatility impact price change dispersion or frequency due to potential omitted variables. In order to identify this relationship I will exploit heterogeneity in oil usage across industries to construct industry specific oil demand variables.

\section{III.3 Industry Specific Oil Volatility}

I now construct industry specific oil demand variables in order to identify the effects of oil price volatility on industry level pricing behavior. The empirical strategy uses variation in oil price and volatility interacted with a preexisting share of oil that represents the importance of oil in each industry's cost function. The idea behind the demand variables is to exploit the heterogeneity

\footnotetext{
${ }^{24}$ In Appendix B.4.3, I show that the aggregate empirical price change distribution is more disperse during periods of high oil price volatility relative to low oil price volatility.

${ }^{25}$ Using lagged industry inflation does not change the sign or significance of any other covariate.
} 
in industry oil usage, which is a measure of the importance of oil prices from the cost channel. Industries that use more oil should respond more strongly to oil price shocks than industries that are not as reliant on oil. The industry specific oil demand variables allow me to control for any common shocks over time and any time invariant differences between industries, which enables identification of oil price volatility shocks on price setting behavior.

The oil demand variables are constructed similar to those used in Shea (1993), Perotti (2007), or Nekarda and Ramey (2011) who study the effects of fiscal policy on industries. The Input-Output tables contain information on the dollar amount of oil used as well as industry production. A preexisting oil usage sensitivity is constructed to remove dependence on the current year's oil price. There is substantial variation in experiences after an oil price volatility shock due to the heterogeneity in oil usage across industries. An industry that does not use oil would be unlikely to experience any immediate changes in costs due to oil price volatility changes, while an industry with a large share of oil will need to adjust prices by a larger amount to reset their optimal price. Constructing industry specific oil price variables allows use of industry and time fixed effects, thereby studying the partial equilibrium effects of an aggregate volatility shock. This partial equilibrium effect allows me to study the mechanism through which volatility shocks affect price setting behavior. ${ }^{26}$

The Benchmark IO use table at detailed NAICS industry level from 1997 is used to construct the oil sensitivity measure. An industry's oil sensitivity is given by:

$$
s_{o, j}=\frac{\text { Nominal Dollars Spent on Oil Input Industry } j \text { in } 1997}{\text { Nominal Dollars Value Added Industry } j \text { in } 1997}
$$

where $j$ indexes a 4 -digit NAICS industry. ${ }^{27}$ This sensitivity to oil usage is motivated by an industry's oil share of production. ${ }^{28}$ The oil usage measure is constructed using data from before

\footnotetext{
${ }^{26}$ Another reason to focus on the partial equilibrium effect is because it allows me to abstract away from oil in the household consumption function, and focus on producers oil usage as an input.

${ }^{27}$ The oil producing sector is defined at 6-digit NAICS level as NAICS 324110, Petroleum Refining.

${ }^{28}$ In a different context, Edelstein and Kilian (2007) study the response of business fixed investment to changes in energy prices using weighted price shocks. The share of energy inputs in GDP is the sum of nominal value added in oil and gas extraction and imports of petroleum and petroleum products, divided by nominal GDP.
} 
the sample, reducing concerns about reverse causality between oil usage and oil price. ${ }^{29}$

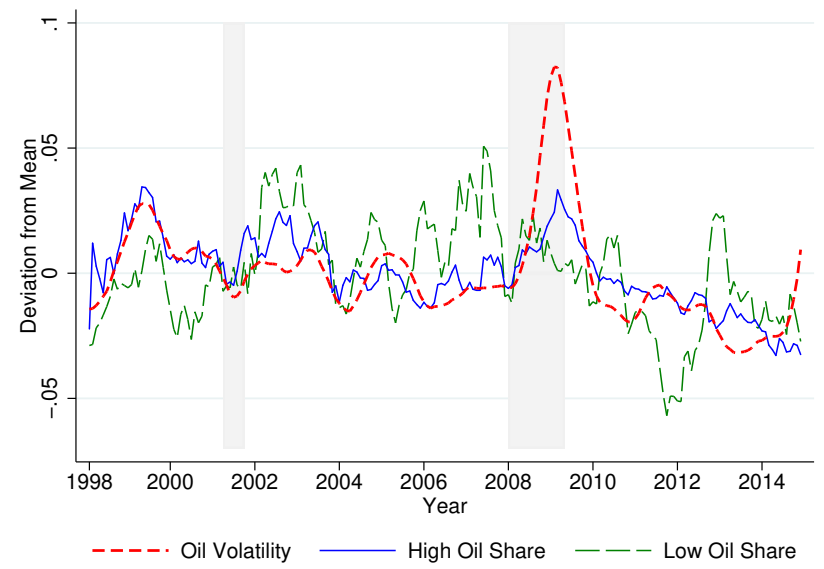

(a) S.D.

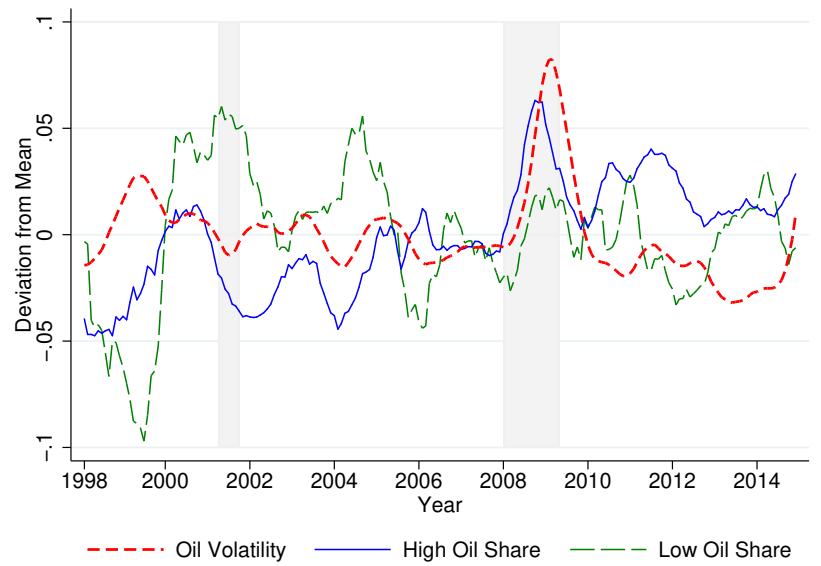

(b) Frequency

Figure 5: Average Pricing Moment for High and Low Oil Share Industries.

Note: In Panel (a), average price change dispersion for the top and bottom $10 \%$ of industries in each month is plotted with the stochastic volatiliy of oil prices. In Panel (b), average price change frequency for the top and bottom $10 \%$ of industries in each month is plotted with the stochastic volatiliy of oil prices. Data is demeaned, seasonally adjusted with the X-12 filter, and then presented as a 6 month moving average. The shaded areas represent NBER-dated recessions.

Oil demand variables for oil price volatility and change are then constructed by interacting the preexisting oil share, $s_{o, j}$, with real oil price volatility or real oil price inflation. These oil demand variables are in the spirit of 'Bartik' style measures, an interaction between a predefined share of oil usage within a narrowly defined manufacturing industry and aggregate changes in real oil price inflation or volatility. The idea behind this measure is that global changes in oil price and volatility differentially impacted industries because of preexisting oil usage technology. The sensitivity, $s_{o, j}$, is a directional measure of the degree to which oil price and volatility movements will affect price setting behavior.

Figure 5 illustrates the identification and previews the main result by comparing the price change dispersion or frequency time series for high and low oil share industries with oil price volatility. I define the high and low oil share sectors as the $10 \%$ of industries with the highest

\footnotetext{
${ }^{29}$ An alternative long run measure of oil usage is constructed by averaging over the detailed IO tables from 1997 , 2002, and 2007 in order to reduce the sensitivity of the measure to short run effects of oil price changes. An industry's oil share of production could change over time due to technological change or substitution towards or away from oil due to changes in oil price. Specifically, $\overline{s_{o, j}}=\sum_{t=1}^{T} \frac{s_{o, j, t}}{T}$, is defined as the long run usage and is in the spirit of Nekarda and Ramey (2011). Results using this measure are in Table 18 and show the results are robust to this measure.
} 
or lowest oil share each period. In Panel (a), price change standard deviation is shown. The correlation between the high oil share sector average price change dispersion and oil price volatility is 0.45 , while the correlation between the low oil share sector average price change dispersion and oil price volatility is only 0.08 . This figure suggests that industries that are more oil intensive have greater price change dispersion during periods of high oil price volatility. In Panel (b), price change frequency is shown. The correlation between the average price change frequency of the high oil share sector and oil price volatility is 0.12 , while the correlation between the low oil share sector average price change frequency and oil price volatility is -0.02 . This figure is consistent with the earlier results that show that price change dispersion is positively related to oil price volatility, while price change frequency has no or little relationship.

However the correlation between price change dispersion or frequency and oil price volatility for high and low oil share industries does not control for aggregate shocks or cyclical changes in production by industry. Using the oil demand variables I control for both industry differences and time variation in common shocks such as aggregate volatility or financial constraints through the use of time fixed effects. The main regressions of interest are the specifications:

$$
\begin{gathered}
S . D \cdot j, t=\eta_{S D} *\left(s_{o, j} * \Delta \log \left(P_{t-1}^{o}\right)\right)+\lambda_{S D} *\left(s_{o, j} * \sigma_{t-1}\right)+\gamma_{S D}^{\prime} X_{j, t}+\alpha_{S D, j}+\alpha_{S D, t}+\epsilon_{S D, j t} \\
\text { Frequency }{ }_{j, t}=\eta_{F} *\left(s_{o, j} * \Delta \log \left(P_{t-1}^{o}\right)\right)+\lambda_{F} *\left(s_{o, j} * \sigma_{t-1}\right)+\gamma_{F}^{\prime} X_{j, t}+\alpha_{F, j}+\alpha_{F, t}+\epsilon_{F, j t}
\end{gathered}
$$

where $S . D \cdot j, t$ is price change standard deviation and Frequency $y_{j, t}$ is price change frequency. The coefficients of interest are $\lambda_{S D}$ and $\lambda_{F}$, and are the marginal effect of an increase in oil price volatility for an industry with oil share $s_{o, j}$ on price change standard deviation or frequency respectively. $X_{j, t}$ are a vector of control variables that can influence pricing behavior. Controls include industrial production growth and industry inflation. Identification of volatility comes from variation across time within an industry for a given $s_{o, j}$. The main results using stochastic volatility of oil prices are in Table $6 . .^{30}$

The identifying assumption is that the interaction of oil price volatility and oil share is not correlated with unobserved shocks to an individual industry. Separate identification of oil price and oil price volatility comes from the fact that oil prices and volatility do not move together. The exogeneity of the variable hinges on each industry being a price taker in the global oil market, as

\footnotetext{
${ }^{30}$ Results using GARCH volatility and realized volatility of real oil price are in Appendix B.3.1. They have similar implications for pricing behavior as stochastic volatility.
} 


\begin{tabular}{|c|c|c|c|c|c|c|c|c|}
\hline \multirow[t]{2}{*}{ Dependent Variable: } & \multicolumn{4}{|c|}{ S.D. } & \multicolumn{4}{|c|}{ Frequency } \\
\hline & (1) & (2) & (3) & (4) & $(5)$ & (6) & (7) & (8) \\
\hline$s_{o, j} * \Delta \log \left(P_{t-1}^{o}\right)$ & $\begin{array}{c}0.249 \\
(0.224)\end{array}$ & $\begin{array}{c}0.239 \\
(0.220)\end{array}$ & $\begin{array}{c}0.175 \\
(0.185)\end{array}$ & $\begin{array}{c}0.207 \\
(0.186)\end{array}$ & $\begin{array}{c}-0.361^{* * *} \\
(0.110)\end{array}$ & $\begin{array}{c}-0.481^{* * *} \\
(0.129)\end{array}$ & $\begin{array}{c}-0.406^{* * *} \\
(0.129)\end{array}$ & $\begin{array}{r}-0.330^{* * *} \\
(0.087)\end{array}$ \\
\hline$s_{o, j} * \sigma_{t-1}$ & $\begin{array}{c}4.511^{* * *} \\
(1.044)\end{array}$ & $\begin{array}{c}4.540^{* * *} \\
(1.059)\end{array}$ & $\begin{array}{c}4.092^{* * *} \\
(0.913)\end{array}$ & $\begin{array}{c}3.864^{* * *} \\
(0.858)\end{array}$ & $\begin{array}{c}-2.486^{* *} \\
(1.115)\end{array}$ & $\begin{array}{c}-2.142 \\
(1.311)\end{array}$ & $\begin{array}{c}-2.376^{*} \\
(1.260)\end{array}$ & $\begin{array}{c}-1.053^{*} \\
(0.625)\end{array}$ \\
\hline$\pi_{j, t}$ & & $\begin{array}{c}0.073 \\
(0.118)\end{array}$ & $\begin{array}{c}0.069 \\
(0.116)\end{array}$ & $\begin{array}{c}0.071 \\
(0.113)\end{array}$ & & $\begin{array}{c}0.851^{* * *} \\
(0.201)\end{array}$ & $\begin{array}{c}0.901^{* * *} \\
(0.223)\end{array}$ & $\begin{array}{c}0.832^{* * *} \\
(0.188)\end{array}$ \\
\hline$\Delta I P_{j, t}$ & & & $\begin{array}{c}0.003 \\
(0.014)\end{array}$ & $\begin{array}{l}-0.001 \\
(0.015)\end{array}$ & & & $\begin{array}{l}-0.046 \\
(0.030)\end{array}$ & $\begin{array}{l}-0.052 \\
(0.035)\end{array}$ \\
\hline S.D. $\cdot j, t-1$ & & & & $\begin{array}{c}0.067^{* * *} \\
(0.016)\end{array}$ & & & & \\
\hline Frequency $_{j, t-1}$ & & & & & & & & $\begin{array}{c}0.547^{* * *} \\
(0.040)\end{array}$ \\
\hline$\overline{s_{o}} * \sigma_{t-1}$ & $\begin{array}{c}0.038^{* * *} \\
(0.009)\end{array}$ & $\begin{array}{c}0.038^{* * *} \\
(0.009)\end{array}$ & $\begin{array}{c}0.034^{* * *} \\
(0.008)\end{array}$ & $\begin{array}{c}0.032^{* * *} \\
(0.007)\end{array}$ & $\begin{array}{c}-0.021^{* *} \\
(0.009)\end{array}$ & $\begin{array}{l}-0.018 \\
(0.011)\end{array}$ & $\begin{array}{l}-0.020^{*} \\
(0.011)\end{array}$ & $\begin{array}{l}-0.009^{*} \\
(0.005)\end{array}$ \\
\hline Industry FE & Yes & Yes & Yes & Yes & Yes & Yes & Yes & Yes \\
\hline Time FE & Yes & Yes & Yes & Yes & Yes & Yes & Yes & Yes \\
\hline Number of Industries & 81 & 81 & 63 & 63 & 81 & 81 & 63 & 63 \\
\hline $\mathrm{N}$ & 13,606 & 13,606 & 10,946 & 10,939 & 13,606 & 13,606 & 10,946 & 10,946 \\
\hline
\end{tabular}

Table 6: Industry Specific Oil Demand Variables Regression

Note: Sample period: 1998:M1 to 2014:M12 at a monthly frequency. The dependent variable is the standard deviation of price change of a 4-digit NAICS industry in the manufacturing sector in columns (1)-(4) and price change frequency in column (5)-(8). All industries within the oil producing NAICS 324 sector are excluded. $s_{o, j} * \Delta \log \left(P_{t-1}^{o}\right)$ and $s_{o, j} * \sigma_{t-1}$ are the industry specific oil demand variables using monthly WTI real price of oil. $\pi_{j, t}$ is the average item level inflation rate for industry j. $\sigma_{t}$ is the extracted stochastic volatility measure of oil price volatility. S.D. $j, t-1$ is lagged industry price change standard deviation. Frequency ${ }_{j, t-1}$ is lagged industry price change frequency. $\overline{s_{o}} * \sigma_{t-1}$ is the transformed coefficient for a marginal change in oil price volatility for an average industry with oil share of 0.008. Robust asymptotic standard errors reported in parentheses are clustered at the industry level: $* p<.10$; ** $p<.05 ;$ and ${ }^{* * *} p<.01$.

well as the degree to which oil usage is irreversible in the short run. However oil is likely to be characterized by large amounts of specific capital or irreversible investment as a material input or energy source which make it difficult to quickly substitute away from.

Columns (1) through (4) show the results when price change standard deviation is the dependent variable. The regression results show that after controlling for differences across time and between industries, an increase in oil price volatility increases price change dispersion for industries that are more oil dependent. As a relative effect, the estimate in column (1) implies that a one standard deviation increase in oil price volatility increases price change dispersion for an industry at the $90^{t h}$ percentile of oil share relative to the $10^{\text {th }}$ percentile of oil share by 0.002 , or almost 2 percent relative to the average price change standard deviation. Changes in industrial production are negatively correlated with price change dispersion in aggregate data as shown by Vavra (2014), 
but at the industry level I find no relationship between industrial production and price change dispersion. Industry specific oil price inflation has no estimated effect on price change dispersion. Columns (2) through (4) show the result is robust to controlling for industry inflation, industrial production growth, and a lagged price change dispersion. ${ }^{31}$

Frequency of price change is the dependent variable in columns (5) through (8). The results show that oil price volatility is negatively associated with price change frequency. After controlling for differences across time and between industries, an increase in oil price volatility decreases price change frequency for industries that are more oil dependent. The estimate in column (5) implies that a one standard deviation increase in oil price volatility decreases price change frequency for an industry at the $90^{t h}$ percentile of oil share relative to the $10^{\text {th }}$ percentile of oil share by 0.001 , or by almost 1 percent relative to the average price change frequency. The result is robust to inclusion of added controls in columns (6) through (8). ${ }^{32}$

It has been argued by Gilchrist et al. (2017) that financial frictions impacted prices differentially during the financial crisis in 2008. Given that this is the same period when the largest movements in oil price volatility occurred, an indicator variable is included to examine if the large changes in oil prices and volatility had differential effects during the financial crisis period of 2008. Column (1) in Table 7 shows that even with the doubling of oil price volatility during 2008, it has the same effect on price change dispersion within and outside of the crisis period. Column (5) shows that the negative relative relationship between price change frequency and oil price volatility is stronger outside of the crisis period.

As an additional robustness exercise, columns (2) and (6) use realized volatility of real oil price rather than the extracted stochastic volatility. This measure is noiser by construction, as it is the within month standard deviation of daily real oil price changes. It shows the same positive relationship between price change dispersion and oil price volatility, and negative relationship between price change frequency and oil price volatility seen using stochastic volatility. Columns (3) and (7) show that results remain unchanged when Brent Crude oil price and its extracted stochastic volatility are used rather than the WTI oil price. Lastly, columns (4) and (8) control for idiosyncratic volatility using the median realized stock volatility within each industry $i$ at time $t$. The variable is not significantly related to either pricing measure. The results show that after

\footnotetext{
${ }^{31}$ Table 26 in the Appendix shows that the results are robust when other measures of price change dispersion such as the interquartile range or standard deviation of price changes including zeros is used.

${ }^{32}$ The results are robust to trimming methodology for price changes. In Appendix B.2.1, I show the results when no monthly industry observations are dropped due to small numbers of price changes.
} 


\begin{tabular}{|c|c|c|c|c|c|c|c|c|}
\hline \multirow[t]{2}{*}{ Dependent Variable: } & \multicolumn{4}{|c|}{ S.D. } & \multicolumn{4}{|c|}{ Frequency } \\
\hline & (1) & $(2)$ & (3) & (4) & (5) & (6) & $(7)$ & (8) \\
\hline$[\text { Crisis }=0]^{*} \Delta \log \left(P_{t-1}^{o}\right)$ & $0.361^{*}$ & & & & $-0.236^{* *}$ & & & \\
\hline$[\text { Crisis }=1]^{*} \Delta \log \left(P_{t-1}^{o}\right)$ & -0.327 & & & & $-1.373^{* * *}$ & & & \\
\hline & $(0.482)$ & & & & $(0.432)$ & & & \\
\hline$[\text { Crisis }=0]^{*} s_{o, j} * \sigma_{t-1}$ & $3.859^{* * *}$ & & & & $-3.781^{* * *}$ & & & \\
\hline$[\text { Crisis }=1]^{*} s_{o, j} * \sigma_{t-1}$ & $\begin{array}{c}(1.246) \\
4.345^{* * *} \\
(1.131)\end{array}$ & & & & $\begin{array}{c}(1.128) \\
-2.143 \\
(2.080)\end{array}$ & & & \\
\hline$s_{o, j} * \Delta \log \left(P_{t-1}^{o}\right)$ & & $\begin{array}{c}0.458 \\
(0.297)\end{array}$ & $\begin{array}{c}0.128 \\
(0.169)\end{array}$ & $\begin{array}{c}0.250 \\
(0.226)\end{array}$ & & $\begin{array}{c}-0.714^{* * *} \\
(0.164)\end{array}$ & $\begin{array}{c}-0.604^{* * *} \\
(0.188)\end{array}$ & $\begin{array}{c}-0.508^{* * *} \\
(0.126)\end{array}$ \\
\hline$s_{o, j} * \sigma_{t-1}$ & & $\begin{array}{c}7.686^{* * *} \\
(2.855)\end{array}$ & $\begin{array}{l}2.081^{*} \\
(1.072)\end{array}$ & $\begin{array}{c}4.411^{* * *} \\
(1.003)\end{array}$ & & $\begin{array}{c}-6.154^{* * *} \\
(1.641)\end{array}$ & $\begin{array}{c}-7.718^{* * *} \\
(1.394)\end{array}$ & $\begin{array}{l}-2.055 \\
(1.390)\end{array}$ \\
\hline$\pi_{j, t}$ & $\begin{array}{c}0.073 \\
(0.119)\end{array}$ & $\begin{array}{c}0.073 \\
(0.118)\end{array}$ & $\begin{array}{c}0.069 \\
(0.119)\end{array}$ & $\begin{array}{c}0.064 \\
(0.123)\end{array}$ & $\begin{array}{c}0.848^{* * *} \\
(0.202)\end{array}$ & $\begin{array}{c}0.849^{* * *} \\
(0.201)\end{array}$ & $\begin{array}{c}0.848^{* * *} \\
(0.201)\end{array}$ & $\begin{array}{c}0.850^{* * *} \\
(0.204)\end{array}$ \\
\hline Realized Stock $\operatorname{Vol}_{j, t}$ & & & & $\begin{array}{c}0.027 \\
(0.028)\end{array}$ & & & & $\begin{array}{l}0.048 \\
(0.029)\end{array}$ \\
\hline Industry FE & Yes & Yes & Yes & Yes & Yes & Yes & Yes & Yes \\
\hline Time FE & Yes & Yes & Yes & Yes & Yes & Yes & Yes & Yes \\
\hline Number of Industries & 81 & 81 & 81 & 80 & 81 & 81 & 81 & 80 \\
\hline $\mathrm{N}$ & 13,606 & 13,606 & 13,606 & 13,162 & 13,606 & 13,606 & 13,606 & 13,162 \\
\hline
\end{tabular}

Table 7: Robustness Analysis

Note: Sample period: 1998:M1 to 2014:M12 at a monthly frequency. Columns (1) and (5) use the stochastic volatility measure of oil price volatility. Crisis year indicator is defined as 1 during 2008 and 0 otherwise. This is the same crisis definition timing as Gilchrist et al. (2015). Columns (2) and (6) use the realized volatility measure of oil price volatility. Columns (3) and (7) uses Brent Crude oil prices and stochastic volatility with 4-digit NAICS industries. Column (4) and (8) uses the stochastic volatility measure of oil price volatility with 4-digit NAICS industries and includes the median industry realized stock volatility. No stock data is available from NAICS 3161, "Leather and Hide Tanning and Finishing", reducing the number of industries. Robust asymptotic standard errors reported in parentheses are clustered at the industry level: ${ }^{*} p<.10 ;{ }^{* *} p<.05$; and ${ }^{* * *} p<.01$.

controlling for an additional measure of industry level volatility, oil price volatility still increases the dispersion of price changes while having a negative effect on frequency.

The empirical analysis provides evidence that oil price volatility, a common cost volatility shock, is positively related to price change dispersion at the industry level. Industries that use more oil exhibit greater price change dispersion in response to high oil price volatility. Further, price change frequency has a negative relative relationship with oil price volatility, causing higher oil usage industries to have relatively higher price stickiness during periods of high oil price volatility. These results imply that aggregate price flexibility should not increase during periods of high oil price volatility. The next section will examine the relationship between oil price volatility and price change dispersion in a state dependent general equilibrium model of price setting. 


\section{Menu Cost Model}

This section presents a menu cost model of price setting in order to quantify the effects of volatility on monetary non-neutrality. The baseline quantitative menu cost model features random menu costs such as in Dotsey et al. (1999) or Luo and Villar (2020). It includes the leptokurtic productivity shocks as in Midrigan (2011) and a small probability of a free price change such as in Nakamura and Steinsson (2010). Oil is modeled as a non-produced input in the firm production function with an exogenous real price as in Blanchard and Galí (2007), with a time varying second moment to represent volatility shocks.

The price setting model features random menu costs, which reduce the selection effect by issuing firms a random heterogeneous menu cost each period. The random menu costs imply firms have a differential likelihood of changing prices based on the menu cost they receive. This mechanism alters the mix of price changes and enables the model to match the positive relationship between the aggregate volatility shock and price change dispersion. ${ }^{33}$ This feature also dampens the increase in price change frequency, by having some fixed costs be large enough such that a firm would never choose to change the price that period.

The model is then augmented with time varying idiosyncratic volatility. With this new mechanism, the model is able to match the empirical facts in Vavra (2014). Increases in idiosyncratic volatility increase both price change frequency and price change dispersion. This result shows that the use of random menu costs do not overturn the implications of his model featuring fixed menu costs.

The random menu cost model with time varying oil price volatility is then extended to a multisector setting in order to quantitatively match the empirical results. Sectors are heterogeneous in their oil usage and pricing behavior. The empirically observed oil price and volatility series are simulated in the model, generating pricing moments that directly map the model to the data. A regression using model generated data shows that it can match the empirical relationship that industries with high oil usage have relatively higher price change dispersion during periods of high oil price volatility.

Monetary policy effectiveness is then quantified in the multisector model. I find that monetary policy is only slightly less effective when oil price volatility is increased. The model shows that monetary policy's ability to stimulate consumption on impact of the monetary shock falls by $0.5 \%$

\footnotetext{
${ }^{33}$ In Appendix A.3, I show that a model featuring fixed menu costs like in Golosov and Lucas (2007) features too strong of a selection effect, causing price change dispersion to fall when oil price volatility is increased.
} 
during a one standard deviation increase in oil price volatility.

\section{IV.1 Households}

A model of price setting with first and second moment shocks to real oil prices is now presented. Households maximize current expected utility, given by

$$
E_{t} \sum_{\tau=0}^{\infty} \beta^{t}\left[\log \left(C_{t+\tau}\right)-\omega L_{t+\tau}\right]
$$

They consume a continuum of differentiated products indexed by $z$. The composite consumption good $C_{t}$ is the Dixit-Stiglitz aggregate of these differentiated goods,

$$
C_{t}=\left[\int_{0}^{1} c_{t}(z)^{\frac{\theta-1}{\theta}} d z\right]^{\frac{\theta}{\theta-1}}
$$

where $\theta$ is the elasticity of substitution between the differentiated goods.

Households decide each period how much to consume of each differentiated good. For any given level of spending in time $t$, households choose the consumption bundle that yields the highest level of the consumption index $C_{t}$. This implies that household demand for differentiated good $z$ is

$$
c_{t}(z)=C_{t}\left(\frac{p_{t}(z)}{P_{t}}\right)^{-\theta}
$$

where $p_{t}(z)$ is the price of good $\mathrm{z}$ at time $\mathrm{t}$ and $P_{t}$ is the price level in period $t$, calculated as

$$
P_{t}=\left[\int_{0}^{1} p_{t}(z)^{1-\theta} d z\right]^{\frac{1}{1-\theta}}
$$

A complete set of Arrow-Debreu securities is traded, which implies that the budget constraint of the household is written as

$$
P_{t} C_{t}+E_{t}\left[D_{t, t+1} B_{t+1}\right] \leq B_{t}+W_{t} L_{t}+\int_{0}^{1} \pi_{t}(z) d z+T_{t}
$$

where $B_{t+1}$ is a random variable that denotes state contingent payoffs of the portfolio of financial assets purchased by the household in period $t$ and sold in period $\mathrm{t}+1 . D_{t+1}$ is the unique stochastic discount factor that prices the payoffs, $W_{t}$ is the wage rate of the economy at time $t, \pi_{t}(z)$ is the 
profit of firm $z$ in period t. $T_{t}$ are lump sum government transfers. A no ponzi game condition is assumed so that household financial wealth is always large enough and future income is high enough to avoid default.

The first order conditions of the household maximization problem are

$$
\begin{gathered}
D_{t, t+1}=\beta\left(\frac{C_{t} P_{t}}{C_{t+1} P_{t+1}}\right) \\
\frac{W_{t}}{P_{t}}=\omega C_{t}
\end{gathered}
$$

where equation (14) describes the relationship between asset prices and consumption, and (15) describes labor supply.

\section{IV.2 Firms}

In the model there are a continuum of firms indexed by $z$ and sector $j$. The production function of firm $z$ is Cobb-Douglas in labor and oil.

$$
y_{t}(z)=A_{t}(z) L_{t}(z)^{1-s_{o, j}} O_{t}(z)^{s_{o, j}}
$$

where $L_{t}(z)$ is labor rented from households and $O_{t}(z)$ is the quantity of oil used to produce output.

Firm $z$ maximizes the present discounted value of future profits

$$
E_{t} \sum_{\tau=0}^{\infty} D_{t, t+\tau} \pi_{t+\tau}(z)
$$

where profits are given by:

$$
\pi_{t}(z)=p_{t}(z) y_{t}(z)-W_{t} L_{t}(z)-Q_{t} O_{t}(z)-\chi_{t, j}(z) W_{t} I_{t}(z), \chi_{t, j}(z) \stackrel{i i d}{\sim} F_{j}(\chi)
$$

and $Q_{t}$ is the nominal price of oil. $I_{t}(z)$ is an indicator function equal to one if the firm changes its price and equal to zero otherwise. $\chi_{t, j}(z)$ is a menu cost drawn from the distribution $F_{j}(\chi) .{ }^{34}$ The random menu cost model uses a continuous distribution where menu costs are drawn independently each period. The next section will further explain this feature. The final term indicates that firms

\footnotetext{
${ }^{34}$ In the fixed menu cost model in Appendix A.3, $F_{j}(\chi)$ is a degenerate distribution which implies a single menu cost $\chi_{j}$ as in the model of Golosov and Lucas (2007).
} 
must hire an extra $\chi_{t, j}(z)$ units of labor if they decide to change prices with probability $1-\alpha_{j}$, or may change their price for free with probability $\alpha_{j} \cdot{ }^{35} \mathrm{~A}$ small probability of receiving a free price change enables the model to generate small price changes.

Total demand for good $z$ is given by:

$$
y_{t}(z)=Y_{t}\left(\frac{p_{t}(z)}{P_{t}}\right)^{-\theta}
$$

The firm problem is to maximize profits in (18) subject to its production function (16), demand for its final good product (19), and the behavior of aggregate variables.

Firms supply all goods demanded at a given price. Cost minimization given oil and labor prices implies:

$$
\frac{1-s_{o, j}}{s_{o, j}} \frac{O_{t}(z)}{L_{t}(z)}=\frac{W_{t}}{Q_{t}}
$$

The log of firm productivity follows a mean reverting process with leptokurtic shocks as in Gertler and Leahy (2008) and Midrigan (2011):

$$
\log A_{t}(z)= \begin{cases}\rho_{a, j} \log A_{t-1}(z)+\sigma_{a, j} \epsilon_{t}(z) & \text { with probability } p_{a, j} \\ \log A_{t-1}(z) & \text { with probability } 1-p_{a, j}\end{cases}
$$

where $\epsilon_{t}(z) \sim \mathrm{N}(0,1)$.

Nominal aggregate spending follows a random walk with drift:

$$
\log \left(S_{t}\right)=\mu+\log \left(S_{t-1}\right)+\sigma_{s} \eta_{t}
$$

where $S_{t}=P_{t} C_{t}$ and $\eta_{t} \sim \mathrm{N}(0,1)$. This is a standard way to model nominal aggregate spending in a menu cost model.

The oil price process follows Blanchard and Galí (2007), by assuming that oil is a non-produced input purchased in a world market at real price $P_{t}^{o}$. The log of $P_{t}^{o}$ follows an $\mathrm{AR}(1)$ process with time varying standard deviation:

$$
\log P_{t}^{o}=\rho_{p} \log P_{t-1}^{o}+e^{\sigma_{t}} \nu_{t}
$$

\footnotetext{
${ }^{35}$ This is a reduced form mechanism representing multiproduct firms in Midrigan (2011).
} 
where $\nu_{t}(z) \sim \mathrm{N}(0,1)$.

To model time varying volatility of oil prices, it is assumed that the standard deviation of oil prices follows a mean reverting $\mathrm{AR}(1)$ process as estimated in section II.3:

$$
\sigma_{t}=\left(1-\rho_{\sigma}\right) \bar{\sigma}+\rho_{\sigma} \sigma_{t-1}+\phi \nu_{\sigma, t}
$$

where $\nu_{\sigma, t}(z) \sim \mathrm{N}(0,1)$ and $\bar{\sigma}$ is the unconditional mean of $\sigma_{t}$.

The state space of the firms problem is an infinite dimensional object because the evolution of the aggregate price level depends on the joint distribution of all firms' prices, productivity levels, and menu costs. It is assumed that firms only perceive the evolution of the price level as a function of a small number of moments of the distribution as in Krusell and Smith (1998). In particular, I assume that firms use a forecasting rule of the form:

$$
\log \left(\frac{P_{t}}{S_{t}}\right)=\gamma_{0}+\gamma_{1} \log P_{t}^{o}+\gamma_{2} \sigma_{t}+\gamma_{3} \log \left(\frac{P_{t-1}}{S_{t}}\right)+\gamma_{4}\left(\log \left(\frac{P_{t-1}}{S_{t}}\right) * \log P_{t}^{o}\right)+\gamma_{5}\left(\log \left(\frac{P_{t-1}}{S_{t}}\right) * \sigma_{t}\right)
$$

The accuracy of the rule is checked using the maximum Den Haan (2010) statistic in a dynamic forecast. ${ }^{36}$

Using equations (14), (15), (16), (18), (19), (20), (25) and market clearing I am able to write the firm problem recursively as:

$$
\begin{array}{r}
V\left(A_{t}(z), \frac{p_{t-1}(z)}{S_{t}}, P_{t}^{o}, \sigma_{t}, \chi_{t, j}(z), \psi_{t}\right)=\max _{p_{t}(z)}\left\{V^{N}\left(A_{t}(z), \frac{p_{t-1}(z)}{S_{t}}, P_{t}^{o}, \sigma_{t}, \psi_{t}\right),\right. \\
\left.V^{A}\left(A_{t}(z), P_{t}^{o}, \sigma_{t}, \chi_{t, j}(z), \psi_{t}\right)\right\}
\end{array}
$$

where $\psi_{t}$ is the Krusell-Smith aggregate state describing the joint distribution of prices, productivities, and menu costs. $\pi_{t}^{R}(z)$ is firm $z$ 's real profits in period $t$, and $D_{t, t+1}^{R}$ is the real stochastic discount factor between periods $t$ and $t+1$. Nominal variables have been normalized by current aggregate nominal spending in the economy to bound the state space. $V^{N}$ and $V^{A}$ are the values of not adjusting and adjusting the current period's relative price. The value of not adjusting is given by:

\footnotetext{
${ }^{36}$ Adding price change dispersion to the forecasting rule does not qualitatively affect the model predictions.
} 


$$
\begin{array}{r}
V^{N}\left(A_{t}(z), \frac{p_{t-1}(z)}{S_{t}}, P_{t}^{o}, \sigma_{t}, \psi_{t}\right)=\pi_{t}^{R}\left(\frac{p_{t-1}(z)}{S_{t}}, A_{t}(z), P_{t}^{o}, \sigma_{t}, \psi_{t}\right) \\
+E_{t}\left[D_{t, t+1}^{R} V\left(A_{t+1}(z), \frac{p_{t-1}(z)}{S_{t+1}}, P_{t+1}^{o}, \sigma_{t+1}, \chi_{t, j}(z), \psi_{t+1}\right)\right]
\end{array}
$$

while the value of adjusting the current price is given by:

$$
\begin{array}{r}
V^{A}\left(A_{t}(z), P_{t}^{o}, \sigma_{t}, \chi_{t, j}(z), \psi_{t}\right)=-\chi_{t, j}(z) \frac{W_{t}}{P_{t}}+\pi_{t}^{R}\left(\frac{p_{t}(z)}{S_{t}}, A_{t}(z), P_{t}^{o}, \sigma_{t}, \psi_{t}\right) \\
+E_{t}\left[D_{t, t+1}^{R} V\left(A_{t+1}(z), \frac{p_{t}(z)}{S_{t+1}}, P_{t+1}^{o}, \sigma_{t+1}, \chi_{t, j}(z), \psi_{t+1}\right)\right]
\end{array}
$$

The model is solved by discretization and simulated using the non-stochastic simulation method of Young (2010). Full details on the solution method are available in the Appendix A.2.

\section{IV.3 Calibration and Results}

I first demonstrate that a one sector random menu cost model calibrated to aggregate pricing moments can generate the observed relationship between oil price volatility and price change dispersion. The model is then augmented with time varying idiosyncratic volatility to demonstrate that the random menu cost model can match the empirical facts in Vavra (2014). This section will discuss the calibration of the model.

There are three sets of parameters that need to be calibrated in the model. The first set are household parameters and aggregate shocks. ${ }^{37}$ These parameters are standard in menu cost models. It is a monthly model so the discount rate is set to $\beta=(0.96)^{\frac{1}{12}}$. Household utility is assumed to be log utility in consumption and linear disutility of labor. The elasticity of substitution is set to $\theta=4$ following Nakamura and Steinsson (2010). ${ }^{38}$ The average oil share of production is set to $s_{o}=0.008$, and matches the average oil share of production from the IO tables in 1997. The nominal shock process is calibrated so $\mu=0.002$ to match the difference between the mean growth rate of nominal GDP and the mean growth rate of real GDP over 1998 to 2012, and $\sigma_{s}=.0037$ to match the standard deviation of nominal GDP growth over the same period. The parameter values are given in Table 8.

The second set of parameters are for the real oil price and oil price volatility processes estimated in Section II.3. The oil price persistence parameter is $\rho_{o}=0.99$, oil price standard deviation

\footnotetext{
${ }^{37}$ These moments are common to the menu cost model in A.3.

${ }^{38}$ Other papers set higher values such as 6.8 in Vavra (2014) or 7 in Golosov and Lucas (2007), which imply lower values of the mark up.
} 


\begin{tabular}{lcc}
\hline Parameter & & Value \\
\hline$\theta$ & Elasticity of Substitution & 4.0 \\
$\beta$ & Discount Factor & $(0.96)^{\frac{1}{12}}$ \\
$\mu$ & Growth of Nominal Spending & 0.002 \\
$\sigma_{s}$ & Standard Deviation of Nominal Spending & 0.0037 \\
$\rho_{a}$ & Idiosyncratic TFP Persistence & 0.70 \\
$s_{o}$ & Oil Share of Production & 0.016 \\
\hline$\rho_{o}$ & Oil Price Persistence & 0.99 \\
$\bar{\sigma}$ & Oil Price Standard Deviation & 0.07 \\
$\rho_{\sigma}$ & Oil Volatility Persistence & 0.88 \\
$\phi$ & Oil Volatility Standard Deviation & 0.14 \\
\hline
\end{tabular}

Table 8: Common Calibration Parameters

$\bar{\sigma}=0.07$, oil price volatility persistence $\rho_{\sigma}=0.88$, and oil price volatility standard deviation is $\phi=0.14$. These numbers imply a high persistence for oil price and relatively low persistence for oil price volatility.

The final set of parameters are internally calibrated to the aggregate pricing moments in the one sector version of the model. These are the persistence and standard deviation of idiosyncratic productivity shocks $\rho_{a}$ and $\sigma_{a}$, the probability of an idiosyncratic productivity shock $p_{a}$, the two parameters related to the menu cost distribution, $\lambda$ and $\xi$, and the probability of a free price change $\alpha$.

The distribution from which random menu costs are drawn is now explained. The random menu costs are drawn from a transformation of an exponential distribution. This particular model specification is taken from Luo and Villar (2020). Specifically, random menu costs are drawn that are independent over time and across firms from the process:

$$
\chi_{t}(z)=\left\{\begin{array}{ll}
0 & \text { with probability } \alpha \\
\tilde{\chi}_{t} & \text { with probability } 1-\alpha,
\end{array} \text { where } F(k)=P(\tilde{\chi} \leq k)=1-e^{-\lambda k^{\xi}}\right.
$$

The parameter $\lambda$ determines the average value of the menu cost that is drawn, while $\xi$ determines the curvature of the distribution. Higher values of $\xi$ imply that a firm is less likely to draw very small or very large menu costs.

The six parameters are calibrated to moments of the price change distribution. Targeted moments are price change frequency, average size, fraction of small price changes, standard deviation 


\begin{tabular}{lcc}
\hline Price Setting Statistic & Data & Model \\
\hline Frequency & 0.154 & 0.153 \\
Average Size of Price Change & 0.071 & 0.087 \\
Fraction Small Price Changes & 0.215 & 0.210 \\
Standard Deviation Price Changes & 0.125 & 0.124 \\
Skewness Price Changes & 0.095 & 0.046 \\
Fraction Price Increases & 0.602 & 0.719 \\
\hline
\end{tabular}

Table 9: One Sector Model Moments

of price changes, skewness of price changes, and the fraction of positive price changes. ${ }^{39}$ In particular, $\lambda=0.16$ and $\xi=0.05$, where $\xi$ is identified by the skewness of the distribution and $\lambda$ helps determine the price change frequency. This implies a relatively high average menu cost, and a distribution that has fat tails. There is substantial probability that firms draw very low or very high menu costs. The persistence of idiosyncratic productivity shocks is set to 0.8 and the probability of a productivity shock is 0.39 , which are jointly identified by the fraction of positive price changes and dispersion of price changes. The volatility of idiosyncratic productivity shocks is set to 0.19 determining the average size, while the probability of a free price change is set to 0.112 and is identified by the fraction of small price changes.

The model moments are listed in Table 9. The model matches frequency, dispersion of price changes, and the fraction small price changes exactly. The model misses on fraction of price increases, but this is primarily determined by the trend growth in the nominal GDP process. ${ }^{40}$ Skewness is positive in the model like in the data, but is slightly lower relative to the data.

In order to test the predictions from the model against the empirical results, I compute the price response on impact of a one standard deviation oil price volatility increase. This is a one period impulse response to an increase in oil price volatility. A one standard deviation increase in oil price volatility increases price change dispersion by $0.12 \%$ and price change frequency by $0.38 \%$. In this random menu cost model, menu costs are drawn independently across firms and over time. This mechanism implies that prices are now a function of the random menu cost draw as well as the state of the economy. Random menu costs attenuate the price change reaction to a common shock and change the mix of price changes. Due to the random menu costs that firms draw, the selection of prices that will change depends less on a common shock than in a model featuring fixed menu

\footnotetext{
${ }^{39}$ Small price changes are defined as $\left|d p_{i, t}\right|<0.01$.

${ }^{40}$ In a model with no trend inflation, the fraction of positive price changes would be 0.5 . A model featuring no trend inflation would have the same implications for volatility.
} 
costs. Price changes also depend on the random menu cost that is drawn by each firm. During an increase in oil price volatility, firms are buffeted by larger realized oil price shocks. This causes some price changes that are primarily responding to the more extreme oil price. But some price changes will occur simply due to a low menu cost draw, and will be relatively small in reaction to idiosyncratic shocks. The overall effect is to create a more disperse price change distribution during periods of high oil price volatility, with a fraction of price changes responding to the oil price volatility shock but substantial mass remaining in the middle of the price change distribution. This implies that the random menu cost model matches the empirical relationship between price change dispersion and oil price volatility.

These model results show that a state dependent pricing model with random menu costs is able to match the positive relationship between oil price volatility shocks and price change dispersion with a muted frequency response. The random menu costs attenuate the reaction to a common cost shock, causing the mix of prices that adjust to depend on both the volatility shock but also on the menu cost draw, increasing dispersion.

\section{IV.4 Time Varying Idiosyncratic Volatility}

The one sector random menu cost model is now augmented with time varying idiosyncratic volatility to ask if it can also match the empirical facts in Vavra (2014) about idiosyncratic volatility. The model set up is the same, but the standard deviation of idiosyncratic volatility also follows an autoregressive process.

Idiosyncratic volatility is modeled the same as in Vavra (2014). Specifically, the log of firm volatility follows the process:

$$
\log A_{t}(z)= \begin{cases}\rho_{a} \log A_{t-1}(z)+d_{t} \sigma_{a} \epsilon_{t}(z) & \text { with probability } p_{a} \\ \log A_{t-1}(z) & \text { with probability } 1-p_{a}\end{cases}
$$

where $\epsilon_{t}(z) \sim \mathrm{N}(0,1)$. The introduction of $d_{t}$ implies that the variance of idiosyncratic shocks can vary over time. The time varying volatility process $d_{t}$ follows

$$
\log d_{t}=\rho_{d} \log d_{t-1}+\sigma_{d} \nu_{t}^{d}
$$

This implies that firms face idiosyncratic shocks with common standard deviation $d_{t}$ that 
changes over time. I assume that idiosyncratic volatility is perfectly negatively correlated with oil price. This implies

$$
\begin{gathered}
\rho_{p}=\rho_{d} \\
\nu_{t}=-\nu_{t}^{d}
\end{gathered}
$$

, that the autocorrelation of idiosyncratic volatility is equal to real oil price autocorrelation, and that idiosyncratic volatility is high when oil prices are low. This is purely for computational simplicity to reduce the state space by one dimension, however oil price inflation is negatively correlated with the business cycle. ${ }^{41}$ Additional support for this assumption is that Kilian and Vigfusson (2017) document that economic downturns are preceeded by oil price increases.

One additional parameter must be calibrated, $\sigma_{d}$, the size of idiosyncratic volatility shocks. To keep the model similar, I follow Vavra (2014) in calibrating the parameter to match the annual coefficient of variation for the standard deviation of firm level TFP equal to 1.01.

The model is shocked with a one standard deviation increase in idiosyncratic volatility. On impact of the shock, price change dispersion increases by $1.2 \%$ and price change frequency increases by $0.5 \%$. These results are consistent with the volatility effect pushing more price changes outside both sides of the Ss bands, increasing both frequency and dispersion. The results are also consistent with the empirical facts in Vavra (2014), that show both moments have a positive relationship with idiosyncratic volatility.

This model exercise shows that a random menu cost model is able to match the positive relationship between idiosyncratic volatility and both price change frequency and dispersion.

\section{IV.5 Multisector Model Calibration and Results}

This section asks if the random menu cost model is able to quantitatively match the empirical results. The baseline random menu cost model is extended to a multisector setting, where sectors are heterogeneous in their oil usage and pricing behavior. ${ }^{42}$ The empirically observed oil price and volatility series are simulated in the model, which generates model implied pricing moments to directly map the model to the data. A regression using model generated data shows that it can match the positive empirical relative relationship between oil price volatility and price change dispersion.

\footnotetext{
${ }^{41}$ In the 1998-2014 sample, real oil price inflation significantly decreases during the two recessionary periods.

${ }^{42}$ The multisector model does not feature time varying idiosyncratic volatility.
} 


\begin{tabular}{lcccccc}
\hline Sector & Oil Share & Frequency & Avg. Size & Fraction Small & S.D. & Skewness \\
\hline 1 & \multicolumn{7}{c}{ Data } \\
2 & 0.00041 & 0.10 & 0.08 & 0.20 & 0.15 & 0.12 \\
3 & 0.00102 & 0.08 & 0.08 & 0.19 & 0.13 & 0.00 \\
4 & 0.00158 & 0.17 & 0.07 & 0.23 & 0.12 & -0.02 \\
5 & 0.00208 & 0.23 & 0.06 & 0.20 & 0.10 & 0.14 \\
6 & 0.00308 & 0.11 & 0.06 & 0.27 & 0.12 & 0.13 \\
7 & 0.00579 & 0.15 & 0.07 & 0.28 & 0.13 & 0.37 \\
8 & 0.01056 & 0.19 & 0.06 & 0.17 & 0.11 & 0.05 \\
\hline & 0.05547 & 0.27 & 0.06 & 0.21 & 0.10 & 0.13 \\
\hline 1 & & & Model & & & \\
2 & 0.00041 & 0.10 & 0.08 & 0.21 & 0.12 & 0.06 \\
3 & 0.00102 & 0.08 & 0.10 & 0.14 & 0.13 & -0.01 \\
4 & 0.00158 & 0.17 & 0.10 & 0.24 & 0.13 & 0.01 \\
5 & 0.00208 & 0.23 & 0.05 & 0.37 & 0.07 & 0.11 \\
6 & 0.00308 & 0.12 & 0.08 & 0.18 & 0.10 & 0.05 \\
7 & 0.00579 & 0.14 & 0.08 & 0.18 & 0.11 & 0.05 \\
8 & 0.01056 & 0.19 & 0.07 & 0.29 & 0.11 & 0.05 \\
\hline
\end{tabular}

Table 10: Sectoral Characteristics of Multisector Model

NotE: The top panel presents the weighted average price setting moments from the PPI data from 1998-2014 at monthly frequency. PPI industries are grouped into octiles according to oil share in column one. S.D. is the standard deviation of price changes, while fraction of small price changes is defined as the percent of prices changes less than $1 \%$ in absolute value.

The model is calibrated to match pricing statistics from eight sectors of equal size. The 81 industries in the empirical section are sorted into octiles according to their oil share. Within each octile, the industries are weighted using value added to construct oil share and pricing moments. The oil share and pricing moments are shown in the top panel of Table 10. The internally calibrated parameters for each industry are targeted to match frequency, average size, fraction of small price changes, standard deviation, and skewness. ${ }^{43}$ The model moments are in the bottom panel, and are close to the data. ${ }^{44}$ The empirical moments do not exhibit any strong patterns across the oil share distribution, and neither do the parameter values in Table 11.

I am able to feed in the observed real oil price inflation and volatility series from 1998 to 2014 into the model and simulate the implied price change dispersion and frequency. This enables the multisector model to estimate the same relative effect of oil price volatility on price change dispersion and frequency, and quantitatively evaluate the model against the empirical results. Within the

\footnotetext{
${ }^{43}$ The autocorrelation of idiosyncratic shocks, $\rho_{a}$, is set to 0.7 for all sectors to reduce computational complexity.

${ }^{44}$ Sector 6 has high empirical skewness that the model was not able to match.
} 


\begin{tabular}{lccccc}
\hline Parameter: & $\sigma_{a, j}$ & $p_{a, j}$ & $\lambda_{j}$ & $\xi_{j}$ & $\alpha_{j}$ \\
\hline Sector & & & & & \\
1 & 0.160 & 0.30 & 0.145 & 0.05 & 0.04 \\
2 & 0.210 & 0.45 & 0.140 & 0.06 & 0.015 \\
3 & 0.200 & 0.48 & 0.145 & 0.05 & 0.13 \\
4 & 0.080 & 0.43 & 0.160 & 0.035 & 0.19 \\
5 & 0.140 & 0.45 & 0.150 & 0.05 & 0.05 \\
6 & 0.150 & 0.50 & 0.220 & 0.05 & 0.02 \\
7 & 0.152 & 0.39 & 0.145 & 0.05 & 0.15 \\
8 & 0.120 & 0.50 & 0.250 & 0.04 & 0.18 \\
\hline
\end{tabular}

Table 11: Sectoral Parameters

NotE: This table presents the multisector model parameters that are calibrated to match the unconditional pricing moments for each sector $j . p_{a, j}$ is the probability that $\log$ firm productivity follows an $\operatorname{AR}(1)$ process with standard deviation $\sigma_{a, j}, \lambda_{j}$ determines the average value of the menu cost that is drawn, $\xi_{j}$ determines the curvature of the menu cost distribution, and $\alpha_{j}$ is the probability of a free price change.

\begin{tabular}{|c|c|c|c|c|}
\hline \multirow[t]{2}{*}{ Dependent Variable: } & \multicolumn{2}{|c|}{ S.D. } & \multicolumn{2}{|c|}{ Frequency } \\
\hline & Data & Model & Data & Model \\
\hline$s_{o, j} * \Delta \log \left(P_{t-1}^{o}\right)$ & $\begin{array}{c}0.249 \\
(0.224)\end{array}$ & 0.055 & $\begin{array}{c}-0.361^{* * *} \\
(0.110)\end{array}$ & 0.093 \\
\hline$s_{o, j} * \sigma_{t-1}$ & $\begin{array}{l}4.511^{* * *} \\
(1.044)\end{array}$ & 3.876 & $\begin{array}{c}-2.486^{* *} \\
(1.115)\end{array}$ & 1.985 \\
\hline Industry FE & Yes & Yes & Yes & Yes \\
\hline Time FE & Yes & Yes & Yes & Yes \\
\hline
\end{tabular}

Table 12: Empirical Results: Model vs. Data

model, regression specifications in (7) and (8) that feature both time and industry fixed effects are estimated. ${ }^{45}$ Results from the model regression are in Table 12.

The model is able to quantitively match the positive relative effect of oil price volatility on price change dispersion. In the data the coefficient is slightly higher, but the model estimated coefficient is within one standard error. However, the negative relative effect of price change frequency in the data is not present in the model. Rather the model implies that industries with greater oil share have higher relative frequency during periods of high oil price volatility.

This section has showed that a model featuring random menu costs can qualitatively match the positive relationship between oil price volatility and price change dispersion. Moreover, extending it to a multisector setting shows that the model dynamics are quantitatively similar

\footnotetext{
${ }^{45}$ After an initial burnin period, I simulate the observed oil price and volatility series 100 times. The average regression coefficients over these simulation are presented.
} 
to the data. Finally, augmenting the random menu cost model with time varying idiosyncratic volatility generates the empirical facts shown in Vavra (2014). The model is able to positively relate price change frequency and dispersion with idiosyncratic volatility.

\section{Implications for Monetary Policy Effectiveness}

The model section has shown that a multisector random menu cost model is able to match the quantitative empirical relationship between oil price volatility and price change dispersion. This section will now show how changes in oil price volatility affect the ability of monetary policy to stimulate output.

I shock the multisector model with a permanent increase of 0.002 to log nominal output in order to assess if the tradeoff between output and inflation is a function of the aggregate volatility in the economy. ${ }^{46}$ This size shock amounts to a one month doubling of the nominal output growth rate. The response of consumption and inflation on impact is examined for periods of heightened oil price volatility relative to the ergodic distribution of oil price volatility. For the baseline level of oil price volatility, $59.1 \%$ of the doubling of log nominal output translates into an increase in output. The other $40.9 \%$ of the increase goes into inflation. When the model is shocked with a one standard deviation increase in oil price volatility and a 0.002 permanent increase in log nominal output, $58.8 \%$ of the increase in nominal output goes into output while $41.2 \%$ goes into the increase in price level. The results show that increases in oil price volatility do not substantially increase the trade off between output stabilization and inflation. During periods of high oil price volatility, there is a decrease of $0.5 \%$ in the efficacy of nominal stimulus to increase consumption on impact. In this model, while pricing behavior does respond to changes in oil price volatility, it does not drastically increase aggregate price level flexibility because the price change frequency response to volatility is muted.

Figure 6 traces out the full impact of the monetary shock during a period of increased oil price volatility relative to steady state oil price volatility. The small decrease in monetary policy effectiveness due to the oil price volatility shock essentially stays constant over time in the model. The share of the monetary shock entering the cumulative consumption response is reduced by less than $1 \%$ during the course of a year.

It is also informative to ask how monetary policy effectivness has varied over the historical

\footnotetext{
${ }^{46}$ This is the same size monetary shock as in Vavra (2014).
} 


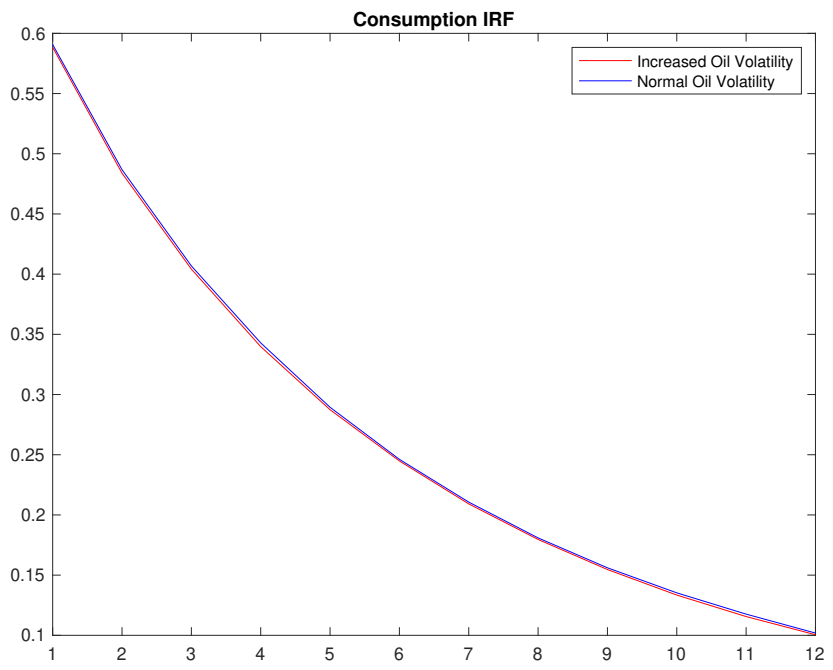

Figure 6: Real Output Response to Nominal Shock

NotE: Impulse response of output in the multisector model to a one time permanent increase in log nominal output of size 0.002 under different levels of oil price volatility.

distribution of oil price volatility. I feed in the observed empirical oil price inflation and volatility series from 1998 to 2014 into the model. At each point in time, the output response on impact to a $0.002 \log$ nominal output shock is calculated. The model finds that the average monetary policy efficacy to stimulate output is $1 \%$ lower on impact during periods of the highest oil price volatility, such as 2009, relative to periods of the lowest oil price volatility such as 2013.

Price change dispersion is a key moment of the price change distribution for measuring monetary non-neutrality after conditioning on price change frequency. Midrigan (2011) shows that increased price change dispersion increases monetary policy effectiveness. In testing how monetary policy effectiveness responds to changes in volatility, price change dispersion is therefore a key moment to examine. Matching the relationship between oil price volatility and price change dispersion in a state dependent model implies that monetary policy effectiveness is nearly time invariant in response to changes in volatility.

\section{Aggregate Evidence}

As supporting evidence of the model, this section presents direct aggregate evidence on the relationship between oil price volatility and monetary policy effectiveness using state-dependent 
local projections and identified monetary shocks. ${ }^{47}$ The results show that prices are not more responsive to monetary shocks during periods of high oil price volatility relative to periods of low oil price volatility.

I examine if there is a differential effect of identified monetary policy shocks when oil price volatility is high or low. Identified monetary shocks from Romer and Romer (2004) are used because they find monetary policy causes an economically meaningful response to the price level. I estimate impulse response functions for the price level using data from 1974 to 2007 to focus on conventional monetary policy. ${ }^{48}$ State dependent local projections as in Auerbach and Gorodnichenko (2013) are estimated to compare the price response under high and low oil price volatility regimes. Specifically, I estimate the following local projections:

$$
\begin{array}{r}
\log \left(p_{p} i_{t+h}\right)=\beta_{h}+I_{\text {OilVol }>M}\left[\theta_{H, h} * M P \text { shock }_{t}+\varphi_{H, h} Y_{t}\right] \\
+\left(1-I_{\text {OilVol }>M}\right)\left[\theta_{L, h} * M P \text { shock }_{t}+\varphi_{L, h} Y_{t}\right]+\epsilon_{t+h}
\end{array}
$$

where $I_{\text {OilVol }>M}$ is the transition function for oil price volatility. It is equal to one if the three month moving average of oil price volatility is greater than the median value over the sample period, and zero otherwise. $\theta_{H, h}$ is the impulse response of the price level to a monetary policy shock $h$ months after the shock when the economy is in a state of high oil price volatility, while $\theta_{L, h}$ is the impulse response when the economy is in a low oil price volatility state. Controls are given by $Y_{t}$, and following Ramey (2015), they include two lags of the monetary policy shock, and current and two lags of the federal funds rate, the log of industrial production index, the unemployment rate, the $\log$ of the PPI, and the log of the real price of oil. The controls are allowed to vary with the state of oil price volatility.

The state dependent impulse responses to an expansionary monetary shock are plotted in Figure 7, along with the response in a linear model. The black line for the linear model shows a positive price response to an expansionary shock, consistent with economic theory. ${ }^{49}$ The red line shows the price response to an expansionary shock in the high oil price volatility state, while the blue line shows the price response in the low oil price volatility state. While the estimate is less

\footnotetext{
${ }^{47}$ Further aggregate evidence in Appendix B.4.1 shows that aggregate price change dispersion is positively associated with oil price volatility. Price change frequency is insignificantly negatively associated with oil price volatility, suggesting aggregate price stickiness does not depend on oil price volatility.

${ }^{48}$ I use RAC oil price because it starts in 1974 in order to extend the aggregate sample, while WTI oil prices only start in 1986.

${ }^{49}$ While not presented in Figure 7, the linear response becomes significantly different from 0 after 30 months at the $10 \%$ level.
} 


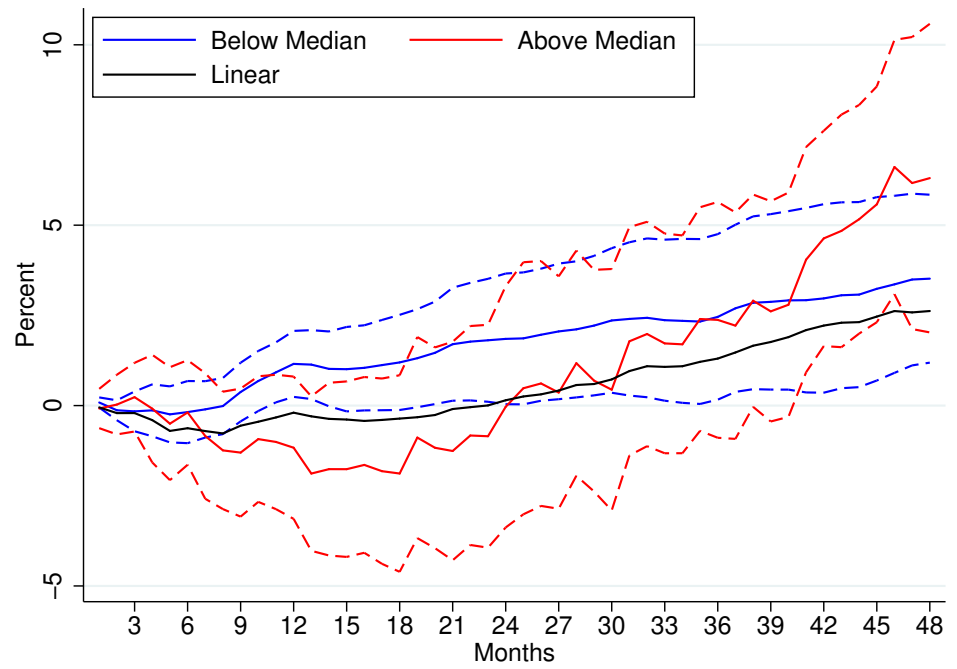

Figure 7: Price Level Response to Identified Monetary Shock

NoTE: Impulse response function for the price level to a contractionary Romer-Romer shock using data from 1974 to 2007. In the above figure, I plot the respectively estimated coefficients $\theta_{H, h}$ and $\theta_{L, h}$ from the following specification: $\log \left(\right.$ ppi $\left._{t+h}\right)=\beta_{h}+I_{O i l V o l>M}\left[\theta_{H, h} * M P s h o c k_{t}+\varphi_{H, h} Y_{t}\right]+\left(1-I_{O i l V o l>M}\right)\left[\theta_{L, h} * M P\right.$ shock $\left.k_{t}+\varphi_{L, h} Y_{t}\right]+\epsilon_{t+h}$ where $p p i_{t+h}$ is the producer price level at time $t$ measured at monthly frequency, $h$ months into the future. The black solid line is $\theta_{\text {Linear }, h}$, the same impulse response estimated without state dependence. Controls include two lags of the RR shock, and current and two lags of the Fed Funds rate, unemployment rate, log of the industrial production, log of the price level, and log of the real price of oil. Standard errors are constructed using the Newey-West correction for serial autocorrelation. Dashed lines present $90 \%$ standard error bands.

precise for the high oil price volatility state, the state dependent impulse responses to an identified monetary shock do not show a significant price level difference following the shock. They also show the significant positive response to an expansionary shock, consistent with the linear response. This state dependent local projection evidence is consistent with the model's implications that monetary policy effectiveness is not a function of oil price volatility.

\section{Conclusion}

This paper argues that changes in aggregate volatility do not substantially reduce monetary policy effectiveness. I do this by showing that the average industry price change dispersion is greater during periods of high oil price volatility, while average price change frequency does not vary with oil price volatility. Then by exploiting the heterogeneity across industries in oil usage, I show that the increase in price change dispersion is larger for sectors with more oil usage. Industries with high oil usage also have lower relative price change frequency during increased oil price volatility. 
In order to match these new pricing facts, I introduce random and heterogeneous menu costs. This mechanism attenuates the price reaction to a common volatility shock and increases price change dispersion during periods of high volatility.

My analysis of the effects of common volatility shocks on price setting behavior can be applied beyond oil price volatility. Policy uncertainty, such as changes in the volatility of fiscal or taxation plans, is another source of time varying volatility to a common shock that can affect prices. Exchange rate volatility and global demand volatility are other examples of common volatility shocks that affect price setting behavior. Does increased monetary policy volatility cause price changes to be more disperse and alter the monetary authority's ability to be effective? In particular, did the effects of nominal stimulus change during 1979 to 1982? During this period the FOMC targeted the quantity of money rather than a federal funds rate, which increased the observed volatility of the federal funds rate.

The tradeoff between output stabilization and inflation is nearly time invariant in response to changes in aggregate volatility, suggesting that policy makers need to take into account the source of volatility. If policy makers increase nominal stimulus more strongly because they believe effectiveness is dampened during periods of increased aggregate volatility, it would be an overreaction and induce unnecessary inflation. 


\section{References}

Auerbach, A. J. and Y. Gorodnichenko (2013). Output spillovers from fiscal policy. American Economic Review 103(3), 141-46.

Bachmann, R., B. Born, S. Elstner, and C. Grimme (2019, January). Time-Varying Business Volatility and the Price Setting of Firms. Journal of Monetary Economics 101, 82-99.

Baley, I. and J. Blanco (2019, January). Firm Uncertainty Cycles and the Propagation of Nominal Shocks. American Economic Journal: Macroeconomics 11(1).

Barsky, R. B., C. L. House, and M. S. Kimball (2007). Sticky-price models and durable goods. American Economic Review 97(3), 984-998.

Bartick, T. (1991). Who Benefits From State and Local Economic Development Policies. Kalamazoo, MI: W.E. Upjohn Institute for Employment Research.

Baumeister, C. and L. Kilian (2015). Understanding the Decline in the Price of Oil since June 2014. Journal of the Association of Environmental and Resource Economist.

Baumeister, C. and L. Kilian (2016). Fourty Years of Oil Price Fluctuations: Why the Price of Oil May Still Surprise Us. Journal of Economic Perspectives 30, 139-160.

Berger, D. and J. Vavra (2019). Shocks vs Responsiveness: What Drives Time-Varying Dispersion? Journal of Political Economy 127(5).

Blanchard, O. J. and J. Galí (2007, June). The Macroeconomic Effects of Oil Price Shocks: Why are the 2000s so different from the 1970s?, pp. 373-421. University of Chicago Press.

Bloom, N. (2009, May). The Impact of Uncertainty Shocks. Econometrica 77, 623-685.

Bloom, N., S. Bond, and J. Van Reenen (2007). Uncertainty and investment dynamics. The review of economic studies 74(2), 391-415.

Bloom, N., M. Floetotto, N. Jaimovich, I. Saporta-Eksten, and S. Terry (2018, May). Really Uncertain Business Cycles. Econometrica (5).

Bodenstein, M., L. Guerrieri, and L. Kilian (2012). Monetary policy responses to oil price fluctuations. IMF Economic Review 60(4), 470-504.

Born, B. and J. Pfeifer (2014). Policy Risk and the Business Cycle. Journal of Monetary Economics 68, 68-28.

Chen, S. (2009). Oil Price Pass-Through into Inflation. Energy Economics 31, 126-133.

Clark, T. and S. Terry (2010). Time Variation in the Inflation Passthrough of Energy Prices. Journal of Money, Credit and Banking 42.

Den Haan, W. J. (2010). Assessing the Accuracy of the Aggregate Law of Motion in Models with Heterogeneous Agents. Journal of Economic Dynamics and Control 32, 79-99.

Dotsey, M., R. King, and A. J. Wolman (1999). State Dependent Pricing and the General Equilibrium Dynamics of Money and Output. Quarterly Journal of Economics 114 (2), 655-690.

Drenik, A. and D. Perez (2016). Price Setting Under Uncertainty About Inflation. Working Paper.

Edelstein, P. and L. Kilian (07 Nov. 2007). The response of business fixed investment to changes in energy prices: A test of some hypotheses about the transmission of energy price shocks. The B.E. Journal of Macroeconomics 7(1).

Elder, J. and A. Serletis (2010). Oil price uncertainty. Journal of Money, Credit and Banking 42(6), $1137-1159$.

Fernandez-Villaverde, J., P. Guerron-Quintana, K. Kuester, and J. Rubio-Ramirez (2015). Fiscal 
Volatility Shocks and Economic Activity. American Economic Review 105(11), 3352-3384.

Gertler, M. and J. Leahy (2008). A Phillips Curve With an Ss Foundation. Journal of Political Economy 116, 533-572.

Gilchrist, S., R. Schoenle, J. Sim, and E. Zakrajsek (2017). Inflation Dynamics during the Financial Crisis. American Economic Review 107(3).

Gilchrist, S. and E. Zakrajsek (2012). Credit Spreads and Business Cycle Fluctuations. American Economic Review 102(4), 1692-1720.

Godsill, S. J., A. Doucet, and M. West (2004). Monte Carlo Smoothing for Nonlinear Time Series. Journal of the American Statistical Association 99(465), 156-168.

Goldberg, P. K. and R. Hellerstein (2009). How Rigid Are Producer Prices? Staff Report No. 407, Federal Reserve Bank of New York.

Golosov, M. and R. Lucas (2007). Menu Costs and Phillips Curves. Journal of Political Economy 115(2).

Gonçalves, S. (2011). The moving blocks bootstrap for panel linear regression models with individual fixed effects. Econometric Theory 27(5), 1048-1082.

Gopinath, G. and O. Itskhoki (2010). Frequency of Price Adjustment and Pass-Through. Quarterly Journal of Economics 125(2), 675-727.

Gorodnichenko, Y. and M. Weber (2016). Are Sticky Prices Costly? Evidence from the Stock Market. The American Economic Review 106(1), 165-199.

Hamilton, J. D. (2009). Causes and Consequences of the Oil Shock of 2007-2008. Brookings Papers on Economic Activity 1, 215-283.

Jo, S. (2014). The Effects of Oil Price Uncertainty on Global Real Economic Activity. Journal of Money, Credit, and Banking 46(6), 1113-1135.

Karadi, P. and A. Reiff (2019). Menu Costs, Aggregate Fluctuations, and Large Shocks. American Economic Journal: Macroeconomics 11(3), 111-146.

Kilian, L. (2008). The Economic Effects of Energy Price Shocks. Journal of Economic Literature 90, $216-240$.

Kilian, L. (2017). The impact of the fracking boom on arab oil producers. The Energy Journal 38(6).

Kilian, L. and B. Hicks (2013). Did Unexpectedly Strong Economic Growth Caue the Oil Price Shock of 2003-2008? Journal of Forecasting 32(5), 385-394.

Kilian, L. and T. K. Lee (2014). Quantifying the Speculative Component in the Real Price of Oil: The Role of Global Oil Inventories. Journal of International Money and Finance 42, 71-87.

Kilian, L. and L. T. Lewis (2011). Does the fed respond to oil price shocks? The Economic Journal 121(555), 1047-1072.

Kilian, L. and D. P. Murphy (2014). The Role of Inventories and Speculative Trading in the Global Market for Crude Oil. Journal of Applied Econometrics 29(3), 454-478.

Kilian, L. and R. J. Vigfusson (2017). The role of oil price shocks in causing us recessions. Journal of Money, Credit and Banking 49(8), 1747-1776.

Knotek, E. and S. Terry (2008). Alternative Methods of Solving State-Dependent Pricing Models. Federal Reserve Bank of Kansas City Working Paper No. 08-10.

Krusell, P. and A. A. Smith (1998). Income and Wealth Heterogeneity in the Macroeconomy. Quarterly Journal of Economics 106(5), 867-896. 
Lee, Y.-H. and T.-H. Fan (2006). Bootstrapping prediction intervals on stochastic volatility models. Applied Economics Letters 13(1), 41-45.

Luo, S. and D. Villar (2020). The Skewness of the Price Change Distribution: A New Touchstone for Sticky Price Models. Journey of Money, Credit and Banking.

Midrigan, V. (2011). Menu Costs, Multiproduct Firms, and Aggregate Fluctuations. Econometrica 79.

Nakamura, E. and J. Steinsson (2008). Five Facts About Prices: A Reevaluation of Menu Cost Models. Quarterly Journal of Economics 123(4).

Nakamura, E. and J. Steinsson (2010). Monetary Non-Neutrality in a Multisector Menu Cost Model. Quarterly Journal of Economics 125(3).

Nekarda, C. and V. Ramey (2011). Industry Evidence on the Effects of Government Spending. American Economic Journal: Macroeconomics 3(1), 36-59.

Perotti, R. (2007). In Search of the Transmission Mechanism of Fiscal Policy. NBER Working Paper Series, No. 13143.

Plante, M. and N. Traum (2012). Time-Varying Oil Price Volatility and Macroeconomic Aggregates. Center for Applied Economics and Policy Research Working Paper 2012-002.

Ramey, V. A. (2015). Macroeconomic shocks and their propagation. Handbook of Macroeconomics, forthcoming.

Roberts, G. O., A. Gelman, and W. R. Gilks (1996). Efficient Metropolis Jumping Rules. Bayesian Statistics 5, 599-607.

Romer, C. D. and D. H. Romer (2004). A new measure of monetary shocks: Derivation and implications. American Economic Review 94(4), 1055-1084.

Shea, J. (1993). Do Supply Curves Slope Up? Quarterly Journal of Economics 108(1), 1-32.

Stein, L. C. and E. C. Stone (2010). The effect of uncertainty on investment, hiring, and r\&d: Causal evidence from equity options. Working Paper.

Stella, A. (2014). The Magnitude of Menu Costs: A Structural Estimation. Meeting Papers 2014 (No. 436). Society for Economic Dynamics.

Vavra, J. (2014). Inflation Dynamics and Time Varying Volatility: New Evidence and an SS Interpretation. Quarterly Journal of Economics 129(1).

Young, E. (2010). Solving the Incomplete Markets Model with Aggregate Uncertainty Using the Krusell-Smith Algorithm and Non-Stochastic Simulations. Journal of Economic Dynamics \&3 Control 34, 36-41. 


\section{A Model Appendix}

This section has further details about the menu cost model. In section A.1 is shows how the profit function can be written in terms of $A_{t}(z), \frac{P_{t-1}}{S_{t}}, P_{t}^{o}$, and $\sigma_{t}$ that enables the model to be solved recursively. It then discusses the model solution in section A.2. Lastly in section A.3 it presents the menu cost model that features a fixed menu cost and shows that it counterfactually predicts decreased price dispersion during periods of high oil price volatility.

\section{A.1 Profit Function}

This section shows how to write the profit function in terms of $A_{t}(z), \frac{P_{t-1}}{S_{t}}, P_{t}^{o}$, and $\sigma_{t}$.

To write the firm flow profits in real terms, I divide by $P_{t}$.

$$
\pi_{t}^{R}(z)=\left(\frac{p_{t}(z)}{P_{t}}\right) y_{t}(z)-\frac{W_{t}}{P_{t}} L_{t}(z)-\frac{Q_{t}}{P_{t}} O_{t}(z)-\chi_{t}(z) \frac{W_{t}}{P_{t}} I_{t}(z)
$$

Then using equation (20) I substitute out for $O_{t}(z)$ which gives after simplification

$$
\pi_{t}^{R}(z)=\left(\frac{p_{t}(z)}{P_{t}}\right) y_{t}(z)-\frac{W_{t}}{P_{t}} \frac{s_{o}}{1-s_{o}} L_{t}(z)-\chi_{t}(z) \frac{W_{t}}{P_{t}} I_{t}(z)
$$

After using firm cost minimization to write the production function as $y_{t}(z)=A_{t}(z) L_{t}(z)$, I substitute out for labor $L_{t}(z)$.

$$
\pi_{t}^{R}(z)=\left(\frac{p_{t}(z)}{P_{t}}\right) y_{t}(z)-\left(1-s_{o}\right)^{s_{o}-1} s_{o}^{-s_{o}} \frac{W_{t}}{P_{t}}\left(\frac{W_{t}}{P_{t}} \frac{P_{t}}{Q_{t}}\right)^{s_{o}} \frac{y_{t}(z)}{A_{t}(z)}-\chi_{t}(z) \frac{W_{t}}{P_{t}} I_{t}(z)
$$

Now I substitute in the firm's demand curve (19) and labor supply (15) to give

$$
\pi_{t}^{R}(z)=\left(\frac{p_{t}(z)}{P_{t}}\right)^{1-\theta} Y_{t}-\left(1-s_{o}\right)^{s_{o}-1} s_{o}^{-s_{o}}\left(\omega C_{t}\right)^{1-s_{o}}\left(\frac{Q_{t}}{P_{t}}\right)^{s_{o}} \frac{1}{A_{t}(z)} Y_{t}\left(\frac{p_{t}(z)}{P_{t}}\right)^{-\theta}-\chi_{t}(z)\left(\omega C_{t}\right) I_{t}(z)
$$

Lastly, the aggregate resource constraint implies that $Y_{t}=C_{t}$. This gives the equation

$$
\pi_{t}^{R}(z)=\left(\frac{p_{t}(z)}{P_{t}}\right)^{1-\theta} C_{t}-\frac{1}{A_{t}(z)} C_{t}\left(\frac{p_{t}(z)}{P_{t}}\right)^{-\theta}\left(1-s_{o}\right)^{s_{o}-1} s_{o}^{-s_{o}}\left(\omega C_{t}\right)^{1-s_{o}}\left(\frac{Q_{t}}{P_{t}}\right)^{s_{o}}-\chi_{t}(z)\left(\omega C_{t}\right) I_{t}(z)
$$

Thus I am able to rewrite flow profits as a function of $\left(A_{t}(z), \frac{p_{t-1}(z)}{P_{t}}, P_{t}^{o}, \sigma_{t}\right)$.

To simplify notation, I can write

$$
\pi_{t}^{R}(z)=\left(\frac{p_{t}(z)}{P_{t}}-\frac{1}{A_{t}(z)} \frac{Q_{t}}{P_{t}}\left(\omega C_{t}\right)^{1-s_{o}}\right)\left(\frac{p_{t}(z)}{P_{t}}\right)^{-\theta} C_{t}-\chi_{t}(z)\left(\omega C_{t}\right) I_{t}(z)
$$

I need to write firm profits as a function of $\frac{p_{t}}{S_{t}}$ in order to bound the state space. To do this, first note that from equation (25) I can write $\frac{P_{t}}{S_{t}}$ as

$$
\frac{P_{t}}{S_{t}}=e^{\gamma_{0}+\gamma_{1} \log P_{t}^{o}+\gamma_{2} \sigma_{t}+\gamma_{3} \log \left(\frac{P_{t-1}}{S_{t}}\right)+\gamma_{4}\left(\log \left(\frac{P_{t-1}}{S_{t}}\right) * \log P_{t}^{o}\right)+\gamma_{5}\left(\log \left(\frac{P_{t-1}}{S_{t}}\right) * \sigma_{t}\right)}
$$


and I can write $C_{t}$ as

$$
C_{t}=e^{-\left(\gamma_{0}+\gamma_{1} \log P_{t}^{o}+\gamma_{2} \sigma_{t}+\gamma_{3} \log \left(\frac{P_{t-1}}{S_{t}}\right)+\gamma_{4}\left(\log \left(\frac{P_{t-1}}{S_{t}}\right) * \log P_{t}^{o}\right)+\gamma_{5}\left(\log \left(\frac{P_{t-1}}{S_{t}}\right) * \sigma_{t}\right)\right)}
$$

Then I take firm profits, multiply and divide by $S_{t}$, and replace $C_{t}=\frac{S_{t}}{P_{t}}$.

$$
\pi_{t}^{R}(z)=\left(\frac{\frac{p_{t}(z)}{S_{t}}}{\frac{P_{t}}{S_{t}}}-\frac{1}{A_{t}(z)}\left(\frac{Q_{t}}{P_{t}}\right)^{s_{o}}\left(\omega C_{t}\right)^{1-s_{o}}\right)\left(\frac{\frac{p_{t}(z)}{S_{t}}}{\frac{P_{t}}{S_{t}}}\right)^{-\theta} \frac{S_{t}}{P_{t}}-\chi_{t}(z)\left(\omega \frac{S_{t}}{P_{t}}\right) I_{t}(z)
$$

Finally I replace $\frac{P_{t}}{S_{t}}$ and $C_{t}$ with the expressions from the law of motion.

$$
\pi_{t}^{R}(z)=\left(\frac{p_{t}(z)}{S_{t}} e^{-\left(\Theta_{t}\right)}-\frac{1}{A_{t}(z)}\left(P_{t}^{o}\right)^{s_{o}}\left(\omega e^{-\Theta_{t}}\right)^{1-s_{o}}\right)\left(\frac{p_{t}(z)}{S_{t}} e^{-\left(\Theta_{t}\right)}\right)^{-\theta}\left(e^{-\left(\Theta_{t}\right)}\right)-\chi_{t}(z)\left(\omega e^{-\left(\Theta_{t}\right)}\right) I_{t}(z)
$$

where $\Theta_{t}$ is the expression for the law of motion of $\frac{P_{t}}{S_{t}}$. Rearranging gives

$$
\left.\pi_{t}^{R}(z)=\left(\frac{p_{t}(z)}{S_{t}}-\frac{1}{A_{t}(z)}\left(P_{t}^{o}\right)^{s_{o}}(\omega)^{1-s_{o}} e^{\Theta_{t} s_{o}}\right)\right)\left(\frac{p_{t}(z)}{S_{t}}\right)^{-\theta}\left(e^{\left(\Theta_{t}\right)}\right)^{\theta-2}-\chi_{t}(z)\left(\omega e^{-\left(\Theta_{t}\right)}\right) I_{t}(z)
$$

which is the value function written in terms of $\left(A_{t}(z), \frac{p_{t-1}(z)}{S_{t}}, P_{t}^{o}, \sigma_{t}\right)$. I also need to rewrite the stochastic discount factor as

$$
D_{t, t+1}^{R}=\beta \frac{C_{t}}{C_{t+1}}=\beta \frac{e^{-\left(\gamma_{0}+\gamma_{1} \log P_{t}^{o}+\gamma_{2} \sigma_{t}+\gamma_{3} \log \left(\frac{P_{t-1}}{S_{t}}\right)+\gamma_{4}\left(\log \left(\frac{P_{t-1}}{S_{t}}\right) * \log P_{t}^{o}\right)+\gamma_{5}\left(\log \left(\frac{P_{t-1}}{S_{t}}\right) * \sigma_{t}\right)\right)}}{e^{-\left(\gamma_{0}+\gamma_{1} \log P_{t+1}^{o}+\gamma_{2} \sigma_{t+1}+\gamma_{3} \log \left(\frac{P_{t}}{S_{t+1}}\right)+\gamma_{4}\left(\log \left(\frac{P_{t}}{S_{t+1}}\right) * \log P_{t+1}^{o}\right)+\gamma_{5}\left(\log \left(\frac{P_{t}}{S_{t+1}}\right) * \sigma_{t+1}\right)\right)}}
$$

where expectations can be formed by using the law of motions for $P_{t}^{o}, \sigma_{t}, S_{t}$.

\section{A.2 Model Solution}

The recursive problem is solved on a discretized grid using value function iteration. Knotek and Terry (2008) argue in favor of discretization over colocation in state dependent pricing models due to robustness. The productivity grid is discretized using 21 points, the real price grid has 171 points, oil price has 15 grid points, and oil price volatility has 5 points. Expectations must be taken over the monetary growth rate and are discretized using 7 points, while the Krusell-Smith aggregate state is discretized with 8 points.

The model is simulated using the non-stochastic simulation method of Young (2010). Nonstochastic simulation tracks a histogram of firm states rather than a large number of firms which removes Monte Carlo sampling error, and increases the speed of the simulation compared to large firm panels. The overall numerical solution is outlined below.

1. Guess a set of $\gamma_{i}$ for $\mathrm{i} \in\{0,1,2,3,4,5\}$ in the aggregate law of motion.

2. Firms choose relative price to solve profit maximization given the conjectured forecast for the aggregate state. They are maximizing equation (26). 
3. Given the policy function from step 2, the model is simulated using non-stochastic simulation. This implies that the aggregate variables $P_{t}^{o}, \sigma_{t}$, and $S_{t}$ are simulated from their discretized transition matrices. A histogram of weights is tracked over the idiosyncratic variables $\frac{p_{t}(z)}{P_{t}}$, $A_{t}(z)$, and $\chi_{t}(z)$. The density of prices at each individual state is updated each period using the transition matrix for each variable.

4. Using the simulated data, the aggregate law of motion is re-estimated using the data.

5. $\gamma_{i}^{i t e r+1}$ are updated using the new values.

6. Check if the equilibrium has converged. The maximum Den Haan (2010) statistic is computed over the full simulation of 2000 periods (166.66 years). The maximum Den Haan statistic is the maximum difference between the simulated value of $\log \left(\frac{P_{t}}{S_{t}}\right)$ from the model, and a dynamic forecast of $\log \left(\frac{P_{t}}{S_{t}}\right)^{D H}$. The dynamic forecast of $\log \left(\frac{P_{t}}{S_{t}}\right)$ is constructed by repeated application of the Krusell and Smith forecasting equation, using the resulting predicted dependent variable in the construction of the following periods forecast. This method allows for accumulation of prediction error within the forecasting system. The specific equilibrium convergence criterion is $\left|D H_{\text {iter }+1}^{\max }-D H_{\text {iter }}^{\max }\right|<.0001$. After this criterion is met the aggregate law of motion has converged and model equilibrium is reached.

\section{A.3 Fixed Menu Cost Model: Volatility Implications}

This section discusses the calibration of a fixed menu cost model like in Golosov and Lucas (2007), and shows that it is not capable of matching the new empirical facts. This model features a strong selection effect that implies prices react strongly to a common oil price volatility change, decreasing dispersion and increasing frequency.

The model is the same as in Section IV, except for the nature of menu costs. The menu cost distribution is reduced to a single point mass at $\chi$, implying that a firm can change their price at any point if they pay the fixed menu cost. The model is calibrated to match the same moments of the data, but skewness of price change is not targeted. The persistence of idiosyncratic productivity is set to $\rho_{a}=0.7$, which matches Nakamura and Steinsson (2008). Then the remaining four parameters $\chi, \sigma_{a}, p_{a}$, and $\alpha$ are set to target four moments of the PPI data. The moments are frequency of price change, average size of price change, standard deviation of price changes, and the fraction of small price changes. The value of the fixed menu cost is set to $\chi=0.20$. However a fraction $\alpha=0.125$ of firms receive a free opportunity to change prices. This parameter is identified by the fraction of small price changes. $^{50}$ The volatility and probability of receiving an idiosyncratic productivity shock determines the average size and dispersion of price changes. The standard deviation of shocks is set to 0.105 and the probability of receiving a shock is set to 0.4 . This enables the model to match the large absolute average size of price change and the large dispersion of price change. Moments of the model are in Table 13.

\footnotetext{
${ }^{50}$ The pricing parameters imply that total adjustment costs in the economy are $\chi *(F r e q-\alpha) * \frac{\theta-1}{\theta}=0.42 \%$ of revenues per month. Estimates from Levy et al. (1997) suggest that menu costs are 0.7\% of revenues, while Stella (2014) estimates menu costs to be bounded between $0.22 \%$ and $0.59 \%$.
} 


\begin{tabular}{lcc}
\hline Price Setting Statistic & Data & Model \\
\hline Frequency & 0.154 & 0.152 \\
Average Size of Price Change & 0.071 & 0.097 \\
Fraction Small Price Changes & 0.215 & 0.142 \\
Standard Deviation Price Changes & 0.125 & 0.124 \\
Skewness Price Changes & 0.095 & -0.195 \\
Fraction Price Increases & 0.602 & 0.648 \\
\hline
\end{tabular}

Table 13: Fixed Menu Cost Model Moments

The model matches frequency and dispersion exactly. Fraction of small price changes is slightly too low, and this causes the average size to be too large. Fraction of positive price changes is also too high like in the random menu cost model, but this is primarily determined by the nominal GDP process. While not targeted, the model is not capable of matching the positive skewness in the data.

In order to test the predictions of the model against the empirical results, I compute the price response on impact of a one standard deviation increase in oil price volatility. In this fixed menu cost model calibration, a one standard deviation increase in oil price volatility decreases price change dispersion by $2.7 \%$. The volatility effect dominates the real options effect, increasing the frequency of price adjustment as frequency of price change increases by $8.1 \%$. The increase in oil price volatility creates a larger realized oil price, which increases the gap between a firm's current price and optimal price. The common volatility increase pushes more price changes in one direction, decreasing price change dispersion. There is an increase in the directional synchronization of price changes that does not occur during an increase in idiosyncratic volatility. During periods of increased oil price volatility, more price changes move in the direction of the larger oil price shock, causing a decrease in price change dispersion.

This section has showed that a menu cost model with a fixed menu cost does not match the positive relationship between oil price volatility and price change dispersion that is seen in the data. Rather, a strong selection effect generates a counterfactual decrease in price change dispersion and an increase in price change frequency when oil price volatility is increased.

\section{B Data Appendix}

In B.1, estimation and details of the stochastic volatility process are discussed. Next in Section B.2, I discuss data sets that are used in the paper including the BLS micro-price data and show robustness to the oil price series used. Section B.3 presents additional robustness exercises such as robustness to oil volatility series used, generated regressor standard errors, and robustness to price change dispersion. Lastly, Section B.4 presents additional results on aggregate pricing moment regressions, industry dependent oil price pass-through, empirical price distributions, and a balance check of observables across high and low oil usage industries. 


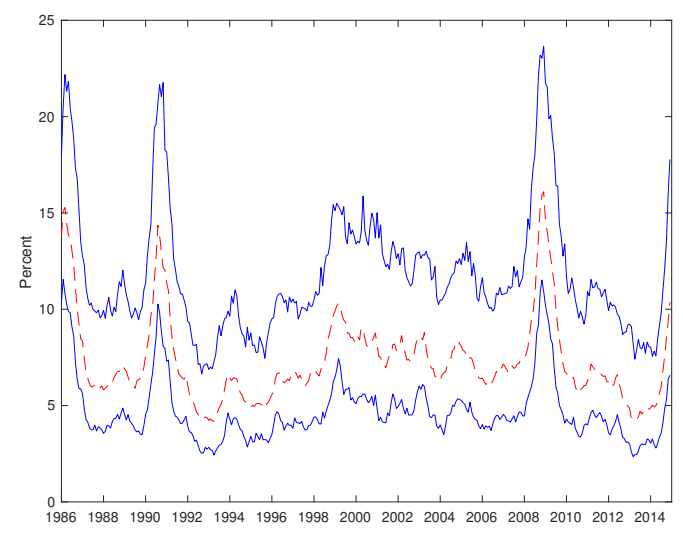

Figure 8: Stochastic Oil Price Volatility

Note: Red dashed line is the smoothed estimate of stochastic volatility in percent, $100 * e^{\sigma_{t}}$. The top and bottom solid blue lines represent the 95 percent probability interval.

\section{B.1 Stochastic Volatility Model}

The stochastic volatility model for real oil prices $P_{t}^{o}$ is given by

$$
\begin{gathered}
\log P_{t}^{o}=\rho_{p} \log P_{t-1}^{o}+e^{\sigma_{t}} \nu_{t} \\
\sigma_{t}=\left(1-\rho_{\sigma}\right) \bar{\sigma}+\rho_{\sigma} \sigma_{t-1}+\phi \nu_{\sigma, t}
\end{gathered}
$$

The process for $\sigma_{t}$ is latent, and following Plante and Traum (2012), Fernandez-Villaverde et al. (2015), and Born and Pfeifer (2014), a sequential importance resampling particle filter is used to evaluate the likelihood function due to the nonlinearity in the SV model. Once the likelihood function of the data is constructed, a random walk Metropolis-Hastings algorithm is used to compute the posterior distribution of the four parameters. Uniform priors are used for each parameter. The particle filter uses 40,000 particles to construct the likelihood, while 150,000 draws are used in the RWMH algorithm with the first 50,000 discarded. The final acceptance ratio of proposals is 0.32 , within the recommended window of $15 \%$ to $40 \%$ in Roberts et al. (1996). In order to obtain the volatility series of the data, the backwards-smoothing routine of Godsill et al. (2004) is used.

The mean estimates of the volatility process imply that a positive one standard deviation increase in the oil volatility increases the standard deviation of the oil price level shock by $\left(e^{\phi}-1\right) \times$ $100 \%=15 \% .^{51}$

The prior and posterior distributions are in Table 3. In Figure 8, I plot the estimated historical smoothed time varying volatility with 95 percent posterior probability interval. Estimates show that there is a large amount of variability in oil price volatility, such as the increase during the Great Recession.

\footnotetext{
${ }^{51} \mathrm{~A}$ one standard deviation increase in the oil volatility shock increases the standard deviation of the oil price shock from $e^{-2.607}=0.074$ to $e^{-2.607+0.14}=0.085$.
} 


\section{B.1.1 Particle Filter Algorithm}

A Sequential Importance Resampling particle filter is used to obtain the filtering density $p\left(\sigma_{t} \mid P_{t}^{o} ; \Theta\right)$, the probability of $\sigma_{t}$ given the oil price observations and process parameters. The likelihood of observing a series of oil prices $P_{T}^{o}$, given an initial value $P_{0}^{o}$, can be written as:

$$
\begin{aligned}
p\left(P_{o}^{T} ; \Theta\right) & =\prod_{t=1}^{T} p\left(P_{o}^{t} \mid P_{o}^{t-1} ; \Theta\right) \\
& =\int \frac{1}{e^{\sigma_{0}} \sqrt{2 \pi}} \exp \left[-\frac{1}{2}\left(\frac{P_{o}^{1}-\rho_{p} P_{o}^{0}}{e^{\sigma_{0}}}\right)^{2}\right] d \sigma_{0} \\
\times \prod_{t=2}^{T} \frac{1}{e^{\sigma_{t} \sqrt{2 \pi}}} \exp \left[-\frac{1}{2}\left(\frac{P_{o}^{t}-\rho_{p} P_{o}^{t-1}}{e^{\sigma_{0}}}\right)^{2}\right] p\left(\sigma^{t} \mid P_{o}^{t-1} ; \Theta\right) d \sigma_{t} &
\end{aligned}
$$

The particle filter approximates the filtering density $p\left(\sigma_{t} \mid P_{o}^{t-1} ; \Theta\right)$ with a simulated distribution. The distribution is formed with particles:

$$
p\left(\sigma_{t} \mid P_{o}^{t} ; \Theta\right) \cong \sum_{i=0}^{N} \omega_{t}^{i} \delta_{\sigma_{t}^{i}}\left(\sigma_{t}\right)
$$

where $\sum_{i=0}^{N} \omega_{t}^{i}=1$ and $\omega_{t}^{i} \geq 0$. The SIR is a two step prediction and filtering procedure that starts with an initial condition $p\left(\sigma_{0} \mid P_{o}^{t} ; \Theta\right)=p\left(\sigma_{0} ; \Theta\right)$.

Using equation (46) I construct the conditional density $p\left(\sigma_{1} \mid P_{o}^{0} ; \Theta\right)=p\left(\nu_{\sigma, 1}\right) p\left(\sigma_{0} ; \Theta\right)$. To do this given $\mathrm{N}$ draws $\left(\sigma_{t \mid t}^{i}\right)_{i}^{N}$ from $p\left(\sigma_{t} \mid P_{o}^{t} ; \Theta\right)$ and a draw of exogenous shocks $\nu_{\sigma, t}^{i} \sim N(0,1)$, equation (46) is used to compute $\left(\sigma_{t+1 \mid t}^{i}\right)_{i}^{N}$.

The filtering step uses importance sampling to update the conditional probability from $p\left(\sigma_{t} \mid P_{o}^{t-1} ; \Theta\right)$ to $p\left(\sigma_{t} \mid P_{o}^{t} ; \Theta\right)$. Assign to each draw a weight defined by $\omega_{t}^{i}=p\left(\sigma_{t} \mid P_{o}^{t-1}, \sigma_{t-1} ; \Theta\right)=$ $\frac{1}{e^{\sigma_{t} \sqrt{2 \pi}}} \exp \left[-\frac{1}{2}\left(\frac{P_{o}^{1}-\rho_{p} P_{0}^{0}}{e^{\sigma_{t}}}\right)^{2}\right]$. The weights are then normalized to

$$
\tilde{\omega}_{t}^{i}=\frac{\omega_{t}^{i}}{\sum_{i=1}^{N} \omega_{t}^{i}}
$$

The prediction step is then repeated for time period $t+1$ up to time period $\mathrm{T}$. The likelihood function is then approximated by

$$
\begin{array}{r}
p\left(P_{o}^{T} ; \Theta\right) \cong \frac{1}{N} \sum_{i=1}^{N} \frac{1}{e^{\sigma_{0}^{i}} \sqrt{2 \pi}} \exp \left[-\frac{1}{2}\left(\frac{P_{o}^{1}-\rho_{p} P_{o}^{0}}{e^{\sigma_{0}^{i}}}\right)^{2}\right] \\
\times \prod_{t=2}^{T} \frac{1}{N} \sum_{i=1}^{N} \frac{1}{e^{\sigma_{t \mid t-1}^{i} \sqrt{2 \pi}}} \exp \left[-\frac{1}{2}\left(\frac{P_{o}^{t}-\rho_{p} P_{o}^{t-1}}{e^{\sigma_{t \mid t-1}^{i}}}\right)^{2}\right]
\end{array}
$$




\section{B.1.2 Particle Smoother}

I use the backward-smoothing routine of Godsill et al. (2004) to extract the historical distribution of the volatilities. The factorization of the joint likelihood is given by

$$
p\left(\sigma^{T} \mid P_{o}^{t} ; \Theta\right)=p\left(\sigma_{T} \mid P_{o}^{t} ; \Theta\right) \prod_{t=1}^{T-1} p\left(\sigma_{t} \mid \sigma_{t+1: T}, P_{o}^{T} ; \Theta\right)
$$

The second factor is then simplified to

$$
\begin{array}{r}
p\left(\sigma_{t} \mid \sigma_{t+1: T}, P_{o}^{T} ; \Theta\right)=p\left(\sigma_{t} \mid \sigma_{t+1}, P_{o}^{t} ; \Theta\right) \\
=\frac{p\left(\sigma_{t} \mid P_{o}^{t} ; \Theta\right) f\left(\sigma_{t+1} \mid \sigma_{t}\right)}{p\left(\sigma_{t+1} \mid P_{o}^{t}\right)} \\
\propto p\left(\sigma_{t} \mid P_{o}^{t} ; \Theta\right) f\left(\sigma_{t+1} \mid \sigma_{t}\right)
\end{array}
$$

The first equality comes from the Markovian properties of the model, $\mathrm{f}$ is the state transition density from 46 . Equation 48 allows us to construct $p\left(\sigma_{t} \mid P_{o}^{t} ; \Theta\right)$ by forward filtering, therefore I can approximate the above equation RHS by

$$
p\left(\sigma_{t} \mid \sigma_{t+1}, P_{o}^{t} ; \Theta\right) \cong \sum_{i=0}^{N} \omega_{t \mid t+1}^{i} \delta_{\sigma_{t}^{i}}\left(\sigma_{t}\right)
$$

The weights are given by

$$
\omega_{t \mid t+1}^{i}=\frac{\omega_{t}^{i} f\left(\sigma_{t+1} \mid \sigma_{t}^{i}\right)}{\sum_{i=1}^{N} \omega_{t}^{i} f\left(\sigma_{t+1} \mid \sigma_{t}^{i}\right)}
$$

where the $\omega_{t}^{i}$ are the weights from the filtering step. Denote $\tilde{\sigma}_{t}^{i}$ the $i^{\text {th }}$ draw from the smoothing density at time $t$. At time $\mathrm{T}$, draws $\tilde{\sigma}_{T}^{i}$ are obtained from $p\left(\sigma_{T} \mid P_{o}^{T}\right)$ with the weights $\omega_{T}^{i}$. Progressing backwards in time, the recursions iteratively obtain draws $\tilde{\sigma}_{t}^{i}$ by resampling with the weights 54 .

This process is repeated many times using different independent smoothing trajectories to construct the smoothing distribution. Given the sequence of smoothed states the smoothed residuals for both the level and volatility equations can also be extracted. The smoothed volatilities were constructed using the mean of the posterior distribution using 10,000 trajectories with 40,000 particles each.

\section{B.1.3 RWMC Algorithm}

The random walk Metropolis-Hastings algorithm estimates the oil process parameters $\rho_{o}, \rho_{\sigma}, \bar{\sigma}$, and $\phi$. The algorithm works as follows:

1) Starting from an initial guess $\Theta^{*}$, the parameter vector, generate the random walk proposal density

$$
\Theta_{j+1}^{\text {prop }}=\Theta_{j}^{\text {prop }}+c N(0,1), \mathrm{j}=1, \ldots, 150,000
$$

where $\mathrm{j}$ is the number of draws and $\mathrm{c}$ is a scaling parameter set to induce an acceptance ratio suggested in Roberts et al. (1996). 
2) The Metropolis-Hasting step. Compute the acceptance ratio $\psi=\min \left(\frac{p\left(\Theta_{j+1}^{\text {prop }} \mid p^{T}\right.}{p\left(\Theta_{j}^{\text {prop }} \mid p^{T}\right.}, 1\right)$. A random number $\mathrm{m}$ is drawn from a uniform distribution over the unit interval. Then $\Theta_{j+1}=\Theta_{j+1}^{\text {prop }}$ if $\mathrm{m}<\psi$ and $\Theta_{j+1}=\Theta_{j+1}$ otherwise. This procedure is repeated for all draws.

The first 50,000 draws are used as a burn-in period, and the remaining 100,000 draws are used as the invariant distribution of the resulting Markov Chain.

\section{B.2 Data}

This section gives details about data sets used in the analysis and shows robustness to the oil price series used.

\section{B.2.1 Price Data}

The BLS sampling process is now described in more detail. Prices are collected from a survey that asks producers for the price as of Tuesday of the week containing the 13 th of the month. The BLS uses a a three stage procedure to select individual items to include in the PPI. An industry is considered the starting point of sampling by the BLS. The first sampling stage is selecting establishments within an industry. An industry's frame of establishments are drawn from all firms listed in Unemployment Insurance as well as supplementary public lists used to refine the sampling population.

A price forming unit is created by clustering establishments within an industry in the second step. Within a price forming unit, all members must belong to the same industry. Within an industry, strata may then be established before sampling units due to differences in price determining behavior due to firm characteristics such as production technology or geographic location. In each strata a price forming unit is selected to be in the sample in proportion to its shipment value or number of employees.

In the third step, after an establishment is selected and chooses to participate the BLS uses disaggregation to select specific items to sample. This technique selects a category of items to be included in the PPI by assigning a probability of selection proportional to the value of the category within the reporting unit. The categories are broken into smaller units until individual goods and services are identified. If an individual item selected is sold at more than one price due to some characteristic such as customer, size of order, or color, then the particular transaction is selected also by probabilistic sampling.

Resampling of an industry accounts for changing market conditions every five to seven years. In practice, many reporters and items are included before and after the resampling. Nakamura and Steinsson (2008) exploit a two month period in 2001 when the BLS collected all data via by phone survey, rather than in the paper survey, and show that the data collection method does not change price behavior.

The BLS item level data is used to construct all dispersion and frequency variables. The monthly industry level data is trimmed in the panel regressions if there are less than 50 items within the industry in month $t$, and less than 15 observed price changes during month $t$. Having a reasonable number of price changes for industry $j$ during month $t$ is important to create an accurate measure of price change dispersion. Increasing the number of observed price changes does not change the results. Industry level inflation used as an independent variable comes from the official published Bureau of Labor Statistics numbers. Constructing average item level inflation 


\begin{tabular}{|c|c|c|c|c|c|c|c|c|}
\hline Dependent Variable: & & & & & & Freq & lency & \\
\hline & (1) & (2) & (3) & (4) & (5) & (6) & (7) & (8) \\
\hline$s_{o, j} * \Delta \log \left(P_{t-1}^{o}\right)$ & 0.098 & 0.073 & 0.082 & 0.140 & -0.194 & $-0.325^{* *}$ & -0.208 & $-0.218^{*}$ \\
\hline & $(0.217)$ & $(0.215)$ & $(0.228)$ & $(0.222)$ & $(0.168)$ & $(0.154)$ & $(0.198)$ & $(0.123)$ \\
\hline$s_{o, j} * \sigma_{t-1}$ & $3.266^{* *}$ & $3.330^{* *}$ & $2.999^{*}$ & $2.921^{* *}$ & $-2.156^{*}$ & -1.789 & -1.938 & -0.796 \\
\hline & $(1.461)$ & $(1.465)$ & $(1.587)$ & $(1.453)$ & $(1.181)$ & $(1.378)$ & $(1.366)$ & $(0.744)$ \\
\hline$\pi_{j, t}$ & & 0.159 & 0.073 & -0.024 & & $0.886^{* * *}$ & $1.139^{* * *}$ & $1.063^{* * *}$ \\
\hline & & $(0.115)$ & $(0.121)$ & $(0.109)$ & & $(0.326)$ & $(0.361)$ & $(0.323)$ \\
\hline$\Delta I P_{j, t}$ & & & 0.006 & 0.006 & & & $-0.060^{* * *}$ & $-0.051^{*}$ \\
\hline & & & $(0.021)$ & $(0.019)$ & & & $(0.024)$ & $(0.027)$ \\
\hline S.D. $\cdot j, t-1$ & & & & $0.060^{* * *}$ & & & & \\
\hline & & & & $(0.016)$ & & & & \\
\hline Frequency $_{j, t-1}$ & & & & & & & & $0.509^{* * *}$ \\
\hline & & & & & & & & $(0.057)$ \\
\hline Industry FE & Yes & Yes & Yes & Yes & Yes & Yes & Yes & Yes \\
\hline Time FE & Yes & Yes & Yes & Yes & Yes & Yes & Yes & Yes \\
\hline Number of Industries & & & & & & & & \\
\hline $\mathrm{N}$ & 15,808 & 15,808 & 12,321 & 12,215 & 16,122 & 16,122 & 12,542 & 12,529 \\
\hline
\end{tabular}

Table 14: Industry Specific Oil Demand Variables Regression - Robustness to Trimming

Note: Sample period: 1998:M1 to 2014:M12 at a monthly frequency. The dependent variable is the standard deviation of price change of a 4-digit NAICS industry in the manufacturing sector in columns (1)-(4) and price change frequency in column (5)-(8). This table shows results when no observations are trimmed due to small numbers of price changes. All industries within the oil producing NAICS 324 sector are excluded. $s_{o, j} * \Delta \log \left(P_{t-1}^{o}\right)$ and $s_{o, j} * \sigma_{t-1}$ are the industry specific oil demand variables using monthly WTI real price of oil. $\pi_{j, t}$ is the average item level inflation rate for industry j. $\sigma_{t}$ is the extracted stochastic volatility measure of oil price volatility. S.D. $j, t-1$ is lagged industry price change standard deviation. Frequency ${ }_{j, t-1}$ is lagged industry price change frequency. Robust asymptotic standard errors reported in parentheses are clustered at the industry level: ${ }^{*} p<.10$; ${ }^{* *} p<.05$; and $* * * p<.01$.

within a month does not affect the coefficient on oil price volatility, but does remove significance for the lagged inflation coefficient.

Table 14 replicates the main regression results in Table 6, but does not trim the pricing data if there are only few price changes or less than 50 items within a industry in a month. The table shows this trimming methodology does not affect the results. 


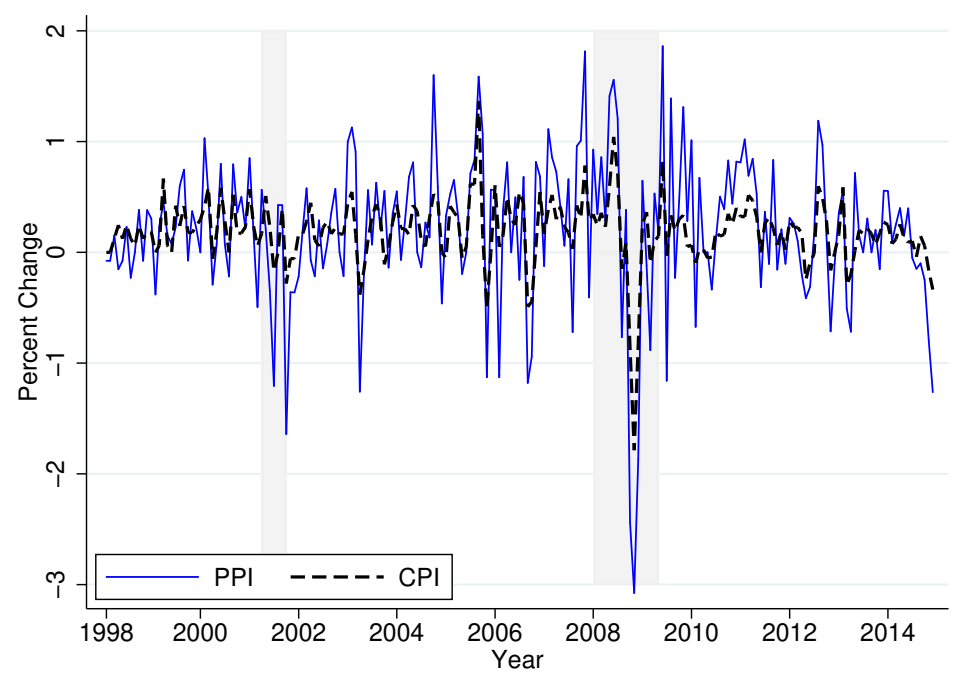

Figure 9: Monthly PPI Inflation and CPI Inflation

Note: Consumer Price Index for all Urban Consumers and Producer Price Index by Commodity for Finished Goods. Both indices are seasonally adjusted.

\section{B.2.2 Price Data Comparison}

Figure 9 shows producer price inflation plotted against consumer price inflation for the sample period. The month over month producer inflation rate is more volatile than the consumer inflation rate. The correlation between the two series is 0.82 . The price setting statistics are broadly similar except for a lower fraction of small price changes in the PPI.

\section{B.2.3 Industrial Production}

Industrial production is taken from the Federal Reserve Board website. It covers manufacturing, mining, and electric and gas utilities and is intended to measure variation in national output over the course of the business cycle.

\section{B.2.4 Oil Prices}

This section describes the oil price series used and shows robustness to alternatives.

Daily oil prices are taken from the Department of Energy website. It is measured as the spot price of West Texas Intermediate (WTI) crude oil in Cushing, OK. This data is available daily from 1986-2014 to construct realized volatility. Monthly measures are the average monthly spot price. All nominal amounts are transformed into real prices by deflating with the PPI Finished goods index. For the stochastic volatility model and GARCH model estimation, data from 1986 to 2014 is used.

Composite Refiners Acquisition Cost and Brent Crude oil prices are used for robustness. RAC is a weighted average of domestic and imported oil. Brent Crude is extracted from the North Sea and is a leading price benchmark for Atlantic basin crude oils. All three data series are available from the U.S. Energy Information Administration. 
A large literature attempts to explain movements in the price of oil. This section will summarize some of the main findings, which show that most movements in the price of oil that have been identified come from outside of the United States.

US oil prices were regulated by government agencies prior to 1973, leading to long periods of constant price followed by infrequent adjustments. Due to the oil price increase in 1973 and 1974, it became too difficult to provide a ceiling on the price of oil and prices have since been allowed to fluctuate in response to supply and demand. In the early 1980's there was an increase in oil production in non-OPEC countries, which decreased the market share of OPEC from 43 percent in 1980 to 28 percent in 1985 as documented by Baumeister and Kilian (2016). During this time, OPEC's efforts to influence the price of oil were unsuccessful.

There was a drop in the price of oil in the late 1990's due to a decrease in the demand for the price of oil that was partially caused by the Asian financial crisis of 1997. Kilian and Murphy (2014) show the increase in the price of oil following in 1999 reflected a combination of factors including higher demand for oil from a global demand recovery, and increased inventory demand due to coordinated supply cuts. A brief increase in the price of oil in late 2002 and early 2003 were related to two global oil supply disruptions. The first disruption was the Venezuelan oil strike from December 2002 to February 2003. The second oil supply disruption was due to the Iraq War in 2003

The large, long price increase in the nominal price of oil from $\$ 28$ in 2003 to $\$ 134$ in mid 2008, an increase of over 350 percent, or 250 percent in real terms is generally considered to be due to increases in demand. Hamilton (2009), Kilian (2008), and Kilian and Hicks (2013) argue that the demand shifts are associated to the expansion of the global economy and in particular additional demand from Asia. Oil producers were unable to supply the increase in demand during this time, leading to the increase in price.

Oil prices plummeted from $\$ 134$ in June 2008 to $\$ 34$ in February 2009 due to anticipation of a global recession. Baumeister and Kilian (2015) provided evidence that when it became clear the financial system would not collapse in 2009 , oil prices stabilized at $\$ 100$ per barrel. Kilian and Lee (2014) establish that a brief spike in prices in 2011 is related to the Libyan uprising. Between June 2014 and January 2015 the price of oil fell nearly fifty percent. This decline is attributed by Baumeister and Kilian (2015) to a decline in global activity. Kilian (2017) estimates that oil prices were about $\$ 10$ lower due the increase in the supply of oil from to U.S. fracking.

I now present the main regressions when using alternative oil prices. First, I replicate regression specifications (4) and (5) in Table 15. The column title denotes the oil price series used. Columns (1) through (3) show that all three oil price series predict increased price change dispersion, measured using standard deviation of price change, during periods of high oil price volatility. Columns (7) through (9) confirm this finding using the interquartile range of price changes. Price change frequency is used as the dependent variable in columns (4) through (6). Results show that there is not a positive relationship between price change frequency and oil price volatility. Brent oil price volatility is negatively related to price change frequency.

The main regression specifications (7) and (8) using RAC and Brent oil prices are in Table 16. Columns (1) through (4) show that both RAC and Brent oil price volatility cause increased price change dispersion. Columns (5) through (8) show that price change frequency is negatively related to oil price volatility using either price series. These results are consistent with the main results in Table 6 . 


\begin{tabular}{|c|c|c|c|c|c|c|c|c|c|}
\hline \multirow{2}{*}{$\begin{array}{l}\text { Dependent Variable: } \\
\text { Oil Price: }\end{array}$} & \multicolumn{3}{|c|}{ S.D. } & \multicolumn{3}{|c|}{ Frequency } & \multicolumn{3}{|c|}{$\mathrm{IQR}$} \\
\hline & $\begin{array}{l}\text { WTI } \\
(1)\end{array}$ & $\begin{array}{c}\text { RAC } \\
(2)\end{array}$ & $\begin{array}{c}\text { Brent } \\
(3)\end{array}$ & $\begin{array}{l}\text { WTI } \\
(4)\end{array}$ & $\begin{array}{c}\mathrm{RAC} \\
(5)\end{array}$ & $\begin{array}{c}\text { Brent } \\
(6)\end{array}$ & $\begin{array}{l}\text { WTI } \\
(7)\end{array}$ & $\begin{array}{c}\mathrm{RAC} \\
(8)\end{array}$ & $\begin{array}{c}\text { Brent } \\
(9)\end{array}$ \\
\hline$\Delta \log \left(P_{t-1}^{o}\right)$ & $\begin{array}{c}0.007 \\
(0.009)\end{array}$ & $\begin{array}{c}0.021^{* *} \\
(0.051)\end{array}$ & $\begin{array}{c}0.005 \\
(0.008)\end{array}$ & $\begin{array}{l}-0.036 \\
(0.025)\end{array}$ & $\begin{array}{l}-0.051^{*} \\
(0.029)\end{array}$ & $\begin{array}{l}-0.029 \\
(0.022)\end{array}$ & $\begin{array}{c}0.003 \\
(0.006)\end{array}$ & $\begin{array}{c}0.015^{* *} \\
(0.007)\end{array}$ & $\begin{array}{c}0.001 \\
(0.006)\end{array}$ \\
\hline$\sigma_{t-1}$ & $\begin{array}{c}0.259^{* * *} \\
(0.073)\end{array}$ & $\begin{array}{c}0.207^{* * *} \\
(0.051)\end{array}$ & $\begin{array}{c}0.254^{* * *} \\
(0.066)\end{array}$ & $\begin{array}{c}0.014 \\
(0.149)\end{array}$ & $\begin{array}{l}-0.110 \\
(0.117)\end{array}$ & $\begin{array}{c}-0.372^{\text {*** }} \\
(0.144)\end{array}$ & $\begin{array}{c}0.395^{* * *} \\
(0.048)\end{array}$ & $\begin{array}{c}0.280^{* * * *} \\
(0.036)\end{array}$ & $\begin{array}{c}0.286^{* * *} \\
(0.042)\end{array}$ \\
\hline $\mathrm{EBP}_{t-1}$ & $\begin{array}{c}0.002 \\
(0.002)\end{array}$ & $\begin{array}{c}0.003^{* *} \\
(0.002)\end{array}$ & $\begin{array}{c}0.003^{*} \\
(0.002)\end{array}$ & $\begin{array}{c}0.002 \\
(0.004)\end{array}$ & $\begin{array}{c}0.004 \\
(0.004)\end{array}$ & $\begin{array}{c}0.009^{* *} \\
(0.004)\end{array}$ & $\begin{array}{l}-0.000 \\
(0.001)\end{array}$ & $\begin{array}{c}0.002^{*} \\
(0.001)\end{array}$ & $\begin{array}{l}0.002^{*} \\
(0.001)\end{array}$ \\
\hline Realized Stock Vol ${ }_{j, t}$ & $\begin{array}{c}0.009 \\
(0.013)\end{array}$ & $\begin{array}{c}0.013 \\
(0.015)\end{array}$ & $\begin{array}{c}0.005 \\
(0.013)\end{array}$ & $\begin{array}{c}0.137^{* * *} * \\
(0.018)\end{array}$ & $\begin{array}{c}0.143^{* * *} \\
(0.019)\end{array}$ & $\begin{array}{c}0.165^{* * *} \\
(0.024)\end{array}$ & $\begin{array}{c}0.015^{* *} \\
(0.007)\end{array}$ & $\begin{array}{c}0.022 \\
(0.014)\end{array}$ & $\begin{array}{l}0.016^{*} \\
(0.010)\end{array}$ \\
\hline$\pi_{j, t}$ & $\begin{array}{c}0.083 \\
(0.115)\end{array}$ & $\begin{array}{c}0.087 \\
(0.114)\end{array}$ & $\begin{array}{c}0.083 \\
(0.115)\end{array}$ & $\begin{array}{c}1.320^{* * *} \\
(0.340)\end{array}$ & $\begin{array}{c}1.317^{* * *} \\
(0.343)\end{array}$ & $\begin{array}{c}1.304^{* * *} \\
(0.344)\end{array}$ & $\begin{array}{c}0.020 \\
(0.112)\end{array}$ & $\begin{array}{c}0.028 \\
(0.112)\end{array}$ & $\begin{array}{c}0.015 \\
(0.115)\end{array}$ \\
\hline$\Delta I P_{j, t}$ & $\begin{array}{c}0.004 \\
(0.016)\end{array}$ & $\begin{array}{c}0.006 \\
(0.015)\end{array}$ & $\begin{array}{c}0.007 \\
(0.015)\end{array}$ & $\begin{array}{c}-0.053^{*} \\
(0.032)\end{array}$ & $\begin{array}{l}-0.058^{*} \\
(0.031)\end{array}$ & $\begin{array}{c}-0.071^{* *} \\
(0.031)\end{array}$ & $\begin{array}{c}0.001 \\
(0.009)\end{array}$ & $\begin{array}{c}0.003 \\
(0.009)\end{array}$ & $\begin{array}{c}-0.000 \\
(0.010)\end{array}$ \\
\hline Industry FE & Yes & Yes & Yes & Yes & Yes & Yes & Yes & Yes & Yes \\
\hline Number of Industries & 63 & 63 & 63 & 63 & 63 & 63 & 63 & 63 & 63 \\
\hline $\mathrm{N}$ & 10,586 & 10,586 & 10,586 & 10,586 & 10,586 & 10,586 & 10,586 & 10,586 & 10,586 \\
\hline
\end{tabular}

Table 15: Price Setting Behavior and Macroeconomic Shocks - Robustness to Oil Price

Note: Sample period: 1998:M1 to 2014:M12 at a monthly frequency. The dependent variable is the standard deviation of price change of a 4-digit NAICS industry in the manufacturing sector in columns (1)-(3), frequency of price change in columns (4)-(6), and the interquartile range of price change sin columns (7)-(9). All industries within the oil producing NAICS 324 sector are excluded. $\Delta \log \left(P_{t-1}^{o}\right)$ and $\sigma_{t-1}$ are real oil price inflation and oil price volatility using the extracted stochastic volatility measure for each oil price series. $\pi_{j, t}$ is the average item level inflation rate for industry $j$, Realized Stock $\mathrm{Vol}_{j, t}$ is the median industry realized stock volatility of industry $j$ at time $t, \mathrm{EBP}$ is the excess bond premium, and $\Delta I P_{j, t}$ is the change in the industrial production index of industry $j$ at time $t$. The column title denotes the oil price series Robust asymptotic standard errors reported in parentheses are double clustered at the industry-month level: ${ }^{*} p<.10 ;{ }^{* *} p<.05 ;$ and ${ }^{* * *} p<.01$.

\begin{tabular}{|c|c|c|c|c|c|c|c|c|}
\hline Dependent Variable: & & S.D & & & & Freq1 & ency & \\
\hline Oil Price: & $\begin{array}{c}\mathrm{RAC} \\
(1)\end{array}$ & $\begin{array}{c}\mathrm{RAC} \\
(2)\end{array}$ & $\begin{array}{c}\text { Brent } \\
(3)\end{array}$ & $\begin{array}{c}\text { Brent } \\
(4)\end{array}$ & $\begin{array}{c}\mathrm{RAC} \\
(5)\end{array}$ & $\begin{array}{c}\mathrm{RAC} \\
(6)\end{array}$ & $\begin{array}{c}\text { Brent } \\
(7)\end{array}$ & $\begin{array}{c}\text { Brent } \\
(8)\end{array}$ \\
\hline$s_{o, j} * \Delta \log \left(P_{t-1}^{o}\right) \mathrm{rac}$ & $\begin{array}{c}0.278 \\
(0.190)\end{array}$ & $\begin{array}{c}0.266 \\
(0.187)\end{array}$ & $\begin{array}{c}0.139 \\
(0.174)\end{array}$ & $\begin{array}{c}0.128 \\
(0.169)\end{array}$ & $\begin{array}{c}-0.471^{* * *} \\
(0.133)\end{array}$ & $\begin{array}{c}-0.614^{* * *} \\
(0.158)\end{array}$ & $\begin{array}{c}-0.470^{* * *} \\
(0.132)\end{array}$ & $\begin{array}{c}-0.604^{* * *} \\
(0.188)\end{array}$ \\
\hline$s_{o, j} * \sigma_{t-1} \mathrm{rac}$ & $\begin{array}{c}3.500^{* * *} * \\
(0.765)\end{array}$ & $\begin{array}{c}3.532^{* * * *} \\
(0.779)\end{array}$ & $\begin{array}{l}2.066^{*} \\
(1.063)\end{array}$ & $\begin{array}{l}2.081^{*} \\
(1.072)\end{array}$ & $\begin{array}{c}-4.004^{* * *} \\
(0.822)\end{array}$ & $\begin{array}{c}-3.638^{* * *} \\
(0.854)\end{array}$ & $\begin{array}{c}-7.895^{* * *} \\
(1.489)\end{array}$ & $\begin{array}{c}-7.718^{* * *} \\
(1.394)\end{array}$ \\
\hline$\pi_{j, t}$ & & $\begin{array}{c}0.075 \\
(0.118)\end{array}$ & & $\begin{array}{c}0.069 \\
(0.119)\end{array}$ & & $\begin{array}{c}0.847^{* * *} \\
(0.201)\end{array}$ & & $\begin{array}{c}0.848^{* * *} \\
(0.201)\end{array}$ \\
\hline Time \& Industry FE & Yes & Yes & Yes & Yes & Yes & Yes & Yes & Yes \\
\hline Number of Industries & 81 & 81 & 81 & 81 & 81 & 81 & 81 & 81 \\
\hline $\mathrm{N}$ & 13,606 & 13,606 & 13,606 & 13,606 & 13,606 & 13,606 & 13,606 & 13,606 \\
\hline
\end{tabular}

Table 16: Industry Specific Oil Regression: Alternative Oil Prices

Note: Sample period: 1998:M1 to 2014:M12 at a monthly frequency. The dependent variable is the standard deviation of price change of a 4-digit NAICS industry in the manufacturing sector in columns (1)-(4) and price change frequency in column (5)-(8). All industries within the oil producing NAICS 324 sector are excluded. $s_{o, j} * \Delta \log \left(P_{t-1}^{o}\right)$ and $s_{o, j} * \sigma_{t-1}$ are the industry specific oil demand variables using either RAC or Brent real price of oil indicated in the column title. $\pi_{j, t}$ is the average item level inflation rate for industry j. $\sigma_{t}$ is volatility measure of oil price volatility indicated in the column title. Robust asymptotic standard errors reported in parentheses are clustered at the industry level: ${ }^{*} p<.10 ;{ }^{* *} p<.05$; and ${ }^{* * *} p<.01$. 


\begin{tabular}{lclc}
\hline Rank & Industry & Name & $\theta$ \\
\hline 1 & 3251 & Basic Chemical Manufacturing & 0.161 \\
2 & 3365 & Railroad Rolling Stock Manufacturing & 0.051 \\
3 & 3259 & Other Chemical Product and Preparation Manufacturing & 0.043 \\
4 & 3255 & Paint, Coating, and Adhesive Manufacturing & 0.032 \\
5 & 3252 & Resin, Synthetic Rubber, and Artificial Synthetic Fibers and Filaments Manufacturing & 0.026 \\
6 & 3256 & Soap, Cleaning Compound, and Toilet Preparation Manufacturing & 0.024 \\
7 & 3221 & Pulp, Paper, and Paperboard Mills & 0.020 \\
8 & 3311 & Iron and Steel Mills and Ferroalloy Manufacturing & 0.023 \\
9 & 3362 & Motor Vehicle Body and Trailer Manufacturing & 0.022 \\
10 & 3253 & Pesticide, Fertilizer, and Other Agricultural Chemical Manufacturing & 0.021 \\
\hline \multicolumn{5}{c}{ P10 } & & 0.001 \\
\multicolumn{7}{c}{ Average } & P90 & 0.008 \\
& &
\end{tabular}

Table 17: NAICS 4 Industry Oil Share

\section{B.2.5 Input Output Tables}

Detailed Input Output "Use" tables from the Bureau of Economic are constructed every 5 years. I use the 1997 table to construct value added weights to aggregate industries for price statistics. The oil share of value added is also constructed using the Input Output tables. The oil producing sector is defined as NAICS 324110, Petroleum Refineries. The NAICS definition of this category is:

This industry comprises establishments primarily engaged in refining crude petroleum into refined petroleum. Petroleum refining involves one or more of the following activities: (1) fractionation; (2) straight distillation of crude oil; and (3) cracking.

The overall average, 10th percentile, and 90th percentile of dollar share of oil to value added is listed in Table 17 along with the four digit industries with the largest oil share in 1997.

An alternative long run measure of oil usage is constructed by averaging over the oil usage from the detailed IO tables from 1997, 2002, and 2007 in order to reduce the sensitivity of the measure to short run effects of oil price changes. An industry's oil share of production could change over time due to technological change or substitution towards or away from oil due to changes in oil

price. Specifically, $\overline{s_{o, j}}=\sum_{t=1}^{T} \frac{s_{o, j, t}}{T}$, is defined as the long run usage and is in the spirit of Nekarda and Ramey (2011). Results using this measure are in Table 18. Columns (1) through (4) show that price change dispersion is associated with increased oil price volatility using the long run oil usage. Columns (5) through (8) show no relationship between price change frequency and oil price volatility. 


\begin{tabular}{|c|c|c|c|c|c|c|c|c|}
\hline \multirow[t]{2}{*}{ Dependent Variable: } & \multicolumn{4}{|c|}{ S.D. } & \multicolumn{4}{|c|}{ Frequency } \\
\hline & (1) & (2) & (3) & (4) & $(5)$ & $(6)$ & $(7)$ & (8) \\
\hline$\overline{s_{o, j}} * \Delta \log \left(P_{t-1}^{o}\right)$ & $\begin{array}{c}0.076 \\
(0.110)\end{array}$ & $\begin{array}{c}0.066 \\
(0.111)\end{array}$ & $\begin{array}{l}-0.030 \\
(0.097)\end{array}$ & $\begin{array}{c}0.021 \\
(0.094)\end{array}$ & $\begin{array}{c}-0.217^{* *} \\
(0.094)\end{array}$ & $\begin{array}{c}-0.323^{* * *} \\
(0.100)\end{array}$ & $\begin{array}{c}-0.315^{* * *} \\
(0.109)\end{array}$ & $\begin{array}{l}-0.150 \\
(0.091)\end{array}$ \\
\hline$\overline{s_{o, j}} * \sigma_{t-1}$ & $\begin{array}{c}3.448^{* * *} \\
(0.969)\end{array}$ & $\begin{array}{c}3.471^{* * *} \\
(0.976)\end{array}$ & $\begin{array}{c}3.456^{* * *} \\
(1.094)\end{array}$ & $\begin{array}{c}3.290^{* * *} \\
(1.022)\end{array}$ & $\begin{array}{c}0.307 \\
(1.792)\end{array}$ & $\begin{array}{c}0.553 \\
(1.937)\end{array}$ & $\begin{array}{c}0.743 \\
(2.239)\end{array}$ & $\begin{array}{c}0.577 \\
(0.988)\end{array}$ \\
\hline$\pi_{j, t}$ & & $\begin{array}{c}0.077 \\
(0.117)\end{array}$ & $\begin{array}{c}0.079 \\
(0.113)\end{array}$ & $\begin{array}{c}0.103 \\
(0.112)\end{array}$ & & $\begin{array}{c}0.858^{* * * *} \\
(0.203)\end{array}$ & $\begin{array}{c}0.911^{* * * *} \\
(0.226)\end{array}$ & $\begin{array}{c}0.787^{* * *} \\
(0.187)\end{array}$ \\
\hline$\Delta I P_{j, t}$ & & & $\begin{array}{c}0.002 \\
(0.014)\end{array}$ & $\begin{array}{c}0.013 \\
(0.016)\end{array}$ & & & $\begin{array}{l}-0.046 \\
(0.029)\end{array}$ & $\begin{array}{l}-0.042 \\
(0.036)\end{array}$ \\
\hline S.D. $\cdot j, t-1$ & & & & $\begin{array}{c}0.075^{* * *} \\
(0.016)\end{array}$ & & & & \\
\hline Frequency $_{j, t-1}$ & & & & & & & & $\begin{array}{c}0.572^{* * *} \\
(0.038)\end{array}$ \\
\hline Industry FE & Yes & Yes & Yes & Yes & Yes & Yes & Yes & Yes \\
\hline Time FE & Yes & Yes & Yes & Yes & Yes & Yes & Yes & Yes \\
\hline Number of Industries & 81 & 81 & 63 & 63 & 81 & 81 & 63 & 63 \\
\hline $\mathrm{N}$ & 13,606 & 13,606 & 10,946 & 10,939 & 13,606 & 13,606 & 10,946 & 10,946 \\
\hline
\end{tabular}

Table 18: Industry Specific Oil Demand Variables Regression- Long Run Oil Sensitivity

Note: Sample period: 1998:M1 to 2014:M12 at a monthly frequency. The dependent variable is the standard deviation of price change of a 4-digit NAICS industry in the manufacturing sector in columns (1)-(4) and price change frequency in column (5)-(8). All industries within the oil producing NAICS 324 sector are excluded. $\overline{s_{o, j}} * \Delta \log \left(P_{t-1}^{o}\right)$ and $\overline{s_{o, j}} * \sigma_{t-1}$ are the industry specific oil demand variables using the time averaged oil usage from the 1997, 2002, and 2007 Input Output tables and monthly WTI real price of oil. $\pi_{j, t}$ is the average item level inflation rate for industry $j . \sigma_{t}$ is the extracted stochastic volatility measure of oil price volatility. S.D. ${ }_{j, t-1}$ is lagged industry price change standard deviation. Frequency $y_{j, t-1}$ is lagged industry price change frequency. Robust asymptotic standard errors reported in parentheses are clustered at the industry level: ${ }^{*} p<.10{ }^{* *} p<.05$; and ${ }^{* * *} p<.01$.

\section{B.3 Additional Robustness Exercises}

This section presents additional robustness exercises. It first describes alternative oil price volatility series, then presents robustness exercises on the relationship between pricing behavior and oil price volatility.

\section{B.3.1 Alternative Oil Price Volatility Measures}

The main text of the paper uses stochastic volatility of real oil prices, however alternative oil price volatility measures can be constructed. In this section I construct two alternative measures, GARCH and realized volatility of real oil prices, and show the results on price setting behavior are robust to measurement of volatility.

First, a GARCH model of volatility is estimated, and the extracted volatility series shows that GARCH volatility and stochastic volatility measure the same underlying process. The estimated GARCH model is

$$
\log P_{t}^{o}=\rho_{p} \log P_{t-1}^{o}+\epsilon_{t}
$$




\begin{tabular}{llcccc}
\hline & & SV & GV & RV & $\Delta \log \left(P_{t}^{o}\right)$ \\
\cline { 5 - 6 } $\mathrm{SV}$ & & 1.00 & & & \\
$\mathrm{GV}$ & & 0.74 & 1.00 & & \\
$\mathrm{RV}$ & & 0.68 & 0.57 & 1.00 & \\
$\Delta \log \left(P_{t}^{o}\right)$ & -0.16 & -0.05 & -0.39 & 1.00 \\
\hline
\end{tabular}

Table 19: Oil Price and Volatility Correlation Matrix

NotE: Sample period: 1998:M1 to 2014:M12 at a monthly frequency. Number of observation=203. SV is stochastic volatility of real oil price, GV is GARCH volatility of real oil price, RV is realized volatility of real oil price, and $\Delta \log \left(P_{t}^{o}\right)$ is monthly real oil price inflation.

where $\epsilon_{t}=\sigma_{t} z_{t}$, and $z_{t} \sim \mathrm{N}(0,1)$

$$
\sigma_{t}^{2}=\omega+\alpha \epsilon_{t-1}^{2}+\beta \sigma_{t-1}^{2}
$$

The estimated GARCH parameters are $\rho_{p}=0.997$ (0.003), $\omega=0.001$ (0.001), $\alpha=0.199(0.050)$, $\beta=0.615$ (0.102). The conditional heteroskedasticity of oil prices in the estimated $\operatorname{GARCH}(1,1)$ model of oil prices has both significant autoregressive and moving average components.

The final measure of volatility for robustness is the realized volatility of daily real oil price returns. The monthly realized volatility value is constructed as:

$$
R V_{t}=\sqrt{\frac{\sum_{n=1}^{N}\left(d p_{n}-\overline{d p_{t}}\right)^{2}}{N-1}}
$$

where $d p_{n}$ is the log difference in daily real oil prices between days and $n$ indexes number of trading days in month $t$. This volatility measure differs significantly from the extracted stochastic volatility and GARCH processes. The realized volatility series is more volatile than the other two because it only relies on within month variation in oil prices without any between month smoothing mechanism due to autocorrelation in the oil price volatility process.

The three series are highly correlated, as shown in Table 19, suggesting they are picking up a common volatility component. The volatility series are plotted in Figure 10 and their summary statistics are in Table 20. It shows that the GARCH volatility series is noisier than the stochastic volatility series, but they are following the same latent volatility process with a correlation of 0.74 between the two series. GARCH volatility shows a large increase in volatility during 2009 that is also present in the stochastic volatility measure. Additionally, realized volatility is noisier than the other two series but is still highly correlated. Realized volatility also shows the large increase in 2009. All three series are negatively correlated with real oil price inflation.

Large movements in the volatility of oil price are correlated across all three series. There is a spike in volatility in all three measures during the last months of 2002 and early 2003 that occurs during the Venezuelan oil strike and beginning of the Iraq War. Between March 2008 and December 2008 , stochastic volatility more than doubles from 0.078 to 0.172 . GARCH and realized volatility have similar large increases during the same time period. GARCH volatility rises from 0.06 to 0.15 , and realized volatility nearly quadruples from 0.04 to 0.15 . All three series also have large increases 


\begin{tabular}{cccccc}
\hline Variable & Mean & Median & Standard Dev & Max & Min \\
\hline Stochastic Vol & 0.0759 & 0.0718 & 0.0198 & 0.1579 & 0.0433 \\
GARCH Vol & 0.0783 & 0.0736 & 0.0183 & 0.1939 & 0.0587 \\
Realized Vol & 0.0225 & 0.0198 & 0.0106 & 0.0741 & 0.0072 \\
$\Delta \log \left(P_{t}^{o}\right)$ & 0.0042 & 0.0119 & 0.0820 & 0.2130 & -0.3132 \\
\hline
\end{tabular}

Table 20: Oil Price Summary Statistics

NoTE: Summary statistics for monthly WTI real oil prices over 1998:M1-2014:M12.

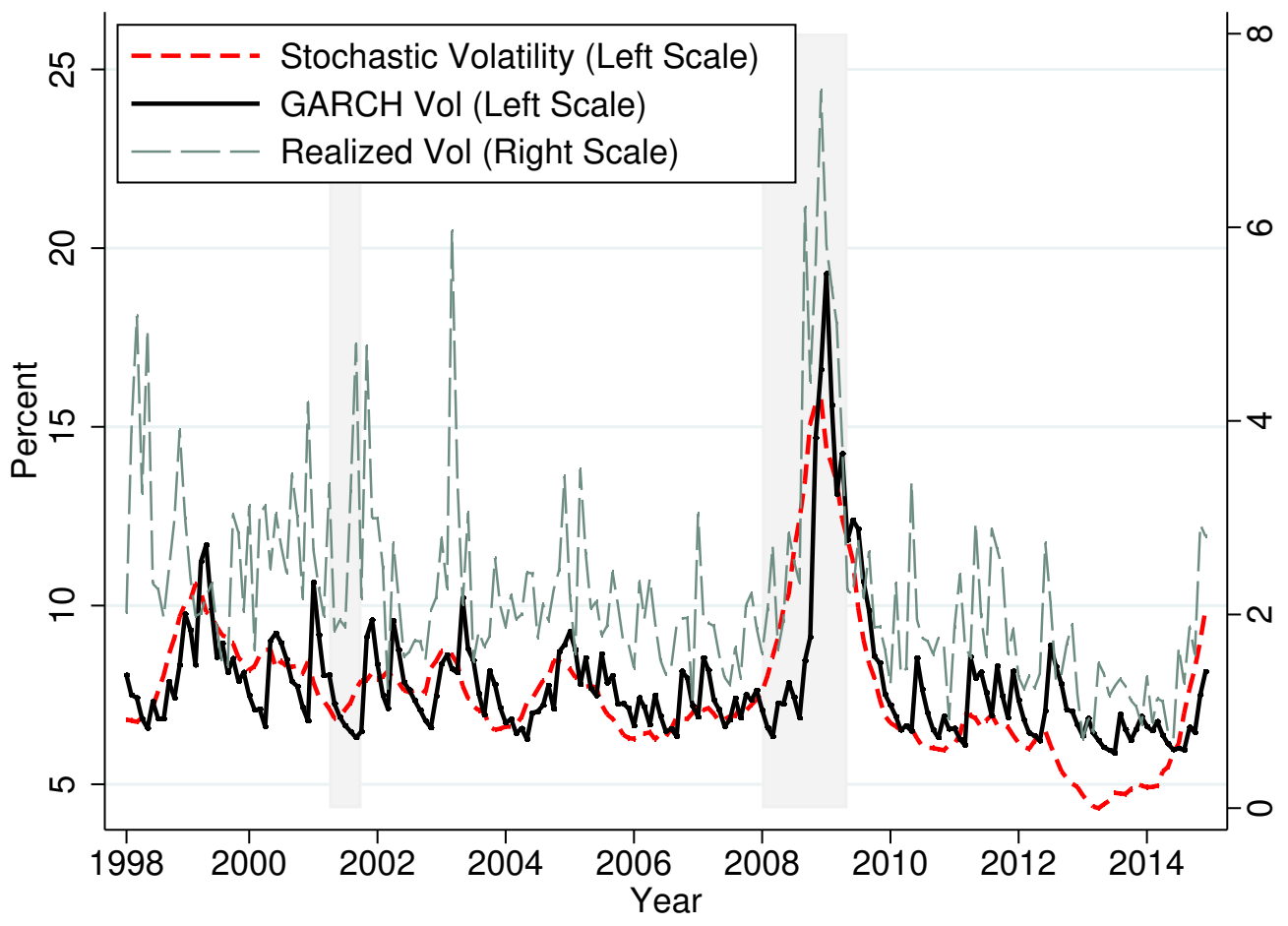

Figure 10: Oil Price Volatility

Note: The thick dotted red line shows the extracted stochastic volatility of oil prices, $100 * e^{\sigma_{t}}$, while the solid black line shows the GARCH volatility, $100 * \sigma_{t}$. The thin dotted gray line shows within month realized volatility of daily oil prices in percentage.

during the second half of 2014.

I now show that the main results are robust to alternative oil price volatility measures. First, Table 21 shows results from regression specifications (4) and (5). Columns (1) through (3) show that price change dispersion is associated with increased oil price volatility using all of the three measures. Columns (4) through (6) show no relationship between price change frequency and oil price volatility.

Next, I replicate regression specifications (7) and (8) using GARCH and realized volatility of oil prices. Results are in Table 22. The table shows that both GARCH and realized volatility cause increased relative price change dispersion. Price change frequency is negatively related to both 


\begin{tabular}{|c|c|c|c|c|c|c|}
\hline \multirow{2}{*}{$\begin{array}{l}\text { Dependent Variable: } \\
\text { Volatility Measure: }\end{array}$} & \multicolumn{3}{|c|}{ S.D. } & \multicolumn{3}{|c|}{ Frequency } \\
\hline & $\begin{array}{l}\text { Stochastic } \\
\text { (1) }\end{array}$ & $\begin{array}{l}\text { GARCH } \\
\quad(2)\end{array}$ & $\begin{array}{l}\text { Realized } \\
\text { (3) }\end{array}$ & $\begin{array}{c}\text { Stochastic } \\
\text { (4) }\end{array}$ & $\begin{array}{c}\text { GARCH } \\
(5)\end{array}$ & $\begin{array}{l}\text { Realized } \\
\quad(6)\end{array}$ \\
\hline$\Delta \log \left(P_{t-1}^{o}\right)$ & $\begin{array}{c}0.007 \\
(0.009)\end{array}$ & $\begin{array}{c}0.003 \\
(0.009)\end{array}$ & $\begin{array}{c}0.014 \\
(0.011)\end{array}$ & $\begin{array}{l}-0.036 \\
(0.025)\end{array}$ & $\begin{array}{l}-0.037 \\
(0.025)\end{array}$ & $\begin{array}{l}-0.035 \\
(0.024)\end{array}$ \\
\hline$\sigma_{t-1}$ & $\begin{array}{c}0.259^{* * *} \\
(0.073)\end{array}$ & $\begin{array}{c}0.181^{* * *} \\
(0.057)\end{array}$ & $\begin{array}{c}0.243^{* *} \\
(0.120)\end{array}$ & $\begin{array}{c}0.014 \\
(0.149)\end{array}$ & $\begin{array}{c}0.042 \\
(0.133)\end{array}$ & $\begin{array}{c}0.022 \\
(0.274)\end{array}$ \\
\hline $\mathrm{EBP}_{t-1}$ & $\begin{array}{c}0.002 \\
(0.002)\end{array}$ & $\begin{array}{c}0.005^{* * *} \\
(0.001)\end{array}$ & $\begin{array}{c}0.005^{* * *} \\
(0.002)\end{array}$ & $\begin{array}{c}0.002 \\
(0.004)\end{array}$ & $\begin{array}{c}0.002 \\
(0.003)\end{array}$ & $\begin{array}{c}0.003 \\
(0.003)\end{array}$ \\
\hline Realized Stock Vol $\mathrm{V}_{j, t}$ & $\begin{array}{c}0.009 \\
(0.013)\end{array}$ & $\begin{array}{c}0.017 \\
(0.016)\end{array}$ & $\begin{array}{c}0.019 \\
(0.015)\end{array}$ & $\begin{array}{c}0.137^{* * *} \\
(0.018)\end{array}$ & $\begin{array}{c}0.137^{* * *} \\
(0.019)\end{array}$ & $\begin{array}{c}0.138^{* * *} \\
(0.018)\end{array}$ \\
\hline$\pi_{j, t}$ & $\begin{array}{c}0.083 \\
(0.115)\end{array}$ & $\begin{array}{c}0.097 \\
(0.115)\end{array}$ & $\begin{array}{c}0.083 \\
(0.117)\end{array}$ & $\begin{array}{c}1.320^{* * * *} \\
(0.340)\end{array}$ & $\begin{array}{c}1.326^{* * * *} \\
(0.341)\end{array}$ & $\begin{array}{c}1.321^{* * *} \\
(0.340)\end{array}$ \\
\hline$\Delta I P_{j, t}$ & $\begin{array}{c}0.004 \\
(0.016) \\
\end{array}$ & $\begin{array}{l}-0.003 \\
(0.016) \\
\end{array}$ & $\begin{array}{l}-0.002 \\
(0.016)\end{array}$ & $\begin{array}{l}-0.053^{*} \\
(0.032) \\
\end{array}$ & $\begin{array}{l}-0.053 \\
(0.033) \\
\end{array}$ & $\begin{array}{l}-0.053 \\
(0.033) \\
\end{array}$ \\
\hline $\begin{array}{l}\text { Industry FE } \\
\text { Number of Industries }\end{array}$ & $\begin{array}{l}\text { Yes } \\
63\end{array}$ & $\begin{array}{l}\text { Yes } \\
63\end{array}$ & $\begin{array}{l}\text { Yes } \\
63\end{array}$ & $\begin{array}{l}\text { Yes } \\
63\end{array}$ & $\begin{array}{l}\text { Yes } \\
63\end{array}$ & $\begin{array}{l}\text { Yes } \\
63\end{array}$ \\
\hline $\mathrm{N}$ & 10,586 & 10,586 & 10,586 & 10,586 & 10,586 & 10,586 \\
\hline
\end{tabular}

Table 21: Price Setting Behavior and Macroeconomic Shocks - Robustness to Volatility

Note: Sample period: 1998:M1 to 2014:M12 at a monthly frequency. The dependent variable is the standard deviation of price change of a 4-digit NAICS industry in the manufacturing sector in columns (1) through (3), and the frequency of price change in columns (3) through (6). All industries within the oil producing NAICS 324 sector are excluded. $\Delta \log \left(P_{t-1}^{o}\right)$ and $\sigma_{t-1}$ are real oil price inflation and oil price volatility using the extracted stochastic volatility measure. $\pi_{j, t}$ is the average item level inflation rate for industry $j$,ealized Stock $\mathrm{Vol}_{j, t}$ is the median industry realized stock volatility of industry $j$ at time $t$, EBP is the excess bond premium, and $\Delta I P_{j, t}$ is the change in the industrial production index of industry $j$ at time $t$. Column title denotes the measure of real oil price volatility used. Robust asymptotic standard errors reported in parentheses are double clustered at the industry-month level: ${ }^{*} p<.10 ;{ }^{* *} p<.05 ;$ and ${ }^{* * *} p<.01$.

measures of volatility, but significantly so for realized volatility. These result are consistent with the stochastic volatility measure. 


\begin{tabular}{|c|c|c|c|c|c|c|c|c|}
\hline \multirow{2}{*}{$\frac{\text { Dependent Variable: }}{\text { Volatility Measure: }}$} & \multicolumn{4}{|c|}{ S.D. } & \multicolumn{4}{|c|}{ Frequency } \\
\hline & $\begin{array}{c}\text { GARCH } \\
(1)\end{array}$ & $\begin{array}{c}\text { GARCH } \\
(2)\end{array}$ & $\begin{array}{c}\text { Realized } \\
\text { (3) }\end{array}$ & $\begin{array}{c}\text { Realized } \\
\text { (4) }\end{array}$ & $\begin{array}{c}\text { GARCH } \\
(5)\end{array}$ & $\begin{array}{c}\text { GARCH } \\
(6)\end{array}$ & $\begin{array}{c}\text { Realized } \\
(7)\end{array}$ & $\begin{array}{c}\text { Realized } \\
(8)\end{array}$ \\
\hline$s_{o, j} * \Delta \log \left(P_{t-1}^{o}\right)$ & $\begin{array}{c}0.127 \\
(0.212)\end{array}$ & $\begin{array}{c}0.116 \\
(0.209)\end{array}$ & $\begin{array}{c}0.466 \\
(0.302)\end{array}$ & $\begin{array}{c}0.458 \\
(0.297)\end{array}$ & $\begin{array}{c}-0.269^{* * *} \\
(0.106)\end{array}$ & $\begin{array}{c}-0.393^{* * *} \\
(0.137)\end{array}$ & $\begin{array}{c}-0.624^{* * *} \\
(0.140)\end{array}$ & $\begin{array}{c}-0.714^{* * *} \\
(0.164)\end{array}$ \\
\hline$s_{o, j} * \sigma_{t-1}$ & $\begin{array}{c}3.805^{* * *} \\
(0.999)\end{array}$ & $\begin{array}{c}3.870^{* * *} \\
(1.018)\end{array}$ & $\begin{array}{c}7.612^{* * *} \\
(2.811)\end{array}$ & $\begin{array}{c}7.686^{* * *} \\
(2.855)\end{array}$ & $\begin{array}{l}-0.284 \\
(0.959)\end{array}$ & $\begin{array}{c}0.450 \\
(1.285)\end{array}$ & $\begin{array}{c}-7.003^{* * *} \\
(1.689)\end{array}$ & $\begin{array}{c}-6.154^{* * *} \\
(1.641)\end{array}$ \\
\hline$\pi_{j, t}$ & & $\begin{array}{c}0.076 \\
(0.118)\end{array}$ & & $\begin{array}{c}0.073 \\
(0.118)\end{array}$ & & $\begin{array}{c}0.854^{* * *} \\
(0.201)\end{array}$ & & $\begin{array}{c}0.849^{* * *} \\
(0.201)\end{array}$ \\
\hline Time \& Industry FE & Yes & Yes & Yes & Yes & Yes & Yes & Yes & Yes \\
\hline Number of Industries & 81 & 81 & 81 & 81 & 81 & 81 & 81 & 81 \\
\hline $\mathrm{N}$ & 13,606 & 13,606 & 13,606 & 13,606 & 13,606 & 13,606 & 13,606 & 13,606 \\
\hline
\end{tabular}

Table 22: Industry Specific Oil Regression: Alternative Oil Volatility Measures

Note: Sample period: 1998:M1 to 2014:M12 at a monthly frequency. The dependent variable is the standard deviation of price change of a 4-digit NAICS industry in the manufacturing sector in columns (1)-(4) and price change frequency in column (5)-(8). All industries within the oil producing NAICS 324 sector are excluded. $s_{o, j} * \Delta \log \left(P_{t-1}^{o}\right)$ and $s_{o, j} * \sigma_{t-1}$ are the industry specific oil demand variables using monthly WTI real price of oil. $\pi_{j, t}$ is the average item level inflation rate for industry j. $\sigma_{t}$ is volatility measure of oil price volatility indicated in the column title. Robust asymptotic standard errors reported in parentheses are clustered at the industry level: ${ }^{*} p<.10 ;{ }^{* *} p<.05$; and $* * * p<.01$. 


\section{B.3.2 Generated Regressor}

Both stochastic volatility and GARCH volatility are latent processes and must be generated in an estimation procedure. Therefore, I incorporate estimation uncertainty for the volatility process from the stochastic volatility and GARCH volatility processes by employing a two stage bootstrap procedure to adjust the standard errors. This two step procedure then incorporates estimation uncertainty from the oil price volatility process as well as within-industry correlation and arbitrary residual correlation across industries in proximate time periods.

The bootstrap procedure to address the generated regressor standard errors is a two step procedure. First estimation uncertainty for the volatility process is constructed and second the estimation uncertainty is included in the baseline regressions of interest. I first follow Lee and Fan (2006) to bootstrap the stochastic volatility process, then include the estimation uncertainty in the regression by using the panel moving blocks bootstrap of Goncalves (2011) in the second step.

The first step to construct estimation uncertainty in the stochastic volatility process is summarized as follows. First, the stochastic volatility model is estimated:

$$
\log P_{t}^{o}=\rho_{p} \log P_{t-1}^{o}+e^{\sigma_{t}} \nu_{t}
$$

where $\nu_{t}(z) \sim \mathrm{N}(0,1)$.

$$
\sigma_{t}=\left(1-\rho_{\sigma}\right) \bar{\sigma}+\rho_{\sigma} \sigma_{t-1}+\phi \nu_{\sigma, t}
$$

where $\nu_{\sigma, t}(z) \sim \mathrm{N}(0,1)$.

The parameters of the model, $\theta=\left\{\rho_{p}, \rho_{\sigma}, \bar{\sigma}, \phi\right\}$, are estimated by $\hat{\theta}=\left\{\hat{\rho}_{p}, \hat{\rho}_{\sigma}, \hat{\bar{\sigma}}, \hat{\phi}\right\}$, using the full sample of data. The residuals, $\hat{\nu_{t}}$ and $\hat{\nu}_{\sigma, t}$ are then computed, $t=1, \ldots T$.

The second step is to generate $K$ bootstrap replicates of oil prices and volatilities using the following recursions:

$$
\begin{gathered}
\sigma_{t}^{*}=\left(1-\hat{\rho}_{\sigma}\right) \hat{\bar{\sigma}}+\hat{\rho_{\sigma}} \sigma_{t-1}^{*}+\hat{\phi} \nu_{\sigma, t}^{*} \\
\log P_{t}^{* o}=\hat{\rho}_{p} \log P_{t-1}^{* o}+e^{\sigma_{t}^{*}} \nu_{t}^{*}
\end{gathered}
$$

where $\nu_{t}^{*}$ and $\nu_{\sigma, t}^{*}$ are jointly generated using a moving block bootstrap resampling with replacement from the empirical distribution function of centered residuals, while $\hat{\sigma}_{1}^{* 2}=\hat{\sigma}_{1}^{2}$ and $\log P_{1}^{* o}=\log P_{1}^{o}$. I use a block length of 12 and set $K=200$.

The final step to construct estimation uncertainty is using the $K$ bootstrapped replicates of oil prices to then re-estimate the stochastic volatility model to generate the bootstrapped estimates $\hat{\theta}^{*}$ $=\left\{\hat{\rho}_{p}^{*}, \hat{\rho}_{\sigma}^{*}, \hat{\bar{\sigma}}^{*}, \hat{\phi}^{*}\right\}$. The $K$ bootstrap parameter estimates are then used to construct forecasts of oil price volatility. Specifically, using the bootstrap estimated parameters the following recursion generates volatility forecasts:

$$
\begin{gathered}
\log P_{t}^{o}=\hat{\rho}_{p}^{*} \log P_{t-1}^{o}+e^{\sigma t, k} \nu_{t, k} \\
\sigma_{t, k}=\left(1-\hat{\rho}_{\sigma}^{*}\right) \hat{\bar{\sigma}}^{*}+{\hat{\rho_{\sigma}}}^{*} \sigma_{t-1, k}+\hat{\phi}^{*} \nu_{\sigma, t, k}
\end{gathered}
$$

where $\sigma_{t, k}^{2}, t=1, \ldots T$, for bootstrap iteration $k=1, \ldots, K$, are the bootstrapped values of 


\begin{tabular}{|c|c|c|c|c|c|c|c|c|}
\hline \multirow[t]{2}{*}{ Dependent Variable: } & \multicolumn{4}{|c|}{ S.D. } & \multicolumn{4}{|c|}{ Frequency } \\
\hline & $(1)$ & $(2)$ & (3) & (4) & (5) & (6) & (7) & (8) \\
\hline$s_{o, j} * \Delta \log \left(P_{t-1}^{o}\right)$ & 0.263 & 0.249 & 0.201 & 0.230 & -0.256 & -0.295 & -0.347 & -0.298 \\
\hline & {$[-0.235,0.942]$} & {$[-0.251,0.938]$} & {$[-0.281,0.849]$} & {$[-0.259,0.854]$} & {$[-1.241,0.545]$} & {$[-1.298,0.489]$} & {$[-1.267,0.435]$} & {$[-0.866,0.242]$} \\
\hline$s_{o, j} * \sigma_{t-1}$ & 7.485 & 7.486 & 7.094 & 6.726 & -4.131 & -3.955 & -4.119 & -1.786 \\
\hline & {$[1.603,20.403]$} & {$[1.603,20.263]$} & {$[1.446,21.095]$} & {$[1.255,20.096]$} & {$[-15.129,6.526]$} & {$[-14.759,8.410]$} & {$[-12.530,4.295]$} & {$[-5.902,2.178]$} \\
\hline$\pi_{j, t}$ & & 0.075 & 0.086 & 0.088 & & 0.393 & 0.930 & 0.855 \\
\hline & & {$[-0.128,0.284]$} & {$[-0.110,0.293]$} & {$[-0.103,0.285]$} & & {$[-0.067,0.791]$} & {$[0.451,1.424]$} & {$[0.539,1.163]$} \\
\hline$\Delta I P_{j, t}$ & & & 0.002 & -0.001 & & & -0.048 & -0.051 \\
\hline & & & {$[-0.040,0.041]$} & {$[-0.043,0.035]$} & & & {$[-0.088,-0.009]$} & {$[-0.092,-0.010]$} \\
\hline S.D. $\cdot j, t-1$ & & & & 0.065 & & & & \\
\hline & & & & {$[0.037,0.092]$} & & & & \\
\hline Frequency $_{j, t-1}$ & & & & & & & & 0.065 \\
\hline & & & & & & & & {$[0.037,0.092]$} \\
\hline Industry FE & Yes & Yes & Yes & Yes & Yes & Yes & Yes & Yes \\
\hline Time FE & Yes & Yes & Yes & Yes & Yes & Yes & Yes & Yes \\
\hline Number of Industries & 81 & 81 & 63 & 63 & 81 & 81 & 63 & 63 \\
\hline $\mathrm{N}$ & 13,606 & 13,606 & 10,946 & 10,939 & 13,606 & 13,606 & 10,946 & 10,946 \\
\hline
\end{tabular}

Table 23: Industry Specific Oil Demand Robustness: Stochastic Volatility Standard Errors

Note: Sample period: 1998:M1 to 2014:M12 at a monthly frequency. The dependent variable is the standard deviation of price change of a 4-digit NAICS industry in the manufacturing sector in columns (1)-(4) and price change frequency in column (5)-(8). All industries within the oil producing NAICS 324 sector are excluded. $s_{o, j} * \Delta \log \left(P_{t-1}^{o}\right)$ and $s_{o, j} * \sigma_{t-1}$ are the industry specific oil demand variables using monthly WTI real price of oil. $\pi_{j, t}$ is the average item level inflation rate for industry j. $\sigma_{t}$ is the extracted stochastic volatility measure of oil price volatility. S.D. $\cdot j, t-1$ is lagged industry price change standard deviation. Frequency ${ }_{j, t-1}$ is lagged industry price change frequency. Point estimates are the mean from the two-step panel moving blocks bootstrap and the $95 \%$ bootstrap confidence intervals are reported in brackets below the parameter estimates.

volatility.

The second step of the procedure is to incorporate the estimation uncertainty from the stochastic volatility model into the regressions of interest. Specifically, for the main regression of interest I use the panel moving blocks bootstrap of Gonçalves (2011) while incorporating the uncertainty from the first stage estimation. For each of the $k$ bootstrapped volatility series, I estimate:

$$
Y_{j, t}=\eta_{k} *\left(s_{o, j} * \Delta \log \left(P_{t-1}^{o}\right)\right)+\lambda_{k} *\left(s_{o, j} * \sigma_{t-1, k}\right)+\gamma_{k}^{\prime} X_{j, t}+\alpha_{j, k}+\alpha_{t, k}+\epsilon_{j, t, k}
$$

where $Y_{j, t}$ is price change dispersion or frequency, and the bootstrap procedure resamples the data with replacement using a moving block bootstrap on the vector containing all industries in a given time period. The bootstrap length is 3 . The panel bootstrap is estimated for each of the $k$ volatility series. This two step procedure then incorporates estimation uncertainty from the oil price volatility process as well as within-industry correlation and arbitrary residual correlation across industries in proximate time periods. Table 23 presents the results. The point estimate is the mean and the $95 \%$ bootstrapped confidence intervals are below. The table shows that estimation uncertainty does not diminish the statistical significance of the relationship between oil price volatility and price change dispersion. It does show that price change frequency has a more tenuous negative relationship than in the main regression table. Results from a two-step estimation procedure using GARCH volatility are constructed in an analogous manner and yield similar results. GARCH volatility results are in Table 24. Finally, I can employ the moving block bootstrap standard errors using realized volatility without needing to construct the generated regressor in a first stage. Results for this method using realized volatility are in Table 25 . 


\begin{tabular}{|c|c|c|c|c|c|c|c|c|}
\hline \multirow{2}{*}{ Dependent Variable: } & \multicolumn{4}{|c|}{ S.D. } & \multicolumn{4}{|c|}{ Frequency } \\
\hline & (1) & $(2)$ & (3) & (4) & (5) & (6) & (7) & (8) \\
\hline$s_{o, j} * \Delta \log \left(P_{t-1}^{o}\right)$ & 0.137 & 0.121 & 0.087 & 0.122 & -0.204 & -0.340 & -0.285 & -0.268 \\
\hline & {$[-0.401,0.879]$} & {$[-0.386,0.876]$} & {$[-0.427,0.745]$} & {$[-0.366,0.763]$} & {$[-1.121,0.542]$} & {$[-1.319,0.388]$} & {$[-1.076,0.415]$} & {$[-0.790,0.222]$} \\
\hline$s_{o, j} * \sigma_{t-1}$ & 4.118 & 4.195 & 4.065 & 3.789 & -1.536 & -0.745 & -0.844 & -0.222 \\
\hline & {$[0.411,8.873]$} & {$[0.500,8.969]$} & {$[0.549,8.508]$} & {$[0.334,8.056]$} & {$[-8.390,2.881]$} & {$[-7.503,3.650]$} & {$[-6.696,2.844]$} & {$[-3.156,1.902]$} \\
\hline$\pi_{j, t}$ & & 0.101 & 0.089 & 0.091 & & 0.879 & 0.931 & 0.855 \\
\hline & & {$[-0.105,0.357]$} & {$[-0.106,0.300]$} & {$[-0.102,0.293]$} & & {$[0.300,1.404]$} & {$[0.447,1.422]$} & {$[0.538,1.167]$} \\
\hline$\Delta I P_{j, t}$ & & & 0.001 & -0.002 & & & -0.048 & -0.051 \\
\hline & & & {$[-0.040,0.041]$} & {$[-0.043,0.035]$} & & & {$[-0.087,-0.009]$} & {$[-0.091,-0.010]$} \\
\hline $\mathrm{S} . \mathrm{D} \cdot j, t-1$ & & & & 0.065 & & & & \\
\hline & & & & {$[0.037,0.092]$} & & & & \\
\hline Frequency $_{j, t-1}$ & & & & & & & & $\begin{array}{c}0.544 \\
{[0.505,0.581]}\end{array}$ \\
\hline Industry FE & Yes & Yes & Yes & Yes & Yes & Yes & Yes & Yes \\
\hline Time FE & Yes & Yes & Yes & Yes & Yes & Yes & Yes & Yes \\
\hline Number of Industries & 81 & 81 & 63 & 63 & 81 & 81 & 63 & 63 \\
\hline $\mathrm{N}$ & 13,606 & 13,606 & 10,946 & 10,939 & 13,606 & 13,606 & 10,946 & 10,946 \\
\hline
\end{tabular}

Table 24: Industry Specific Oil Demand Robustness: GARCH Volatility Standard Errors

Note: Sample period: 1998:M1 to 2014:M12 at a monthly frequency. The dependent variable is the standard deviation of price change of a 4-digit NAICS industry in the manufacturing sector in columns (1)-(4) and price change frequency in column (5)-(8). All industries within the oil producing NAICS 324 sector are excluded. $s_{o, j} * \Delta \log \left(P_{t-1}^{o}\right)$ and $s_{o, j} * \sigma_{t-1}$ are the industry specific oil demand variables using monthly WTI real price of oil. $\pi_{j, t}$ is the average item level inflation rate for industry j. $\sigma_{t}$ is the extracted GARCH volatility measure of oil price volatility. S.D. $j, t-1$ is lagged industry price change standard deviation. Frequency ${ }_{j, t-1}$ is lagged industry price change frequency. Point estimates are the mean from the two-step panel moving blocks bootstrap and the $95 \%$ bootstrap confidence intervals are reported in brackets below the parameter estimates.

\begin{tabular}{|c|c|c|c|c|c|c|c|c|}
\hline \multirow{2}{*}{ Dependent Variable: } & \multicolumn{4}{|c|}{ S.D. } & \multicolumn{4}{|c|}{ Frequency } \\
\hline & (1) & (2) & (3) & (4) & (5) & (6) & (7) & (8) \\
\hline$s_{o, j} * \Delta \log \left(P_{t-1}^{o}\right)$ & 0.445 & 0.431 & 0.361 & 0.390 & -0.604 & -0.714 & -0.589 & -0.345 \\
\hline & {$[-0.123,1.261]$} & {$[-0.125,1.258]$} & {$[-0.175,1.080]$} & {$[-0.137,1.092]$} & {$[-1.645,0.188]$} & {$[-1.876,0.135]$} & {$[-1.588,0.138]$} & {$[-1.012,0.171]$} \\
\hline$s_{o, j} * \sigma_{t-1}$ & 7.118 & 7.162 & 6.349 & 6.178 & -8.396 & -7.729 & -6.319 & -1.595 \\
\hline & {$[3.131,10.889]$} & {$[3.259,10.834]$} & {$[1.699,10.203]$} & {$[1.801,9.770]$} & {$[-20.315,-0.580]$} & {$[-19.992,0.570]$} & {$[-14.842,0.157]$} & {$[-6.607,2.597]$} \\
\hline$\pi_{j, t}$ & & 0.098 & 0.086 & 0.087 & & 0.875 & 0.929 & 0.854 \\
\hline & & {$[-0.108,0.355]$} & {$[-0.111,0.300]$} & {$[-0.104,0.288]$} & & {$[0.293,1.407]$} & {$[0.447,1.421]$} & {$[0.539,1.164]$} \\
\hline$\Delta I P_{j, t}$ & & & 0.001 & -0.003 & & & -0.046 & -0.051 \\
\hline S.D. $\cdot j, t-1$ & & & {$[-0.041,0.040]$} & $\begin{array}{c}{[-0.044,0.034]} \\
0.065 \\
{[0.037,0.092]}\end{array}$ & & & {$[-0.087,-0.004]$} & {$[-0.091,-0.009]$} \\
\hline Frequency $_{j, t-1}$ & & & & & & & & $\begin{array}{c}0.544 \\
{[0.505,0.581]}\end{array}$ \\
\hline Industry FE & Yes & Yes & Yes & Yes & Yes & Yes & Yes & Yes \\
\hline Time FE & Yes & Yes & Yes & Yes & Yes & Yes & Yes & Yes \\
\hline Number of Industries & 81 & 81 & 63 & 63 & 81 & 81 & 63 & 63 \\
\hline $\mathrm{N}$ & 13,606 & 13,606 & 10,946 & 10,939 & 13,606 & 13,606 & 10,946 & 10,946 \\
\hline
\end{tabular}

Table 25: Industry Specific Oil Demand Robustness: Realized Volatility Standard Errors

Note: Sample period: 1998:M1 to 2014:M12 at a monthly frequency. The dependent variable is the standard deviation of price change of a 4-digit NAICS industry in the manufacturing sector in columns (1)-(4) and price change frequency in column (5)-(8). All industries within the oil producing NAICS 324 sector are excluded. $s_{o, j} * \Delta \log \left(P_{t-1}^{o}\right)$ and $s_{o, j} * \sigma_{t-1}$ are the industry specific oil demand variables using monthly WTI real price of oil. $\pi_{j, t}$ is the average item level inflation rate for industry $j . \sigma_{t}$ is the realized volatility measure of oil price volatility. S.D. $\cdot, t-1$ is lagged industry price change standard deviation. Frequency ${ }_{j, t-1}$ is lagged industry price change frequency. Point estimates are the mean from the panel moving blocks bootstrap and the $95 \%$ bootstrap confidence intervals are reported in brackets below the parameter estimates. 


\begin{tabular}{|c|c|c|c|c|c|c|c|c|}
\hline Dependent Variable: & & & & & & & & \\
\hline & $(1)$ & $(2)$ & $(3)$ & $(4)$ & $(5)$ & (6) & $(7)$ & (8) \\
\hline$s_{o, j} * \Delta \log \left(P_{t-1}^{o}\right)$ & $-0.284^{* *}$ & $-0.287^{* *}$ & $-0.222^{* *}$ & $-0.174^{* *}$ & 0.048 & 0.021 & 0.009 & 0.024 \\
\hline & $(0.118)$ & $(0.119)$ & $(0.094)$ & $(0.084)$ & $(0.076)$ & $(0.072)$ & $(0.066)$ & $(0.052)$ \\
\hline$s_{o, j} * \sigma_{t-1}$ & $2.718^{* * *}$ & $2.726^{* * *}$ & $2.561^{* * *}$ & $2.315^{* * *}$ & $2.958^{* * *}$ & $3.034^{* * *}$ & $2.584^{* * *}$ & $2.377^{* * *}$ \\
\hline & $(1.024)$ & $(1.028)$ & $(0.940)$ & $(0.842)$ & $(0.796)$ & $(0.852)$ & $(0.619)$ & $(0.562)$ \\
\hline$\pi_{j, t}$ & & 0.019 & 0.002 & 0.004 & & $0.190^{* * *}$ & $0.183^{* * *}$ & $0.173^{* * *}$ \\
\hline & & $(0.110)$ & $(0.092)$ & $(0.087)$ & & $(0.072)$ & $(0.072)$ & $(0.067)$ \\
\hline$\Delta I P_{j, t}$ & & & 0.004 & 0.002 & & & 0.005 & 0.010 \\
\hline & & & $(0.009)$ & $(0.008)$ & & & $(0.007)$ & $(0.007)$ \\
\hline S.D. $\cdot j, t-1$ & & & & & & & & $0.123^{* * *}$ \\
\hline & & & & & & & & $(0.021)$ \\
\hline I.Q.R. $\cdot j, t-1$ & & & & $0.136^{* * *}$ & & & & \\
\hline & & & & $(0.043)$ & & & & \\
\hline Time \& Industry FE & Yes & Yes & Yes & Yes & Yes & Yes & Yes & Yes \\
\hline Number of Industries & & & & & & & & \\
\hline $\mathrm{N}$ & 13,606 & 13,606 & 10,946 & 10,944 & 13,606 & 13,606 & 10,946 & 10,944 \\
\hline
\end{tabular}

Table 26: Industry Specific Coefficient: Robust Price Change Dispersion Measures

Note: Sample period: 1998:M1 to 2014:M12 at a monthly frequency. The dependent variable is the standard deviation of price change including zeros of a 4-digit NAICS industry in the manufacturing sector in columns (1)-(4) and interquartile range of price changes in columns (5)-(8). All industries within the oil producing NAICS 324 sector are excluded. $s_{o, j} * \Delta \log \left(P_{t-1}^{o}\right)$ and $s_{o, j} * \sigma_{t-1}$ are the industry specific oil demand variables using monthly WTI real price of oil. $\pi_{j, t}$ is the average item level inflation rate for industry $j . \sigma_{t}$ is the extracted stochastic volatility measure of oil price volatility. S.D. $j_{, t-1}$ is lagged industry price change standard deviation including zeros. I.Q.R. $\cdot j, t-1$ is lagged industry price change frequency. Robust asymptotic standard errors reported in parentheses are clustered at the industry level: ${ }^{*} p<.10 ;{ }^{* *} p<.05$; and ${ }^{* * *} p<.01$.

\section{B.3.3 Alternative Price Dispersion Measures}

Table 26 shows the main regression specification when the dependent variable is standard deviation of price change including zeros in columns (1) through (4) and the interquartile range in columns (5) through (8). The table shows that the results are robust to the measure of dispersion used. 


\begin{tabular}{|c|c|c|}
\hline \multirow[t]{2}{*}{ Dependent Variable: } & S.D. & Frequency \\
\hline & (1) & $(2)$ \\
\hline$\sigma_{t-1}$ & $\begin{array}{l}0.203^{* *} \\
(0.091)\end{array}$ & $\begin{array}{c}-0.093 \\
(0.204)\end{array}$ \\
\hline Sum of coefficients on: & & \\
\hline$\sum_{k=1}^{3}\left(\Delta \log \left(P_{t-k}^{o}\right)\right)$ & $\begin{array}{l}0.073^{* *} \\
(0.032)\end{array}$ & $\begin{array}{c}-0.065^{*} \\
(0.036)\end{array}$ \\
\hline$\sum_{k=1}^{3}\left(\Delta I P_{t-k}\right)$ & $\begin{array}{l}-0.206 \\
(0.347)\end{array}$ & $\begin{array}{l}-1.115 \\
(0.683)\end{array}$ \\
\hline$\sum_{k=1}^{3}\left(\pi_{t-k}\right)$ & $\begin{array}{l}-0.370 \\
(0.449)\end{array}$ & $\begin{array}{l}1.199^{*} \\
(0.648)\end{array}$ \\
\hline $\mathrm{N}$ & 200 & 200 \\
\hline
\end{tabular}

Table 27: Aggregate Pricing Moment Regression

Note: Sample period: 1998:M1 to 2014:M12 at a monthly frequency. Number of observation=200. Newey-West standard errors with lag length of 12 reported in parentheses: $* x<.10 ;{ }^{* *} p<.05$; and ${ }^{* * *} p<.01$.

\section{B.4 Additional Results}

This section presents additional empirical results. It first presents additional aggregate evidence on the relationship between oil price volatility and pricing behavior in Section B.4.1. It then presents additional pass-through results in Section B.4.2. It shows the aggregate empirical price change distribution during high and low oil price volatility in Section B.4.3, presents average moments by high and low oil share in Section B.4.4, and presents the full text of the introductory quote in Section B.4.5.

\section{B.4.1 Additional Aggregate Evidence}

In this subsection I provide additional aggregate time series evidence that oil price volatility affects pricing behavior. To do this I run the following regressions:

$$
Y_{t}=\alpha+\sum_{k=1}^{3} \beta_{k}\left(\Delta \log \left(P_{t-k}^{o}\right)\right)+\eta \sigma_{t-1}+\sum_{k=1}^{3} \gamma_{k}\left(\Delta I P_{t-k}\right)+\sum_{k=1}^{3} \nu_{k}\left(\pi_{t-k}\right)+\epsilon_{t}
$$

where $Y_{t}$ is aggregate price change frequency or standard deviation, $\Delta \log \left(P_{t-k}^{o}\right)$ is real oil price inflation, $\sigma_{t-1}$ is lagged real oil price volatility, $\Delta I P_{t-k}$ is industrial production growth to control for the state of the business cycle, and $\pi_{t-k}$ is PPI inflation. Results are in Table 27. Column (1) shows that increased oil price volatility is associated with greater price change dispersion. Column (2) shows that price change frequency is not associated with oil price volatility. These aggregate results are consistent with the industry-level results.

\section{B.4.2 Industry Specific Oil Pass-Through}

I examine if sectors that use more oil have greater pass-through, by running an industry specific oil pass-through regression with industry and time fixed effects to control for the macroeconomic 


\begin{tabular}{ccc}
\hline Short Run Pass-Through & & 12 Month Cumulative Response \\
\cline { 1 - 1 }$\left(0.224^{* * *}\right.$ & & $2.080^{* * *}$ \\
$(0.034)$ & $(0.504)$ \\
\hline
\end{tabular}

Table 28: Industry Specific Pass-Through Regression

Note: Sample period: 1998:M1 to 2014:M12 at a monthly frequency. Number of observation=7,786. Number of industries $=51 . R^{2}=0.15$. Robust asymptotic standard errors reported in parentheses are clustered at the industry level: ${ }^{*} p<.10{ }^{* *} p<.05$; and ${ }^{* * *} p<.01$.

cycle. Specifically I run a pass-through regression of the form:

$$
\pi_{j, t}=\alpha_{j}+\alpha_{t}+\sum_{i=0}^{12} b_{i}\left(s_{o, j} * \Delta \log P_{t-i}^{o}\right)+\epsilon_{j, t}
$$

If there is greater oil price pass-through for industries with more oil usage then $b_{0}$ and $\sum_{i=0}^{12} b_{i}$ should be positive. The results are in Table 28.

These results show that after conditioning on common aggregate shocks, that industries with greater oil usage have greater pass-through of oil prices. These results are consistent with the main regression results showing that pricing moments depend on the oil usage. 


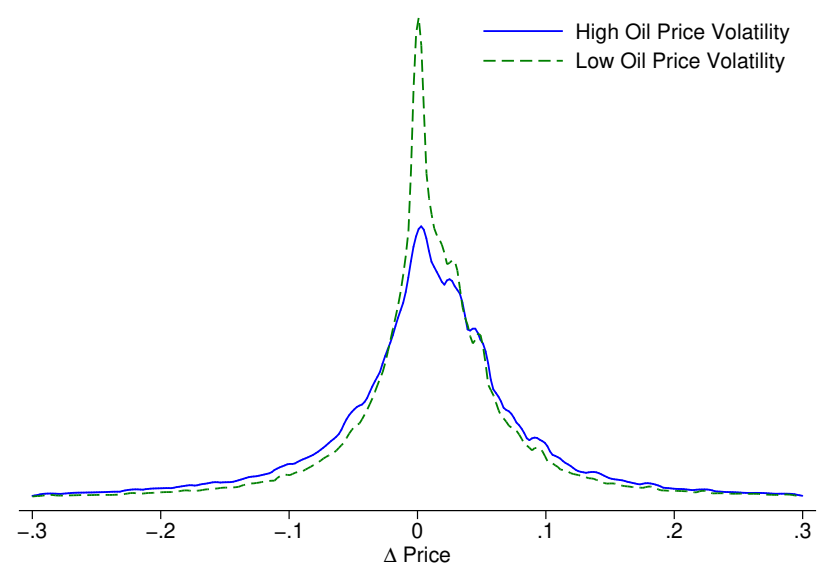

(a) Raw Distribution

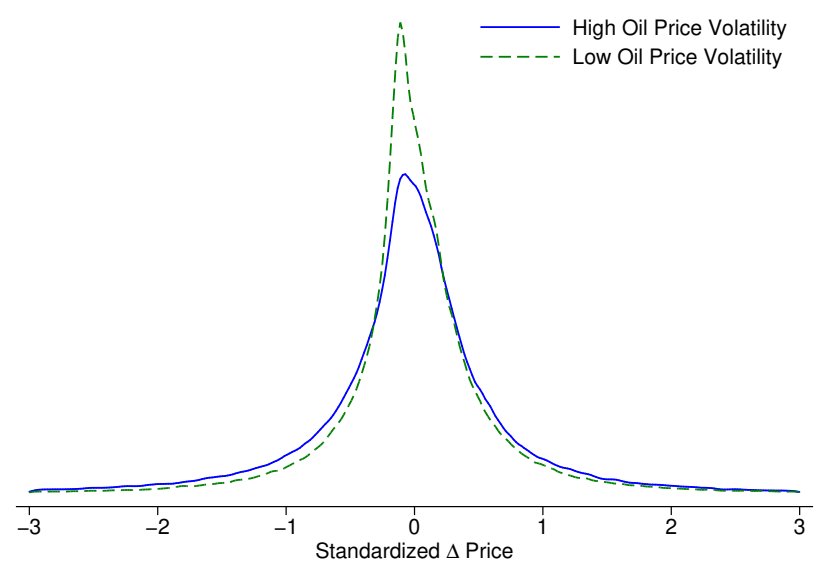

(b) Standardized Distribution

Figure 11: Empirical Price Distributions under Volatility Regimes

\section{B.4.3 Empirical Price Change Distributions}

Figure 11a shows the price change distribution during periods of high and low oil price volatility, where high oil price volatility is defined as a month when oil price volatility is above the median value over the 1998 to 2014 period. Measurement error when aggregating sectors can be problematic, so I standardize price changes at sectoral level then aggregate in Figure 11b. Both distributions show that price change dispersion is greater during periods of high oil price volatility.

\section{B.4.4 Observable Characteristics by Oil Share}

Table 29 presents selected average moments by above and below median oil share over the sample period of 1998 to 2014. The top panel shows the average pricing moments and summary statistics at industry level for 41 industries at or below the median oil share. The bottom panel shows the same variables for the 40 industries above median oil share. The results show that pricing moments and inflation are relatively balanced across the two groups. The high oil share industries have had higher average industrial growth rates over the sample. In the final row in each panel, statistics on the annual real export growth rate are presented. It shows that the export trade characteristics are the same between high and low oil usage industries. ${ }^{52}$

\section{B.4.5 Central Bank Quote}

The full text of Janet Yellen's quote from the "Current Conditions and the Outlook for the Economy" on June 6, 2016 is below.

In particular, an important theme of my remarks today will be the inevitable uncertainty surrounding the outlook for the economy. Unfortunately, all economic projections are certain to turn out to be inaccurate in some respects, and possibly significantly so.

\footnotetext{
${ }^{52}$ Trade data is downloaded from the United States International Trade Commission.
} 


\begin{tabular}{|c|c|c|c|c|c|}
\hline \multicolumn{6}{|c|}{ Low Oil Share } \\
\hline Variable & Mean & STD & Min & $\mathrm{P} 50$ & $\operatorname{Max}$ \\
\hline Frequency & 0.15 & 0.11 & 0.05 & 0.11 & 0.54 \\
\hline Frequency Up & 0.08 & 0.06 & 0.03 & 0.06 & 0.30 \\
\hline Standard Deviation & 0.12 & 0.04 & 0.04 & 0.11 & 0.22 \\
\hline$\overline{\pi_{j, t}}$ & 0.00 & 0.00 & -0.00 & 0.00 & 0.00 \\
\hline Average Size Up & 0.07 & 0.02 & 0.02 & 0.07 & 0.13 \\
\hline Average Size Down & -0.08 & 0.02 & -0.12 & -0.07 & -0.02 \\
\hline$\Delta \log (\mathrm{IP})$ & -0.01 & 0.22 & -0.48 & -0.01 & 0.60 \\
\hline$\Delta$ Annual Exports & 0.02 & 0.04 & -0.11 & 0.02 & 0.10 \\
\hline \multicolumn{6}{|c|}{ High Oil Share } \\
\hline Variable & Mean & STD & Min & $\mathrm{P} 50$ & Max \\
\hline Frequency & 0.21 & 0.15 & 0.07 & 0.13 & 0.51 \\
\hline Frequency Up & 0.12 & 0.08 & 0.04 & 0.08 & 0.28 \\
\hline Standard Deviation & 0.11 & 0.03 & 0.05 & 0.10 & 0.16 \\
\hline$\overline{\pi_{j, t}}$ & 0.00 & 0.00 & 0.00 & 0.00 & 0.00 \\
\hline Average Size Up & 0.06 & 0.01 & 0.04 & 0.06 & 0.10 \\
\hline Average Size Down & -0.06 & 0.02 & -0.12 & -0.06 & -0.03 \\
\hline$\Delta \log (\mathrm{IP})$ & 0.01 & 0.17 & -0.43 & 0.01 & 0.40 \\
\hline$\Delta$ Annual Exports & 0.02 & 0.03 & -0.10 & 0.02 & 0.08 \\
\hline
\end{tabular}

Table 29: Summary Statistics by Oil Share

NotE: Sample period: 1998:M1 to 2014:M12 at a monthly frequency. This table presents average pricing moments and other observable characteristics by high and low oil share. Low oil share is defined as the 41 industries at or below the median oil share, and high oil share is defined as the 40 industries above median oil share. $\Delta$ annual exports defined at an annual frequency. Total exports are deflated by the PPI finished goods index.

Will the economic situation in Europe or China take a turn for the worse or exceed expectations? Will U.S. productivity growth pick up and allow stronger growth of gross domestic product (GDP) and incomes or instead continue to stagnate? What will happen with the price of oil? The uncertainties are sizable, and progress toward our goals and, by implication, the appropriate stance of monetary policy will depend on how these uncertainties evolve. Indeed, the policy path that my colleagues and I judge most likely to achieve and maintain maximum employment and price stability has evolved and will continue to evolve in response to developments that alter our economic outlook and the associated risks to that outlook. 